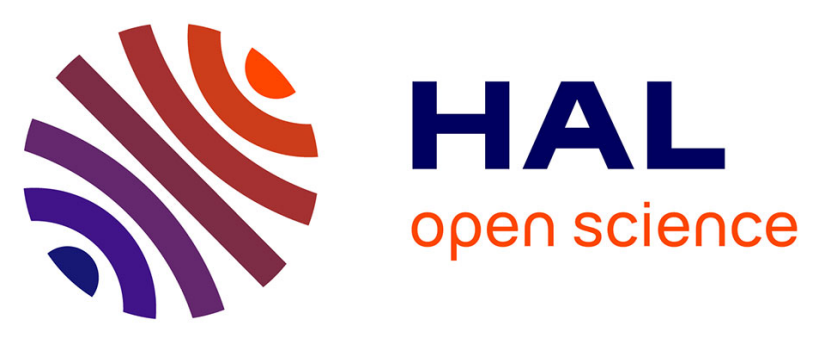

\title{
Trisaccharides of Phenolic Glycolipids Confer Advantages to Pathogenic Mycobacteria through Manipulation of Host-Cell Pattern-Recognition Receptors
}

Ainhoa Arbués, Wladimir Malaga, Patricia Constant, Christophe Guilhot, Jacques Prandi, Catherine Astarie-Dequeker

\section{To cite this version:}

Ainhoa Arbués, Wladimir Malaga, Patricia Constant, Christophe Guilhot, Jacques Prandi, et al.. Trisaccharides of Phenolic Glycolipids Confer Advantages to Pathogenic Mycobacteria through Manipulation of Host-Cell Pattern-Recognition Receptors. ACS Chemical Biology, 2016, 11 (10), pp.28652875. 10.1021/acschembio.6b00568 . hal-02325887

\section{HAL Id: hal-02325887 https://hal.science/hal-02325887}

Submitted on 19 Mar 2021

HAL is a multi-disciplinary open access archive for the deposit and dissemination of scientific research documents, whether they are published or not. The documents may come from teaching and research institutions in France or abroad, or from public or private research centers.
L'archive ouverte pluridisciplinaire HAL, est destinée au dépôt et à la diffusion de documents scientifiques de niveau recherche, publiés ou non, émanant des établissements d'enseignement et de recherche français ou étrangers, des laboratoires publics ou privés. 
Trisaccharides of Phenolic Glycolipids Confer Advantages to Pathogenic Mycobacteria through Manipulation of Host-Cell Pattern-Recognition Receptors

\author{
Ainhoa Arbués ${ }^{a, b}$, Wladimir Malaga ${ }^{a, b}$, Patricia Constant ${ }^{a, b}$, Christophe Guilhot ${ }^{a, b}$, \\ Jacques Prandi ${ }^{\mathrm{a}, \mathrm{b}^{*}}$ and Catherine Astarie-Dequeker ${ }^{\mathrm{a}, \mathrm{b}^{*}}$
}

\title{
Supporting Information
}

I. Procedures for the synthesis of PGL epitopes

1. General procedures

2. Preparation of individual compounds

II. Physico-chemical data for new compounds: optical rotations, ${ }^{1} \mathrm{H}$ and ${ }^{13} \mathrm{C}$ NMR data, high resolution mass spectra data.

III. Copies of ${ }^{1} \mathrm{H}$ and ${ }^{13} \mathrm{C}$ NMR spectra for new compounds

IV. NMR analysis of PGL purified from rBCG $\triangle R v 2959:$ : ML0126. Copy of ${ }^{1} \mathrm{H}$ NMR spectra for DIM and PGL purified from rBCG $\triangle R V 2959:$ : ML0126

V. Methods

VI. References

VII. Supplementary figures 


\section{Procedures for the synthesis of PGL epitopes}

\section{1. General procedures.}

Trichloracetimidates from orthoesters: preparation of 3,4 and 5. The orthoester was dissolved in a tetrahydrofuran (THF)/water mixture $(4 / 1(\mathrm{v} / \mathrm{v}))$, final concentration around 0.16 M) and ( \pm )-camphorsulfonic acid (0.05 equiv.) was added. The reaction was left at room temperature for $1.5 \mathrm{~h}$ and quenched with a $5 \%(\mathrm{w} / \mathrm{v}) \mathrm{NaHCO}_{3}$ solution. Most of the THF was evaporated and the mixture was extracted two times with dichloromethane (DCM). Drying the organic phase and evaporation of the solvent gave the crude hemiacetal which was used directly. The hemiacetal was taken up in $\operatorname{DCM}(0.2 \mathrm{M})$ and treated at $0^{\circ} \mathrm{C}$ with $1,8-$ diazabicyclo[5.4.0]undec-7-ene (0.3 equiv.) and trichloroacetonitrile (4.0 equiv.) for $2 \mathrm{~h}$. The yellow reaction mixture was diluted with saturated aqueous ammonium chloride solution. DCM extraction and chromatography (petroleum ether/ethyl acetate) gave the trichloacetimidate.

Glycosylation of $p$-cresol: preparation of 14,17 and 24. A mixture of a trichloracetimidate (1.0 equiv.) and $p$-cresol (1.3 to 1.5 equiv.) was stirred in (DCM, final concentration., $0.1-$ $0.15 \mathrm{M}$ ) at room temperature for $30 \mathrm{~min}$ in presence or powdered $3 \AA$ molecular sieves. The reaction was then brought to $-30^{\circ} \mathrm{C}$ and trimethylsilyl trifluoromethane sulfonate (TMSOTf, 0.1 equiv., as a $1 \mathrm{M}$ solution in $\mathrm{DCM}$ ) was added dropwise. The reaction mixture was allowed to warm to $-15^{\circ} \mathrm{C}$ over $1 \mathrm{~h}$ and quenched with few drops of triethylamine. The reaction mixture was filtered on Celite $\AA$ and the filtrate was washed twice with $2 \mathrm{~N}$ aqueous sodium hydroxide. The organic phase was dried with magnesium sulfate, filtered and evaporated to dryness. Chromatography (petroleum ether/ethyl acetate) afforded the cresyl glycoside as the pure $\alpha$-anomer.

Other glycosylations with imidates: preparation of 19, 23 and 28 . A mixture of the alcohol (1.0 equiv.) and trichloracetimidate (1.3-1.5 equiv., $0.1-0.15 \mathrm{M})$ was stirred in $\mathrm{DCM}$ at room temperature for $30 \mathrm{~min}$ in presence or powdered $3 \AA$ molecular sieves. The reaction was then brought to $-30^{\circ} \mathrm{C}$ and TMSOTf ( 0.1 equiv., as a $1 \mathrm{M}$ solution in DCM) was added dropwise. The reaction mixture was allowed to warm to $-10^{\circ} \mathrm{C}$ over $2 \mathrm{~h}$ and quenched with few drops of triethylamine. The reaction mixture was filtered on Celite $\AA$ and the filtrate was evaporated to dryness. Chromatography (petroleum ether/ethyl acetate) afforded the glycoside as the pure $\alpha$-anomer.

Glycosylation of 29 with thioglycoside 7. A mixture of disaccharide 29 (1.0 equiv.) and thioglycoside 7 (1.5 equiv., $0.015 \mathrm{M}$ ) was stirred in DCM at room temperature for $30 \mathrm{~min}$ in 
presence or powdered $3 \AA$ molecular sieves. The reaction was then brought to $-20^{\circ} \mathrm{C}$ and were sequencially added $\mathrm{N}$-iodo succinimide (1.95 equiv.), and TMSOTf ( 0.15 equiv., as a 1 $\mathrm{M}$ solution in $\mathrm{DCM}$ ). The reaction mixture was allowed to warm to $0^{\circ} \mathrm{C}$ over $2 \mathrm{~h}$ and quenched with few drops of triethylamine. The reaction mixture was filtered on Celite $₫$ and the filtrate was evaporated to dryness. Chromatography (petroleum ether/ethyl acetate) afforded trisaccharide $\mathbf{3 0}$.

Deacetylation: preparation of 15, 18, 20, OS PGL-1, 25 and OS PGL-tb. The ester was dissolved in a dilute solution of sodium methanolate in methanol (final concentration of substrate $0.05-0.07 \mathrm{M}$, adding some THF was sometimes needed to allow full solubility) and the reaction was left to proceed at room temperature until completion (TLC). The reaction was quenchend with a piece of dry ice and the methanol was evaporated. The residue was taken up in DCM, filtrated on Celite $₫$ and the filtrate was evaporated. The crude product was usually found pure enough but can be purfied by chromatography (toluene/ethyl acetate).

O-Methylation: preparation of 15, 21 and 26. The alcohol was dissolved in THF (0.05 M) and sequencially treated at $0^{\circ} \mathrm{C}$ with sodium hydride $(2.0$ equiv. of a $60 \%(\mathrm{w} / \mathrm{v})$ suspension in mineral oil) and iodomethane (3.0 equiv.). The reaction was allowed to warm to room temperature and allowed to proceed until completion. The reaction was quenched with a few drops of ethanol at $0^{\circ} \mathrm{C}$ and the THF was evaporated. The residue was taken up in DCM and washed with aqueous saturated $\mathrm{NaHCO}_{3}$ and brine. The organic phase was dried with magnesium sulfate, filtered and evaporated to dryness. Chromatography (petroleum ether/ethyl acetate) afforded the methyl ether.

Debenzylation: preparation of OS PGL-bov, OS PGL-ulc, OS PGL-1, 27 and 29. The benzyl ether was dissolved in a mixture of ethyl acetate and methanol. The catalyst was added $\left(10-20 \%(\mathrm{w} / \mathrm{w}) \mathrm{Pd} / \mathrm{C}\right.$ or $\left.\mathrm{Pd}(\mathrm{OH})_{2} / \mathrm{C}\right)$ and the reaction mixture was put under an atmosphere of hydrogen. After completion of the reaction, the catalyst was filtered on Celite $®$ and the filtrate evaporated. The crude product was usually obtained very pure but can be purfied by chromatography (petroleum ether/ethyl acetate or DCM/methanol 95/5 (v/v) for OS PGL-1).

Desilylation: preparation of 22 and OS PGL-tb. The silyl ether was dissolved in THF (0.5 $\mathrm{M}$ ) and treated with a $1 \mathrm{M}$ solution of tetrabutylammonium fluoride in THF (2.8 equiv. per silyl group). The reaction was left overnight at room temperature. The solvent was evaporated and chromatography (petroleum ether/ethyl acetate) gave the product. 


\section{2. Preparation of individual compounds.}

Preparation of stannylene 2. Orthoester 1 was dissolved in toluene $(0.21 \mathrm{M})$ and dibutyltin oxide (1.05 equiv.) was added. The reaction was brought to reflux with a Dean-Stark apparatus. After $3 \mathrm{~h}$, the reaction was over (TLC, DCM/methanol 20/1 (v/v)) and the mixture was allowed to cool to room temperature before evaporation of the toluene. No purification of the stannylene was attempted and the product was always used crude. It was stable for long periods of time in the dry form at $-20^{\circ} \mathrm{C}$.

Preparation of orthoester 9. 2 was dissolved in DMF (1.5 M solution) and treated with $\mathrm{NBu} 4 \mathrm{Br}$ (1.0 equiv.), benzyl bromide (2.0 equiv.) and a small amount of powdered $4 \AA$ molecular sieves. The mixture was brought to $40^{\circ} \mathrm{C}$ and left at this temperature for $36 \mathrm{~h}$. After cooling, most of the DMF was evaporated under reduced pressure and the residue was filtered on silica (ethyl acetate as eluant). The filtrate was evaporated and the crude product was dissolved in DMF $(0.5 \mathrm{M})$, treated with imidazole $(9.0$ equiv. $)$ and tertbutyldimethylchlorosilane (2.0 equiv.) and left at room temperature. After completion of the reaction ( 2 days), the mixture was diluted with ethyl acetate and hydrolyzed with a saturated aqueous ammonium chloride solution. The aqueous phase was extrated two times with ethyl acetate and the organic phase was washed with water and brine. Chromatography (petroleum ether/ethyl acetate/0.5\% triethylamine, 80/20 to $65 / 35(\mathrm{v} / \mathrm{v} / \mathrm{v})$ ) gave compound 9.

Preparation of orthoester 10. 2 was dissolved in DMF (1.5 M solution) and treated with $\mathrm{NBu} 4 \mathrm{Br}$ (1.0 equiv.) and iodomethane (3.0 equiv.) in a glass stoperred flask. The mixture was brought to $40^{\circ} \mathrm{C}$ and left at this temperature overnight. After cooling, the mixture was filtered on silica (THF with $2 \%(v / v)$ of $\mathrm{NEt}_{3}$ as eluant) and the filtrate was evaporated in the cold.

Preparation of orthoester 11. The above solution of 10 in DMF was treated at $0^{\circ} \mathrm{C}$ with sodium hydride (2.0 equiv., as a $60 \%(\mathrm{w} / \mathrm{w})$ dispersion in mineral oil, washed three times with petroleum ether) for $30 \mathrm{~min}$. Benzyl bromide (1.5 equiv.) was added and the reaction was allowed to proceed overtnight at room temperature. The reaction was quenched with methanol, diluted with water and extracted three times with DCM. The combined organic phases were washed with water, brine, dried over $\mathrm{MsSO}_{4}$ and the solvent was evaporated. Chromatography (petroleum ether/ethyl acetate $7 / 3(\mathrm{v} / \mathrm{v})$ ) gave 11.

Preparation of orthoester 12. The above solution of 10 in DMF was treated overnight with imidazole (4.0 equiv.) and tert-butyldimethylchlorosilane (2.0 equiv.) at room temperature for $12 \mathrm{~h}$. The mixture was hydrolyzed and extracted with DCM. The organic phase was washed 
with water and brine, dried over $\mathrm{MsSO}_{4}$ and the solvent was evaporated. Chromatography (petroleum ether/ethyl acetate 2/1 (v/v)) gave 12. 
II. Physico-chemical data for new compounds: optical rotations, ${ }^{1} \mathrm{H}$ and ${ }^{13} \mathrm{C}$ NMR spectra, high resolution mass spectra data.

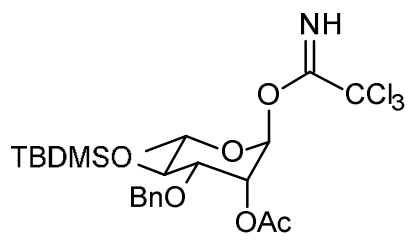

$\mathrm{C}_{23} \mathrm{H}_{34} \mathrm{O}_{6} \mathrm{Cl}_{3} \mathrm{NSi}$ : Calc. 554.96 g.mol ${ }^{-1}$

\section{2-O-acetyl-3-O-benzyl-4-O-tertbutyldimethylsilyl-6-deoxy- $\beta$-L-mannopyranyl trichloroacetimidate (5)}

$[\alpha]_{D}=-40.9^{\circ}(c 1.28$, chloroform $)$

${ }^{1} \mathrm{H}$ NMR $\left(400 \mathrm{MHz}, \mathrm{CDCl}_{3}\right): \delta=8.66(\mathrm{~s}, 1 \mathrm{H}, \mathrm{N}=\mathrm{H}), 6.17\left(\mathrm{~d},{ }^{3} \mathrm{~J}=2.0 \mathrm{~Hz}, 1 \mathrm{H}, \mathrm{H}-1\right), 5.46\left(\mathrm{~m},{ }^{3} \mathrm{~J}\right.$ $=3.0,2.0 \mathrm{~Hz}, 1 \mathrm{H}, \mathrm{H}-2), 4.68$ and $4.51\left(2 \mathrm{~d},{ }^{3} \mathrm{~J}=12.0 \mathrm{~Hz}, 2 \times 1 \mathrm{H}, \mathrm{CH}_{2}-\mathrm{Ph}\right), 3.86\left(\mathrm{~m},{ }^{3} \mathrm{~J}=9.0\right.$, $6.0 \mathrm{~Hz}, 1 \mathrm{H}, \mathrm{H}-5), 3.75$ (dd, ${ }^{3} \mathrm{~J}=9.0,3.0 \mathrm{~Hz}, 1 \mathrm{H}, \mathrm{H}-3$ ), 3.69 (dd, ${ }^{3}{ }^{3} \mathrm{~J}=9.0,9.0 \mathrm{~Hz}, 1 \mathrm{H}, \mathrm{H}-4$ ), $2.18\left(\mathrm{~s}, 3 \mathrm{H}, \mathrm{CH}_{3} \mathrm{CO}\right.$ ), 1.34 (d, $\left.{ }^{3} \mathrm{~J}=6.0 \mathrm{~Hz}, 3 \mathrm{H}, \mathrm{H}-6\right), 0.90$ (s, 9H, tBu-Si), 0.10 and 0.05 (2s, 2 $\left.\times 3 \mathrm{H}, \mathrm{CH}_{3}-\mathrm{Si}\right)$.

${ }^{13} \mathrm{C}$ NMR $\left(100.6 \mathrm{MHz}, \mathrm{CDCl}_{3}\right): \delta=170.0(\mathrm{C}=\mathrm{O}), 160.1(\mathrm{C}=\mathrm{NH}), 137.4,128.3,128.2,128.1$, 127.6, 95.3 (C-1), 77.1 (C-3), 72.4 (C-4), 72.3 (C-5), $71.5\left(\mathrm{CH}_{2}-\mathrm{Ph}\right), 67.4$ (C-2), 25.9 (tBu-Si), $20.6\left(\mathrm{CH}_{3}-\mathrm{Ac}\right), 18.4(\mathrm{C}-6), 18.2(\mathrm{tBu}-\mathrm{Si}),-3.8$ and $-4.6\left(\mathrm{CH}_{3}-\mathrm{Si}\right)$.

HRMS. CAlc. For $\mathrm{C}_{23} \mathrm{H}_{34} \mathrm{O}_{6} \mathrm{Cl}_{3} \mathrm{NSiNa}: 576.1119$. Found : 576.1123 .

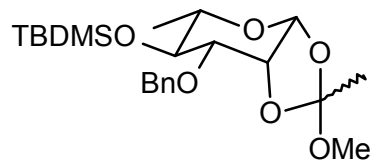

$\mathrm{C}_{22} \mathrm{H}_{36} \mathrm{O}_{6} \mathrm{Si}:$ Calc. 424.60 g.mol ${ }^{-1}$

\section{1,2-O-(1-methoxyethylidene) 3-O-benzyl-4-O-tertbutyldimethylsilyl-6-deoxy- $\beta$-L- mannopyranose (12)}

$[\alpha]_{D}=+4.3^{\circ}(c 1.80$, chloroform $)$

${ }^{1} \mathrm{H}$ NMR $\left(400 \mathrm{MHz}, \mathrm{CDCl}_{3}\right): \delta=5.27\left(\mathrm{~d},{ }^{3} \mathrm{~J}=2.0 \mathrm{~Hz}, 1 \mathrm{H}, \mathrm{H}-1\right), 4.75$ and $4.66\left(2 \mathrm{~d},{ }^{3} \mathrm{~J}=12.0\right.$ $\left.\mathrm{Hz}, 2 \times 1 \mathrm{H}, \mathrm{CH}_{2}-\mathrm{Ph}\right), 4.27\left(\mathrm{~m},{ }^{3} \mathrm{~J}=2.5,2.0 \mathrm{~Hz}, 1 \mathrm{H}, \mathrm{H}-2\right), 3.57\left(\mathrm{dd}, \mathrm{m},{ }^{3} \mathrm{~J}=8.5,8.5 \mathrm{~Hz}, 1 \mathrm{H}, \mathrm{H}-\right.$ 4), $3.47\left(\mathrm{dd},{ }^{3} \mathrm{~J}=8.5,4.0 \mathrm{~Hz}, 1 \mathrm{H}, \mathrm{H}-3\right), 3.25\left(\mathrm{~m},{ }^{3} \mathrm{~J}=8.5,6.0 \mathrm{~Hz}, 1 \mathrm{H}, \mathrm{H}-5\right), 3.23(\mathrm{~s}, 3 \mathrm{H}$, $\left.\mathrm{OCH}_{3}\right), 1.73\left(\mathrm{~s}, 3 \mathrm{H}, \mathrm{CH}_{3}\right), 1.34\left(\mathrm{~d},{ }^{3} \mathrm{~J}=6.0 \mathrm{~Hz}, 3 \mathrm{H}, \mathrm{H}-6\right), 0.93(\mathrm{~s}, 9 \mathrm{H}, t \mathrm{Bu}-\mathrm{Si}), 0.16$ and 0.11 $\left(2 \mathrm{~s}, 2 \times 3 \mathrm{H}, \mathrm{CH}_{3}-\mathrm{Si}\right)$. 
${ }^{13} \mathrm{C}$ NMR $\left(100.6 \mathrm{MHz}, \mathrm{CDCl}_{3}\right): \delta=137.9,128.5,128.4,126.0,123.8,97.3(\mathrm{C}-1), 79.4(\mathrm{C}-3)$, 77.2 (C-2), 72.5 and $72.4\left(\mathrm{C}-4\right.$ and $\left.\mathrm{CH}_{2}-\mathrm{Ph}\right), 71.5(\mathrm{C}-5), 49.6\left(\mathrm{OCH}_{3}\right), 26.0$ (tBu-Si), 24.6 $\left(\mathrm{CH}_{3}\right), 18.3$ (C-6), 18.1 (tBu-Si), -3.7 and $-4.5\left(\mathrm{CH}_{3}-\mathrm{Si}\right)$.

HRMS. Calc. for $\mathrm{C}_{22} \mathrm{H}_{36} \mathrm{O}_{6} \mathrm{SiNa}: 447.2179$. Found : 447.2184.

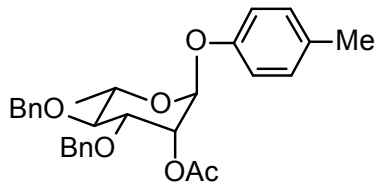

$\mathrm{C}_{29} \mathrm{H}_{32} \mathrm{O}_{6}: 476.56$ g.mol ${ }^{-1}$

\section{4-methylphenyl 2-O-acetyl-3,4-di-O-benzyl-6-deoxy-a-L-mannopyranoside (14)}

$[\alpha]_{D}=-50^{\circ}\left(c 1.15, \mathrm{CHCl}_{3}\right)$

${ }^{1} \mathrm{H}$ NMR $\left(400 \mathrm{MHz}, \mathrm{CDCl}_{3}\right): \delta=7.12$ and $6.95\left(2 \mathrm{brd},{ }^{3} \mathrm{~J}=8.5 \mathrm{~Hz}, 2 \times 2 \mathrm{H}\right.$, Phenol), 5.58 (dd, $\left.{ }^{3} J=3.5,1.5 \mathrm{~Hz}, 1 \mathrm{H}, \mathrm{H}-2\right), 5.46\left(\mathrm{~d},{ }^{3} \mathrm{~J}=1.5 \mathrm{~Hz}, 1 \mathrm{H}, \mathrm{H}-1\right), 4.99$ and $4.65\left(2 \mathrm{~d},{ }^{2} \mathrm{~J}=11.0 \mathrm{~Hz}, 2 \mathrm{x}\right.$ $1 \mathrm{H}, \mathrm{CH}_{2}$-ph), 4.81 and $4.68\left(2 \mathrm{~d},{ }^{2} \mathrm{~J}=10.5 \mathrm{~Hz}, 2 \times 1 \mathrm{H}, \mathrm{CH}_{2}-\mathrm{ph}\right), 4.19$ (dd, ${ }^{3} \mathrm{~J}=9.5,3.5 \mathrm{~Hz}, 1 \mathrm{H}$, $\mathrm{H}-3), 3.93\left(\mathrm{~m},{ }^{3} \mathrm{~J}=9.5,6.0 \mathrm{~Hz}, 1 \mathrm{H}, \mathrm{H}-5\right), 3.55$ (dd, $\left.{ }^{3} \mathrm{~J}=9.5,9.5 \mathrm{~Hz}, 1 \mathrm{H}, \mathrm{H}-4\right), 2.33(\mathrm{~s}, 3 \mathrm{H}$, $\left.\mathrm{CH}_{3}-\mathrm{Ph}\right), 2.23\left(\mathrm{~s}, 3 \mathrm{H}, \mathrm{CH}_{3} \mathrm{C}=\mathrm{O}\right), 1.34\left(\mathrm{~d},{ }^{3} \mathrm{~J}=6.0 \mathrm{~Hz}, 3 \mathrm{H}, \mathrm{H}-6\right)$.

${ }^{13} \mathrm{C}$ NMR $\left(100.6 \mathrm{MHz}, \mathrm{CDCl}_{3}\right): \delta=170.4(\mathrm{C}=\mathrm{O}), 153.9,138.4,138.0,131.8,130.0,128.5$, 128.4, 128.1, 128.0, 127.8, 127.7, 116.3, 96.1 (C-1), 80.0 (C-4), 77.9 (C-3), 75.5 and 72.0 $\left(\mathrm{CH}_{2}-\mathrm{Ph}\right), 68.9$ (C-2), $68.4(\mathrm{C}-5), 21.1\left(\mathrm{CH}_{3} \mathrm{C}=\mathrm{O}\right), 20.6\left(\mathrm{CH}_{3}-\mathrm{Ph}\right), 18.0(\mathrm{C}-6)$.

HRMS. Calc. for $\mathrm{C}_{29} \mathrm{H}_{32} \mathrm{O}_{6} \mathrm{Na}:$ 499.2097. Found : 499.2101.

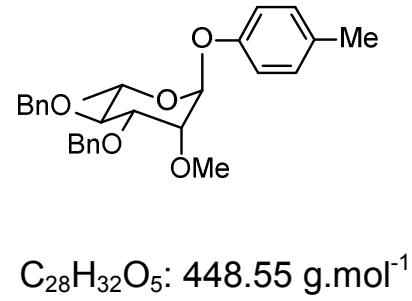

\section{4-methylphenyl 3,4-di-O-benzyl-6-deoxy-2-O-methyl-a-L-mannopyranoside (16)}

$[\alpha]_{D}=-88.8^{\circ}\left(c \quad 0.7, \mathrm{CHCl}_{3}\right)$

${ }^{1} \mathrm{H}$ NMR $\left(400 \mathrm{MHz}, \mathrm{CDCl}_{3}\right): \delta=7.11$ and $6.94\left(2 \mathrm{brd},{ }^{3} \mathrm{~J}=8.5 \mathrm{~Hz}, 2 \times 2 \mathrm{H}\right.$, Phenol), $5.52\left(\mathrm{~d},{ }^{3} \mathrm{~J}\right.$ $=1.5 \mathrm{~Hz}, 1 \mathrm{H}, \mathrm{H}-1), 5.00$ and $4.67\left(2 \mathrm{~d},{ }^{2} \mathrm{~J}=11.0 \mathrm{~Hz}, 2 \times 1 \mathrm{H}, \mathrm{CH}_{2}-\mathrm{ph}\right), 4.82\left(\mathrm{~s}, 2 \mathrm{H}, \mathrm{CH}_{2}-\mathrm{ph}\right)$, $4.10\left(\mathrm{dd},{ }^{3} \mathrm{~J}=9.5,3.0 \mathrm{~Hz}, 1 \mathrm{H}, \mathrm{H}-3\right), 3.84\left(\mathrm{~m},{ }^{3} \mathrm{~J}=9.5,6.0 \mathrm{~Hz}, 1 \mathrm{H}, \mathrm{H}-5\right), 3.73\left(\mathrm{dd},{ }^{3} \mathrm{~J}=3.0,1.5\right.$ $\mathrm{Hz}, 1 \mathrm{H}, \mathrm{H}-2$ ), 3.63 (dd, $\left.{ }^{3} \mathrm{~J}=9.5,9.5 \mathrm{~Hz}, 1 \mathrm{H}, \mathrm{H}-4\right), 3.60$ (s, $\left.3 \mathrm{H}, \mathrm{CH}_{3} \mathrm{O}\right), 2.32\left(\mathrm{~s}, 3 \mathrm{H}, \mathrm{CH}_{3}-\mathrm{Ph}\right.$ ), $1.32\left(\mathrm{~d},{ }^{3} \mathrm{~J}=6.0 \mathrm{~Hz}, 3 \mathrm{H}, \mathrm{H}-6\right)$. 
${ }^{13} \mathrm{C}$ NMR $\left(100.6 \mathrm{MHz}, \mathrm{CDCl}_{3}\right): \delta=154.2,138.5,138.4,131.5,129.9,128.4,128.3,128.0$, 127.9, 127.7, 127.6, 116.1, 95.6 (C-1), 80.4 (C-4), 79.7 (C-3), 78.1 (C-2), 75.5 and 72.5 $\left(\mathrm{CH}_{2}-\mathrm{Ph}\right), 68.6(\mathrm{C}-5), 59.5\left(\mathrm{CH}_{3} \mathrm{O}\right), 20.5\left(\mathrm{CH}_{3}-\mathrm{Ph}\right), 18.0(\mathrm{C}-6)$.

HRMS. Calc. for $\mathrm{C}_{28} \mathrm{H}_{32} \mathrm{O}_{5} \mathrm{Na}: 471.2147$. Found : 471.2148 .

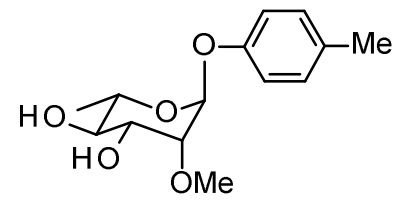

$$
\mathrm{C}_{14} \mathrm{H}_{20} \mathrm{O}_{5}: 268.31 \text { g.mol }{ }^{-1}
$$

\section{4-methylphenyl 6-deoxy-2-O-methyl-a-L-mannopyranoside (OS PGL-bov)}

$[\alpha]_{D}=-105.5^{\circ}$ (c 0.4, methanol)

${ }^{1} \mathrm{H}$ NMR (400MHz, $\left.\mathrm{CD}_{3} \mathrm{OD}\right): \delta=7.11$ and $6.97\left(2 \mathrm{brd},{ }^{3} \mathrm{~J}=8.0 \mathrm{~Hz}, 2 \times 2 \mathrm{H}\right.$, Phenol), 5.52 (d, $\left.{ }^{3} \mathrm{~J}=1.5 \mathrm{~Hz}, 1 \mathrm{H}, \mathrm{H}-1\right), 3.90\left(\mathrm{dd},{ }^{3} \mathrm{~J}=9.5,3.5 \mathrm{~Hz}, 1 \mathrm{H}, \mathrm{H}-3\right), 3.64\left(\mathrm{~m},{ }^{3} \mathrm{~J}=9.5,6.0 \mathrm{~Hz}, 1 \mathrm{H}, \mathrm{H}-5\right)$, $3.62\left(\mathrm{dd},{ }^{3} \mathrm{~J}=3.5,1.5 \mathrm{~Hz}, 1 \mathrm{H}, \mathrm{H}-2\right), 3.53\left(\mathrm{~s}, 3 \mathrm{H}, \mathrm{CH}_{3} \mathrm{O}\right), 3.40\left(\mathrm{dd},{ }^{3} \mathrm{~J}=9.5,9.5 \mathrm{~Hz}, 1 \mathrm{H}, \mathrm{H}-4\right)$, 2.29 (s, 3H, $\left.\mathrm{CH}_{3}-\mathrm{Ph}\right), 1.22$ (d, $\left.{ }^{3} \mathrm{~J}=6.0 \mathrm{~Hz}, 3 \mathrm{H}, \mathrm{H}-6\right)$.

${ }^{13} \mathrm{C}$ NMR (100.6 MHz, CD $\left.\mathrm{CD}_{3} \mathrm{OD}\right): \delta=154.3,131.3,129.5,116.1,95.4$ (C-1), 80.7 (C-2), 72.8 (C-4), 70.8 (C-3), 69.1 (C-5), $58.1\left(\mathrm{CH}_{3} \mathrm{O}\right), 19.26\left(\mathrm{CH}_{3}-\mathrm{Ph}\right), 16.6(\mathrm{C}-6)$.

HRMS. Calc. For $\mathrm{C}_{14} \mathrm{H}_{20} \mathrm{O}_{5}: 268.1311$. Found : 268.1306.

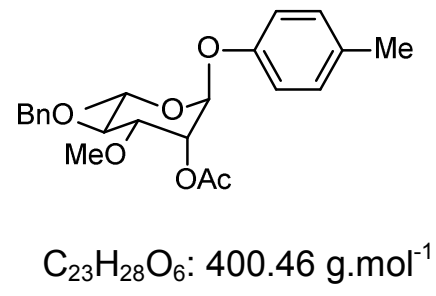

4-methylphenyl 2-O-acetyl-4-O-benzyl-6-deoxy-3-O-methyl-a-L-mannopyranoside (17)

$[\alpha]_{D}=-86.9^{\circ}\left(c 0.72, \mathrm{CHCl}_{3}\right)$

${ }^{1} \mathrm{H}$ NMR $\left(300 \mathrm{MHz}, \mathrm{CDCl}_{3}\right): \delta=7.10$ and $6.94\left(2 \mathrm{brd},{ }^{3} \mathrm{~J}=8.0 \mathrm{~Hz}, 2 \times 2 \mathrm{H}\right.$, Phenol), 5.54 (dd, , $\left.{ }^{3} \mathrm{~J}=3.5,1.5 \mathrm{~Hz}, 1 \mathrm{H}, \mathrm{H}-2\right), 5.44\left(\mathrm{~d},{ }^{3} \mathrm{~J}=1.5 \mathrm{~Hz}, 1 \mathrm{H}, \mathrm{H}-1\right), 4.95$ and $4.67\left(2 \mathrm{~d},,^{2} \mathrm{~J}=11.0 \mathrm{~Hz}\right.$, $2 \times 1 \mathrm{H}, \mathrm{CH}_{2}-\mathrm{Ph}$ ), 3.94-3.84 (m, $\left.2 \mathrm{H}, \mathrm{H}-3, \mathrm{H}-5\right), 3.53\left(\mathrm{~s}, 3 \mathrm{H}, \mathrm{OCH}_{3}\right), 3.46$ (dd, , ${ }^{3} \mathrm{~J}=9.5,9.5 \mathrm{~Hz}$, $1 \mathrm{H}, \mathrm{H}-4), 2.31$ (s, 3H, $\mathrm{CH}_{3}-\mathrm{Ph}$ ), $2.22\left(\mathrm{~s}, 3 \mathrm{H}, \mathrm{CH}_{3} \mathrm{C}=\mathrm{O}\right.$ ), 1.31 (d, $\left.{ }^{3} \mathrm{~J}=6.0 \mathrm{~Hz}, 1 \mathrm{H}, \mathrm{H}-6\right)$. 
${ }^{13} \mathrm{C}$ NMR $\left(75.5 \mathrm{MHz}, \mathrm{CDCl}_{3}\right): \delta=170.4(\mathrm{C}=\mathrm{O}), 153.9,138.9,131.8,130.0,128.4,127.9$, 127.7, 116.3, 96.0 (C-1), 80.1, 79.8, 75.4, 68.6, 68.3, $57.7\left(\mathrm{OCH}_{3}\right), 21.1\left(\mathrm{CH}_{3} \mathrm{C}=\mathrm{O}\right), 20.6$ $\left(\mathrm{CH}_{3}-\mathrm{Ph}\right),, 18.0(\mathrm{C}-6)$.

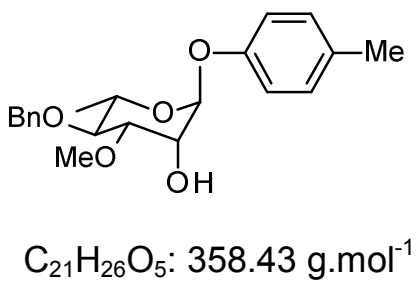

\section{4-methylphenyl 4-O-benzyl-6-deoxy-3-O-methyl-a-L-mannopyranoside (18)}

$[\alpha]_{D}=-122.4^{\circ}\left(c 1.66, \mathrm{CHCl}_{3}\right)$

${ }^{1} \mathrm{H}$ NMR $\left(400 \mathrm{MHz}, \mathrm{CDCl}_{3}\right): \delta=7.11$ and $6.96\left(2 \mathrm{brd},{ }^{3} \mathrm{~J}=8.0 \mathrm{~Hz}, 2 \times 2 \mathrm{H}\right.$, Phenol), $5.54(\mathrm{~d}$, $\left.{ }^{3} J=1.5 \mathrm{~Hz}, 1 \mathrm{H}, \mathrm{H}-1\right), 4.90$ and $4.67\left(2 \mathrm{~d},{ }^{2} \mathrm{~J}=11.0 \mathrm{~Hz}, 2 \times 1 \mathrm{H}, \mathrm{CH}_{2}-\mathrm{Ph}\right), 4.26(\mathrm{~m},, 1 \mathrm{H}, \mathrm{H}-2)$, $3.85\left(\mathrm{~m},{ }^{3} \mathrm{~J}=9.5,6.0 \mathrm{~Hz}, 1 \mathrm{H}, \mathrm{H}-5\right), 3.79\left(\mathrm{dd},{ }^{3} \mathrm{~J}=9.5,3.5 \mathrm{~Hz}, 1 \mathrm{H}, \mathrm{H}-3\right), 3.59(\mathrm{~s}, 3 \mathrm{H}$, $\left.\mathrm{OCH}_{3}\right), 3.46\left(\mathrm{dd},,^{3} \mathrm{~J}=9.5,9.5 \mathrm{~Hz}, 1 \mathrm{H}, \mathrm{H}-4\right), 2.60\left(\mathrm{~d},{ }^{3} \mathrm{~J}=2.0 \mathrm{~Hz}, 1 \mathrm{H}, \mathrm{OH}\right), 2.32\left(\mathrm{~s}, 3 \mathrm{H}, \mathrm{CH}_{3}-\right.$ $\mathrm{Ph}), 1.28\left(\mathrm{~d},{ }^{3} \mathrm{~J}=6.0 \mathrm{~Hz}, 1 \mathrm{H}, \mathrm{H}-6\right)$.

${ }^{13} \mathrm{C}$ NMR $\left(100.6 \mathrm{MHz}, \mathrm{CDCl}_{3}\right): \delta=154.0,138.5,131.6,130.0,128.4,128.0,127.7,116.2$, 97.2 (C-1), 81.5 (C-3), 79.9 (C-4), $75.3\left(\mathrm{CH}_{2}-\mathrm{Ph}\right), 67.9$ and $67.8(\mathrm{C}-2, \mathrm{C}-5), 57.6\left(\mathrm{OCH}_{3}\right)$, $20.6\left(\mathrm{CH}_{3}-\mathrm{Ph}\right), 17.9(\mathrm{C}-6)$.

HRMS. Calc. for $\mathrm{C}_{21} \mathrm{H}_{26} \mathrm{O}_{5} \mathrm{Na}: 381.1678$. Found 381.1672.

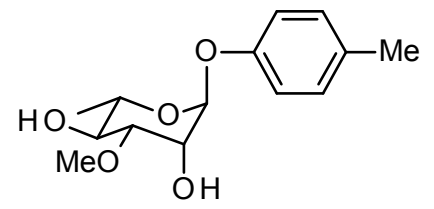

$$
\mathrm{C}_{14} \mathrm{H}_{20} \mathrm{O}_{5}: 268.31 \text { g.mol }{ }^{-1}
$$

\section{4-methylphenyl 6-deoxy-3-O-methyl-a-L-mannopyranoside (OS PGL-ulc)}

$[\alpha]_{D}=-92.8^{\circ}(c 1.23$, methanol)

${ }^{1} \mathrm{H}$ NMR (400MHz, $\mathrm{CD}_{3} \mathrm{OD}$ ): $\delta=7.11$ and 6.96 (2 brd, , ${ }^{3} \mathrm{~J}=8.5 \mathrm{~Hz}, 2 \times 2 \mathrm{H}$, Phenol), 5.41 (d, $\left.{ }^{3} \mathrm{~J}=1.5 \mathrm{~Hz}, 1 \mathrm{H}, \mathrm{H}-1\right), 4.21\left(\mathrm{~m},{ }^{3} \mathrm{~J}=2.0,1.5 \mathrm{~Hz}, 1 \mathrm{H}, \mathrm{H}-2\right), 3.69\left(\mathrm{~m},,^{3} \mathrm{~J}=9.5,6.0 \mathrm{~Hz}, 1 \mathrm{H}, \mathrm{H}-\right.$ 5), 3.56-3.49 (m, 2H, H-3, H-4), $3.53\left(\mathrm{~s}, 3 \mathrm{H}, \mathrm{OCH}_{3}\right), 2.29\left(\mathrm{~s}, 3 \mathrm{H}, \mathrm{CH}_{3}-\mathrm{Ph}\right), 1.24\left(\mathrm{~d},{ }^{3} \mathrm{~J}=6.0\right.$ $\mathrm{Hz}, 1 \mathrm{H}, \mathrm{H}-6)$.

${ }^{13} \mathrm{C}$ NMR (100.6 MHz, CD $\left.{ }_{3} \mathrm{OD}\right): \delta=154.3,131.3,129.5,116.1,98.6$ (C-1), 80.6 (C-3), 71.3 (C-4), 69.1(C-5), 66.7 (C-2), $56.1\left(\mathrm{OCH}_{3}\right), 19.2\left(\mathrm{CH}_{3}-\mathrm{Ph}\right), 16.6(\mathrm{C}-6)$. 
HRMS. Calc. for $\mathrm{C}_{14} \mathrm{H}_{20} \mathrm{O}_{5}: 268.1311$. Found 268.1311.

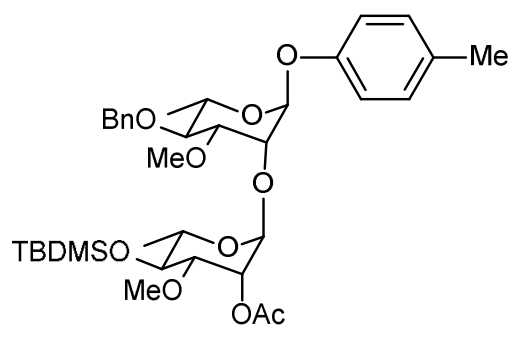

$$
\mathrm{C}_{36} \mathrm{H}_{54} \mathrm{O}_{10} \mathrm{Si}: 674.89 \mathrm{~g} \cdot \mathrm{mol}^{-1}
$$

\section{4-methylphenyl 2-O-(-2-O-acetyl-4-O-tertbutyldimethylsilyl-6-deoxy-3-O-methyl- $\alpha-L-$

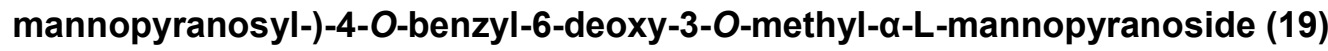

$[\alpha]_{D}=-92.0^{\circ}$ ( 1 1.06, chloroform)

${ }^{1} \mathrm{H}$ NMR $\left(300 \mathrm{MHz}, \mathrm{CDCl}_{3}\right): \delta=7.12$ and $6.97\left(2 \mathrm{brd},{ }^{3} \mathrm{~J}=8.0 \mathrm{~Hz}, 2 \times 2 \mathrm{H}\right.$, Phenol), 5.51 (dd, ${ }^{3} \mathrm{~J}$ $\left.=3.0,1.5 \mathrm{~Hz}, \mathrm{H}-2^{\prime}\right), 5.48\left(\mathrm{~d},{ }^{3} \mathrm{~J}=2.0 \mathrm{~Hz}, 1 \mathrm{H}, \mathrm{H}-1\right), 5.12\left(\mathrm{~d},{ }^{3} \mathrm{~J}=1.5 \mathrm{~Hz}, 1 \mathrm{H}, \mathrm{H}-1^{\prime}\right), 4.95$ and $4.70\left(2 \mathrm{~d},{ }^{3} \mathrm{~J}=10.5 \mathrm{~Hz}, 2 \times 1 \mathrm{H}, \mathrm{CH}_{2}-\mathrm{Ph}\right), 4.26\left(\mathrm{~m},{ }^{3} \mathrm{~J}=3.0,2.0 \mathrm{~Hz}, 1 \mathrm{H}, \mathrm{H}-2\right), 3.84$ (dd, ${ }^{3} \mathrm{~J}=$ 9.0, 3.0 Hz, $1 \mathrm{H}, \mathrm{H}-3$ ), $3.82\left(\mathrm{~m},{ }^{3} \mathrm{~J}=9.0,5.5 \mathrm{~Hz}, 1 \mathrm{H}, \mathrm{H}-5\right), 3.76\left(\mathrm{~m},{ }^{3} \mathrm{~J}=9.0,5.5 \mathrm{~Hz}, 1 \mathrm{H}, \mathrm{H}-5^{\prime}\right)$, $3.52\left(2 \mathrm{dd},{ }^{3} \mathrm{~J}=9.0,9.0 \mathrm{~Hz}, 1 \mathrm{H}, \mathrm{H}-4\right.$ and $\mathrm{H}-4$ '), 3.56 and $3.39\left(2 \mathrm{~s}, 2 \times 3 \mathrm{H}, \mathrm{OCH}_{3}\right), 3.44\left(\mathrm{dd},{ }^{3} \mathrm{~J}\right.$ $\left.=9.0,3.0 \mathrm{~Hz}, 1 \mathrm{H}, \mathrm{H}-3^{\prime}\right), 2.33\left(\mathrm{~s}, 3 \mathrm{H}, \mathrm{CH}_{3}-\mathrm{Ar}\right), 2.17$ (s, 3H, Ac), $1.30\left(2 \mathrm{~d},{ }^{3} \mathrm{~J}=5.5 \mathrm{~Hz}, 2 \times 3 \mathrm{H}\right.$, $\mathrm{H}-6, \mathrm{H}-6$ '), 0.93 (s, 9H, tBu-Si), 0.14 and 0.12 (2s, 2 x 3H, $\left.\mathrm{CH}_{3}-\mathrm{Si}\right)$.

${ }^{13} \mathrm{C}$ NMR $\left(100.6 \mathrm{MHz}, \mathrm{CDCl}_{3}\right): \delta=170.2(\mathrm{C}=\mathrm{O}), 154.0,138.5,131.5,130.0,128.3,128.0$, 127.6, 116.1, 99.1 (C-1'), 997.2 (C-1), 81.6 (C-3), 79.8 (C-4 or C-4'), 79.5 (C-3'), $75.1\left(\mathrm{CH}_{2^{-}}\right.$ $\mathrm{Ph}$ ), 73.0 (C-4 or C-4'), 72.8 (C-2), 69.6 and 68.5 (C-5 and C-5'), 68.1 (C-2'), 57.9 and 57.0 $\left(\mathrm{OCH}_{3}\right), 26.0(t \mathrm{Bu}-\mathrm{Si}), 21.0\left(\mathrm{CH}_{3} \mathrm{C}=\mathrm{O}\right), 20.5\left(\mathrm{CH}_{3}-\mathrm{Ph}\right), 18.3,18.3$ and 18.0 (tBu-Si, C-6 and C-6'), -4.0 and $-4.9\left(\mathrm{CH}_{3}-\mathrm{Si}\right)$.

HRMS. Calc. for $\mathrm{C}_{36} \mathrm{H}_{54} \mathrm{O}_{10} \mathrm{SiNa}:$ 697.3384. Found : 697.3401 .

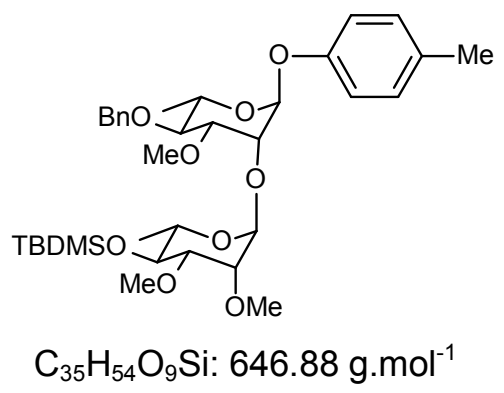

4-methylphenyl 2-0-(-4-O-tertbutyldimethylsilyl-6-deoxy-2,3-di-O-methyl-a-Lmannopyranosyl-)-4-O-benzyl-6-deoxy-3-O-methyl-a-L-mannopyranoside (21) 
$[\alpha]_{D}=-60.4^{\circ}(c \quad 0.72$, chloroform $)$

${ }^{1} \mathrm{H}$ NMR $\left(300 \mathrm{MHz}, \mathrm{CDCl}_{3}\right): \delta=7.11$ and $6.95\left(2 \mathrm{~d},{ }^{3} \mathrm{~J}=8.0 \mathrm{~Hz}, 2 \times 2 \mathrm{H}\right.$, Phenol), $5.46\left(\mathrm{~d},{ }^{3} \mathrm{~J}=\right.$ $2.0 \mathrm{~Hz}, 1 \mathrm{H}, \mathrm{H}-1), 5.18\left(\mathrm{~d},{ }^{3} \mathrm{~J}=1.5 \mathrm{~Hz}, 1 \mathrm{H}, \mathrm{H}^{-1}\right), 4.92$ and $4.69\left(2 \mathrm{~d},{ }^{3} \mathrm{~J}=10.5 \mathrm{~Hz}, 2 \times 1 \mathrm{H}\right.$, $\left.\mathrm{CH}_{2}-\mathrm{Ph}\right), 4.26\left(\mathrm{~m},{ }^{3} \mathrm{~J}=2.5,1.5 \mathrm{~Hz}, 1 \mathrm{H}, \mathrm{H}-2\right), 3.82\left(\mathrm{dd},{ }^{3} \mathrm{~J}=9.0,3.0 \mathrm{~Hz}, 1 \mathrm{H}, \mathrm{H}-3\right), 3.82\left(\mathrm{~m},{ }^{3} \mathrm{~J}\right.$ = 9.0, $5.5 \mathrm{~Hz}, 1 \mathrm{H}, \mathrm{H}-5), 3.75$ (dd, ${ }^{3} \mathrm{~J}=3.0,1.5 \mathrm{~Hz}, \mathrm{H}-2$ '), $3.68\left(\mathrm{~m},{ }^{3} \mathrm{~J}=9.0,5.5 \mathrm{~Hz}, 1 \mathrm{H}, \mathrm{H}-5^{\prime}\right)$, $3.58\left(\mathrm{dd}, \mathrm{m},{ }^{3} \mathrm{~J}=9.0,9.0 \mathrm{~Hz}, 1 \mathrm{H}, \mathrm{H}-4\right), 3.57,3.45$ and $3.45\left(3 \mathrm{~s}, 3 \times 3 \mathrm{H}, \mathrm{OCH}_{3}\right), 3.47$ (dd, $\mathrm{m}$, $\left.{ }^{3} J=9.0,9.0 \mathrm{~Hz}, 1 \mathrm{H}, \mathrm{H}-4^{\prime}\right), 3.37\left(\mathrm{dd},{ }^{3} J=9.0,3.0 \mathrm{~Hz}, 1 \mathrm{H}, \mathrm{H}-3\right.$ '), 2.31 (s, 3H, $\left.\mathrm{CH}_{3}-\mathrm{Ar}\right), 1.29$ (d, $\left.{ }^{3} J=5.5 \mathrm{~Hz}, 3 \mathrm{H}, \mathrm{H}-6\right), 1.25$ (d, ${ }^{3} \mathrm{~J}=5.5 \mathrm{~Hz}, 3 \mathrm{H}, \mathrm{H}-6$ '), 0.91 (s, 9H, tBu-Si), 0.14 and 0.10 (2s, $\left.2 \times 3 \mathrm{H}, \mathrm{CH}_{3}-\mathrm{Si}\right)$.

${ }^{13} \mathrm{C}$ NMR $\left(100.6 \mathrm{MHz}, \mathrm{CDCl}_{3}\right): \delta=154.1,138.5,131.6,130.0,128.4,128.0,127.7,116.2$, 98.8 (C-1'), 97.4 (C-1), 81.8 (C-3), 81.2 (C-3'), 80.0 (C-4), 76.6 (V-2'), $75.1\left(\mathrm{CH}_{2}-\mathrm{Ph}\right), 73.2$ and 73.0 (C-2, C-4), 69.8 (C-5'), 68.5 (C-5), 59.0, 58.1 and $57.1\left(\mathrm{OCH}_{3}\right), 26.1$ (tBu-Si), 20.6 $\left(\mathrm{CH}_{3}-\mathrm{Ph}\right), 18.4$ and 18.3 (C-6, C-6'), 18.1 (tBu-Si), -3.9 and -4.7 $\left(\mathrm{CH}_{3}-\mathrm{Si}\right)$.

HRMS. Calc. for $\mathrm{C}_{35} \mathrm{H}_{54} \mathrm{O}_{9} \mathrm{SiNa}: 669.3435$. Found : 669.3447.

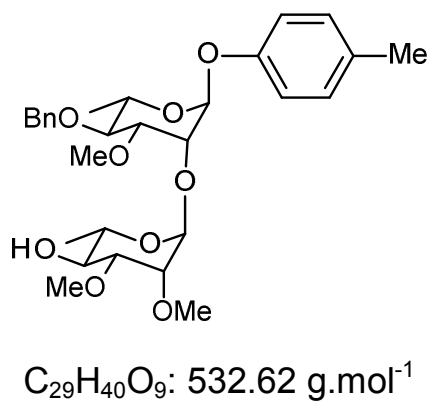

\section{4-methylphenyl 2-O-(-6-deoxy-2,3-di-O-methyl-a-L-mannopyranosyl-)-4-O-benzyl-6-}

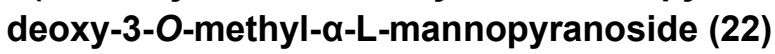

$[\alpha]_{D}=-106^{\circ}(c 1.02$, chloroform $)$

${ }^{1} \mathrm{H} \mathrm{NMR}\left(400 \mathrm{MHz}, \mathrm{CDCl}_{3}\right): \delta=7.11$ and $6.97\left(2 \mathrm{~d},{ }^{3} \mathrm{~J}=8.5 \mathrm{~Hz}, 2 \times 2 \mathrm{H}\right.$, Phenol), $5.47\left(\mathrm{~d},{ }^{3} \mathrm{~J}=\right.$ $1.5 \mathrm{~Hz}, 1 \mathrm{H}, \mathrm{H}-1), 5.21\left(\mathrm{~d},{ }^{3} \mathrm{~J}=1.5 \mathrm{~Hz}, 1 \mathrm{H}, \mathrm{H}-1\right.$ '), 4.92 and $4.68\left(2 \mathrm{~d},{ }^{3} \mathrm{~J}=11.5 \mathrm{~Hz}, 2 \times 1 \mathrm{H}\right.$, $\left.\mathrm{CH}_{2}-\mathrm{Ph}\right), 4.26\left(\mathrm{~m},{ }^{3} \mathrm{~J}=3.0,1.5 \mathrm{~Hz}, 1 \mathrm{H}, \mathrm{H}-2\right), 3.84\left(\mathrm{dd},{ }^{3} \mathrm{~J}=9.5,3.0 \mathrm{~Hz}, 1 \mathrm{H}, \mathrm{H}-3\right), 3.82(\mathrm{~m}$, $1 \mathrm{H}, \mathrm{H}-5$ ), 3.80 (dd, ${ }^{3} \mathrm{~J}=3.0,1.5 \mathrm{~Hz}, \mathrm{H}-2$ '), 3.77 (m, $1 \mathrm{H}, \mathrm{H}-5$ '), 3.61 (ddd, $\mathrm{m},{ }^{3} \mathrm{~J}=9.5,9.5,1.5$ $\mathrm{Hz}, 1 \mathrm{H}, \mathrm{H}-4$ '), 3.59, 3.56 and $3.55\left(3 \mathrm{~s}, 3 \times 3 \mathrm{H}, \mathrm{OCH}_{3}\right), 3.50$ (dd, $\left.{ }^{3} \mathrm{~J}=9.5,3.0 \mathrm{~Hz}, 1 \mathrm{H}, \mathrm{H}-3^{\prime}\right)$, 3.45 (dd, m, $\left.{ }^{3} \mathrm{~J}=9.5,9.5 \mathrm{~Hz}, 1 \mathrm{H}, \mathrm{H}-4\right), 2.42(\mathrm{br}, 1 \mathrm{H}, \mathrm{OH}), 2.32$ (s, 3H, $\mathrm{CH}_{3}-\mathrm{Ar}$ ), 1.33 (d, ${ }^{3} \mathrm{~J}=$ $6.0 \mathrm{~Hz}, 3 \mathrm{H}, \mathrm{H}-6$ '), 1.29 (d, $\left.{ }^{3} \mathrm{~J}=6.0 \mathrm{~Hz}, 3 \mathrm{H}, \mathrm{H}-6\right)$.

${ }^{13} \mathrm{C}$ NMR $\left(100.6 \mathrm{MHz}, \mathrm{CDCl}_{3}\right): \delta=154.0,138.5,131.3,130.0,128.4,128.0,127.7,116.1$, 98.9 (C-1'), 97.1 (C-1), 81.7 (C-3), 80.7 (C-3'), 80.1 (C-4), 75.9 (C-2'), $75.3\left(\mathrm{CH}_{2}-\mathrm{Ph}\right), 73.5$ (C-2), 71.6 (C-4'), 68.7 (C-5'), 68.4 (C-5), 58.9, 58.0 and $57.0\left(\mathrm{OCH}_{3}\right), 20.5\left(\mathrm{CH}_{3}-\mathrm{Ph}\right), 18.0$ (C-6), 17.7 (C-6').

HRMS. Calc. for $\mathrm{C}_{29} \mathrm{H}_{40} \mathrm{O}_{9} \mathrm{Na}: 555.2570$. Found : 555.2575 . 


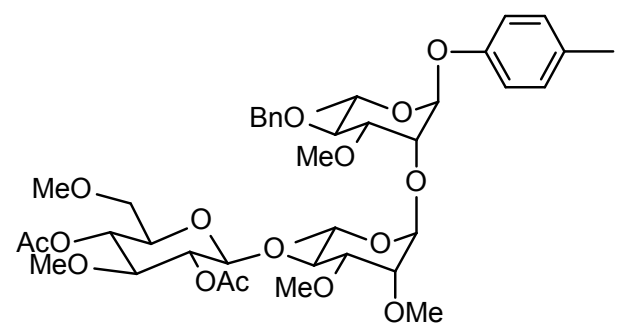

$\mathrm{C}_{41} \mathrm{H}_{58} \mathrm{O}_{16}: 806.89 \mathrm{~g} \cdot \mathrm{mol}^{-1}$

4-methylphenyl 2-O-(-4-O-(2,4-di-O-acetyl-3,6-di-O-methyl- $\beta$-D-glucopyranosyl-)-6deoxy-2,3-di-O-methyl- $\alpha-L-m a n n o p y r a n o s y l-)-4-O-b e n z y l-6-d e o x y-3-O-m e t h y l-\alpha-L-$ mannopyranoside (23)

$[\alpha]_{\mathrm{D}}{ }^{25}=-69.3^{\circ}\left(\mathrm{c} 1.10, \mathrm{CHCl}_{3}\right)$

${ }^{1} \mathrm{H} \mathrm{NMR}\left(400 \mathrm{MHz}, \mathrm{CDCl}_{3}\right): \delta=7.11$ and $6.95\left(2 \mathrm{~d},{ }^{3} \mathrm{~J}=8.5 \mathrm{~Hz}, 2 \times 2 \mathrm{H}\right.$, Phenol), $5.44\left(\mathrm{~d},{ }^{3} \mathrm{~J}=\right.$ $1.5 \mathrm{~Hz}, 1 \mathrm{H}, \mathrm{H}-1$ ), 5.22 (d, $\left.{ }^{3} \mathrm{~J}=1.5 \mathrm{~Hz}, 1 \mathrm{H}, \mathrm{H}-1^{\prime}\right), 5.00$ (dd, ${ }^{3} \mathrm{~J}=9.5,9.5 \mathrm{~Hz}, 1 \mathrm{H}, \mathrm{H}-4$ "), 4.92 (dd, ${ }^{3} \mathrm{~J}=9.5,8.0 \mathrm{~Hz}, 1 \mathrm{H}, \mathrm{H}-2$ "), 4.91 and $4.68\left(2 \mathrm{~d},{ }^{3} \mathrm{~J}=11.0 \mathrm{~Hz}, 2 \times 1 \mathrm{H}, \mathrm{CH}_{2}-\mathrm{Ph}\right), 4.79\left(\mathrm{~d},{ }^{3} \mathrm{~J}\right.$ $=8.0 \mathrm{~Hz}, 1 \mathrm{H}, \mathrm{H}-1$ "), $4.26\left(\mathrm{~m},{ }^{3} \mathrm{~J}=3.0,1.5 \mathrm{~Hz}, 1 \mathrm{H}, \mathrm{H}-2\right), 3.83\left(\mathrm{dd},{ }^{3} \mathrm{~J}=9.0,3.0 \mathrm{~Hz}, 1 \mathrm{H}, \mathrm{H}-3\right)$, $3.81\left(\mathrm{~m}, 1 \mathrm{H}, \mathrm{H}-5\right.$ ), 3.72 (dd, ${ }^{3} \mathrm{~J}=3.5,1.5 \mathrm{~Hz}, \mathrm{H}-2$ ') 3.67 (m, 1H, H-5'), 3.65 (ddd, $\mathrm{m},{ }^{3} \mathrm{~J}=9.5$, $9.5,1.5 \mathrm{~Hz}, 1 \mathrm{H}, \mathrm{H}-4$ '), 3.57, 3.55, 3.52, 3.41 and $3.55\left(5 \mathrm{~s}, 5 \times 3 \mathrm{H}, \mathrm{OCH}_{3}\right), 3.54-3.40(\mathrm{~m}, 6 \mathrm{H}$, H-3', H-3", H-4, H-5", H-6"), 2.31 (s, 3H, $\mathrm{CH}_{3}-\mathrm{Ar}$ ), 2.17 and 2.10 (2s, $\left.2 \times 3 \mathrm{H}, \mathrm{Ac}\right), 1.29$ (d, ${ }^{3} \mathrm{~J}=$ $6.0 \mathrm{~Hz}, 3 \mathrm{H}, \mathrm{H}-6), 1.28$ (d, ${ }^{3} \mathrm{~J}=6.0 \mathrm{~Hz}, 3 \mathrm{H}, \mathrm{H}-6$ ').

${ }^{13} \mathrm{C}$ NMR $\left(100.6 \mathrm{MHz}, \mathrm{CDCl}_{3}\right): \delta=169.7$ and $169.2(\mathrm{C}=0), 153.80,138.5,131.5,130.0$, 129.0, 128.3, 128.2, 128.0, 127.7, 116.0, 100.9 C-1"), 98.1 (C-1'), 97.0 (C-1), 81.9 (C-3), 81.4 (C-3”), 80.7 (C-3'), 80.0 (C-4), 77.5 (C-4'), 76.7 (C-2'), $75.0\left(\mathrm{CH}_{2}-\mathrm{Ph}\right), 73.0$ (C-5”), 72.9 (C-2), 72.2 (C-2"), 72.0 (C-6”), 70.1 (C-4"), 68.4 (C-5), 67.5 (C-5'), 59.6, 58.9, 58.1, 58.1 and $57.3\left(\mathrm{OCH}_{3}\right), 21.1$ and $20.9\left(\mathrm{CH}_{3}-\mathrm{Ac}\right), 20.5\left(\mathrm{CH}_{3}-\mathrm{Ph}\right), 18.0(\mathrm{C}-6$ '), $17.8(\mathrm{C}-6)$.

HRMS. Calc. for $\mathrm{C}_{41} \mathrm{H}_{58} \mathrm{O}_{16} \mathrm{Na}: 829.3623$. Found : 829.3616.

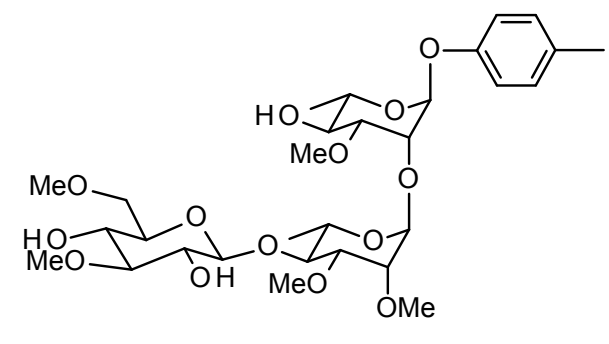

$$
\mathrm{C}_{30} \mathrm{H}_{48} \mathrm{O}_{14} \text { : Calc. } 632.69 \text { g.mol }{ }^{-1}
$$

4-methylphenyl 2-O-(-6-deoxy-4-O-(-3,6-di-O-methyl- $\beta$-D-glucopyranosyl-)-2,3-di-O-

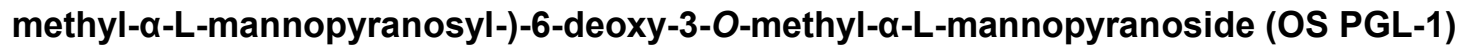
$[\alpha]_{D}^{25}=-66.4^{\circ}\left(c 1.42, \mathrm{CHCl}_{3}\right)$ 
${ }^{1} \mathrm{H} \mathrm{NMR}\left(400 \mathrm{MHz}, \mathrm{CDCl}_{3}\right): \delta=7.12$ and $6.95\left(2 \mathrm{~d},{ }^{3} \mathrm{~J}=8.5 \mathrm{~Hz}, 2 \times 2 \mathrm{H}\right.$, Phenol), $5.45\left(\mathrm{~d},{ }^{3} \mathrm{~J}=\right.$ $1.5 \mathrm{~Hz}, 1 \mathrm{H}, \mathrm{H}-1), 5.12\left(\mathrm{~d},{ }^{3} \mathrm{~J}=1.5 \mathrm{~Hz}, 1 \mathrm{H}, \mathrm{H}-1\right.$ '), 4.43 (d, ${ }^{3} \mathrm{~J}=7.5 \mathrm{~Hz}, 1 \mathrm{H}, \mathrm{H}-1$ '), $4.25\left(\mathrm{~m},{ }^{3} \mathrm{~J}=\right.$ 2.5, $1.5 \mathrm{~Hz}, 1 \mathrm{H}, \mathrm{H}-2)$, 3.81-3.72 (m, 3H, H-2', H-5, H-5'), 3.68-3.57 (m, 6H, H-3, H-3', H-4, H4', H-5", H-6"), 3.55 (dd, ${ }^{3} \mathrm{~J}=9.0,9.0 \mathrm{~Hz}, 1 \mathrm{H}, \mathrm{H}-4$ "), 3.70, 3.55, 3.52, 3.51 and 3.40 (5s, $5 \mathrm{x}$ $3 \mathrm{H}, \mathrm{OCH}_{3}$ ), 3.47-3.41 (m, 2H, H-2", H-6"), 3.18 (dd, dd, ${ }^{3} \mathrm{~J}=9.0,9.0 \mathrm{~Hz}, 1 \mathrm{H}, \mathrm{H}-3$ "), ), 2.32 (s, $\left.3 \mathrm{H}, \mathrm{CH}_{3}-\mathrm{Ar}\right), 1.35$ and $1.29\left(2 \mathrm{~d},{ }^{3} \mathrm{~J}=6.0 \mathrm{~Hz}, 2 \times 3 \mathrm{H}, \mathrm{H}-6, \mathrm{H}-6{ }^{\prime}\right)$.

${ }^{13} \mathrm{C}$ NMR $\left(100.6 \mathrm{MHz}, \mathrm{CDCl}_{3}\right): \delta=153.9,131.7,130.0,116.1,105.6 \mathrm{C}-1$ "), $98.4\left(\mathrm{C}-1^{\prime}\right), 97.3$ (C-1), 85.5 (C-3"), 81.5 and 81.4 (C-3, C-3'), 80.1 (C-4'), 75.7 (C-2'), 75.0 (C-2"), 74.1 (C-5"), 72.8 (C-6”), 72.1 (C-2), 71.8 (C-4), 71.1 (C-4"), 68.9 and 68.2 (C-5, C-5'), 60.5, 59.6, 59.0, 57.6 and $56.5\left(\mathrm{OCH}_{3}\right), 21.1$ and $20.9\left(\mathrm{CH}_{3}-\mathrm{Ac}\right), 20.5\left(\mathrm{CH}_{3}-\mathrm{Ph}\right), 17.7$ and $17.6(\mathrm{C}-6, \mathrm{C}-6)$.

HRMS. Calc. for $\mathrm{C}_{30} \mathrm{H}_{48} \mathrm{O}_{14} \mathrm{Na}:$ 653.2942. Found : 655.2942.

References: (1-3)

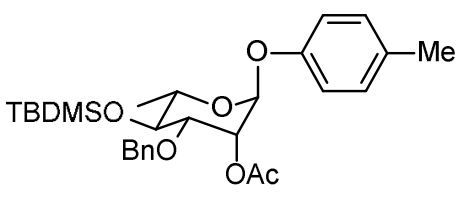

$\mathrm{C}_{28} \mathrm{H}_{40} \mathrm{O}_{6} \mathrm{Si}: 500.70 \mathrm{~g} \cdot \mathrm{mol}^{-1}$

\section{4-methylphenyl 2-O-acetyl-3-O-benzyl-4-O-tertbutyldimethylsilyl-6-deoxy-a-L- mannopyranoside (24)}

$[\alpha]_{D}=-63.2^{\circ}(c 1.20$ chloroform $)$

${ }^{1} \mathrm{H}$ NMR $\left(400 \mathrm{MHz}, \mathrm{CDCl}_{3}\right): \delta=7.10$ and $6.96\left(2 \mathrm{~d},{ }^{3} \mathrm{~J}=8.5 \mathrm{~Hz}, 2 \times 2 \mathrm{H}\right.$, Phenol), $5.52\left(\mathrm{~m},{ }^{3} \mathrm{~J}=\right.$ 3.5, $2.0 \mathrm{~Hz}, 1 \mathrm{H}, \mathrm{H}-2), 5.40\left(\mathrm{~d},{ }^{3} \mathrm{~J}=2.0 \mathrm{~Hz}, 1 \mathrm{H}, \mathrm{H}-1\right), 4.73$ and $4.52\left(2 \mathrm{~d},{ }^{3} \mathrm{~J}=11.0 \mathrm{~Hz}, 2 \times 1 \mathrm{H}\right.$, $\mathrm{CH}_{2}-\mathrm{Ph}$ ), 3.89 (dd, $\left.{ }^{3} \mathrm{~J}=9.0,3.5 \mathrm{~Hz}, 1 \mathrm{H}, \mathrm{H}-3\right), 3.83\left(\mathrm{~m},{ }^{3} \mathrm{~J}=9.0,6.0 \mathrm{~Hz}, 1 \mathrm{H}, \mathrm{H}-5\right), 3.66$ (dd, $\mathrm{m}$, $\left.{ }^{3} \mathrm{~J}=9.0,9.0 \mathrm{~Hz}, 1 \mathrm{H}, \mathrm{H}-4\right), 2.32\left(\mathrm{~s}, 3 \mathrm{H}, \mathrm{CH}_{3}-\mathrm{Ph}\right), 2.17\left(\mathrm{~s}, 3 \mathrm{H}, \mathrm{CH}_{3} \mathrm{CO}\right), 1.28\left(\mathrm{~d},{ }^{3} \mathrm{~J}=6.0 \mathrm{~Hz}\right.$, $3 \mathrm{H}, \mathrm{H}-6), 0.88(\mathrm{~s}, 9 \mathrm{H}, t \mathrm{Bu}-\mathrm{Si}), 0.08$ and $0.02\left(2 \mathrm{~s}, 2 \times 3 \mathrm{H}, \mathrm{CH}_{3}-\mathrm{Si}\right)$.

${ }^{13} \mathrm{C}$ NMR $\left(100.6 \mathrm{MHz}, \mathrm{CDCl}_{3}\right): \delta=170.3(\mathrm{C}=\mathrm{O}), 154.1$ 137.9, 130.0, 128.2, 127.9, 127.5, 116.4, 96.3 (C-1), 77.7 (C-3), 73.0 (C-4), $71.3\left(\mathrm{CH}_{2}-\mathrm{Ph}\right), 69.8$ (C-5), 68.5(C-2), 26.0 (tBu$\mathrm{Si}), 21.0\left(\mathrm{CH}_{3}-\mathrm{Ac}\right), 20.6\left(\mathrm{CH}_{3}-\mathrm{Ph}\right), 18.4(\mathrm{C}-6), 18.2(t \mathrm{Bu}-\mathrm{Si}),-3.7$ and $-4.6\left(\mathrm{CH}_{3}-\mathrm{Si}\right)$.

HRMS. Calc. for $\mathrm{C}_{28} \mathrm{H}_{40} \mathrm{O}_{6} \mathrm{SiNa:}$ 523.2492. Found : 523.2495. 


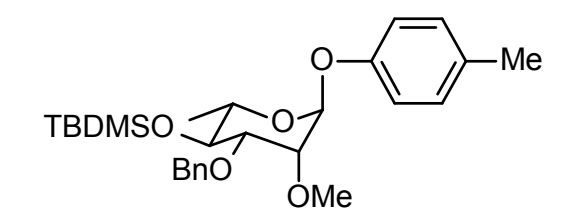

$\mathrm{C}_{27} \mathrm{H}_{40} \mathrm{O}_{5} \mathrm{Si}$ : Calc. 472.689 g.mol ${ }^{-1}$

\section{4-methylphenyl 3-O-benzyl-4-O-tertbutyldimethylsilyl-6-deoxy-2-O-methyl-a-L- mannopyranoside (26)}

$[\alpha]_{D}=-113.2^{\circ}(c 1.30$, chloroform $)$

${ }^{1} \mathrm{H}$ NMR $\left(400 \mathrm{MHz}, \mathrm{CDCl}_{3}\right): \delta=7.11$ and $6.98\left(2 \mathrm{~d},{ }^{3} \mathrm{~J}=8.5 \mathrm{~Hz}, 2 \times 2 \mathrm{H}\right.$, Phenol), $5.45\left(\mathrm{~d},{ }^{3} \mathrm{~J}=\right.$ $2.0 \mathrm{~Hz}, 1 \mathrm{H}, \mathrm{H}-1), 4.74$ and $4.69\left(2 \mathrm{~d},{ }^{3} \mathrm{~J}=11.5 \mathrm{~Hz}, 2 \times 1 \mathrm{H}, \mathrm{CH}_{2}-\mathrm{Ph}\right), 3.82(\mathrm{~m}, 1 \mathrm{H}, \mathrm{H}-3), 3.72$ (m, $2 \mathrm{H}, \mathrm{H}-4, \mathrm{H}-5), 3.62\left(\mathrm{dd},{ }^{3} \mathrm{~J}=3.0,2.0 \mathrm{~Hz}, 1 \mathrm{H}, \mathrm{H}-2\right), 3.49\left(\mathrm{~s}, 3 \mathrm{H}, \mathrm{OCH}_{3}\right), 2.32\left(\mathrm{~s}, 3 \mathrm{H}, \mathrm{CH}_{3}-\right.$ $\mathrm{Ph}), 1.26$ (brd, $\left.{ }^{3} \mathrm{~J}=6.0 \mathrm{~Hz}, 3 \mathrm{H}, \mathrm{H}-6\right), 0.90$ (s, 9H, tBu-Si), 0.11 and $0.09\left(2 \mathrm{~s}, 2 \times 3 \mathrm{H}, \mathrm{CH}_{3}-\mathrm{Si}\right)$.

${ }^{13} \mathrm{C}$ NMR $\left(100.6 \mathrm{MHz}, \mathrm{CDCl}_{3}\right): \delta=154.4138 .5,131.4,129.9,128.3,127.9,127.5,116.3$, 96.0 (C-1), 79.7 (C-3), 77.7 (C-2), 73.0 (C-4), $72.1\left(\mathrm{CH}_{2}-\mathrm{Ph}\right), 70.0(\mathrm{C}-5), 59.3\left(\mathrm{OCH}_{3}\right), 26.0$ (tBu-Si), $20.5\left(\mathrm{CH}_{3}-\mathrm{Ph}\right), 18.4(\mathrm{C}-6), 18.2(t \mathrm{Bu}-\mathrm{Si}),-3.7$ and $-4.6\left(\mathrm{CH}_{3}-\mathrm{Si}\right)$.

HRMS. Calc. For $\mathrm{C}_{27} \mathrm{H}_{40} \mathrm{O}_{5} \mathrm{SiNa}:$ 495.2543. Found : 495.2547.

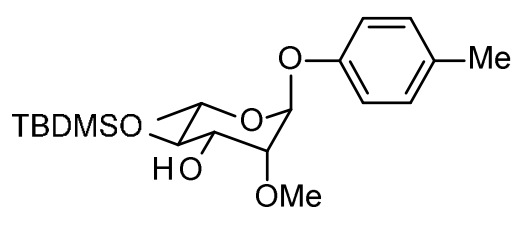

$\mathrm{C}_{20} \mathrm{H}_{34} \mathrm{O}_{5} \mathrm{Si}: 382.57 \mathrm{~g} \cdot \mathrm{mol}^{-1}$

4-methylphenyl 4-O-tertbutyldimethylsilyl-6-deoxy-2-O-methyl-a-L-mannopyranoside (27)

$[\alpha]_{D}=-69.5^{\circ}(c$ 0.97, chloroform)

${ }^{1} \mathrm{H}$ NMR $\left(400 \mathrm{MHz}, \mathrm{CDCl}_{3}\right): \delta=7.12$ and $7.00\left(2 \mathrm{~d},{ }^{3} \mathrm{~J}=8.5 \mathrm{~Hz}, 2 \times 2 \mathrm{H}\right.$, Phenol), $5.53\left(\mathrm{~d},{ }^{3} \mathrm{~J}=\right.$ $1.5 \mathrm{~Hz}, 1 \mathrm{H}, \mathrm{H}-1), 3.90\left(\mathrm{dd},{ }^{3} \mathrm{~J}=9.0,3.5 \mathrm{~Hz} 1 \mathrm{H}, \mathrm{H}-3\right), 3.71\left(\mathrm{~m},{ }^{3} \mathrm{~J}=9.0,6.5 \mathrm{~Hz}, 1 \mathrm{H}, \mathrm{H}-5\right), 3.67$ (dd, $\left.{ }^{3} \mathrm{~J}=3.5,1.5 \mathrm{~Hz}, 1 \mathrm{H}, \mathrm{H}-2\right), 3.55\left(\mathrm{~s}, 3 \mathrm{H}, \mathrm{OCH}_{3}\right.$ ), 3.45 (dd, $\left.{ }^{3} \mathrm{~J}=9.0,9.0 \mathrm{~Hz}, 1 \mathrm{H}, \mathrm{H}-4\right), 2.32$ (s, 3H, $\mathrm{CH}_{3}-\mathrm{Ph}$ ), 2.15 (br s, $\left.1 \mathrm{H}, \mathrm{OH}\right), 1.25\left(\mathrm{~d},{ }^{3} \mathrm{~J}=6.5 \mathrm{~Hz}, 3 \mathrm{H}, \mathrm{H}-6\right), 0.92(\mathrm{~s}, 9 \mathrm{H}, t \mathrm{Bu}-\mathrm{Si}), 0.20$ and $0.13\left(2 \mathrm{~s}, 2 \times 3 \mathrm{H}, \mathrm{CH}_{3}-\mathrm{Si}\right)$.

${ }^{13} \mathrm{C}$ NMR $\left(100.6 \mathrm{MHz}, \mathrm{CDCl}_{3}\right): \delta=154.4131 .5,129.9,116.2,94.7$ (C-1), 80.7 (C-2), 75.4 (C-4), 71.5 (C-3), 69.0 (C-5), $59.0\left(\mathrm{OCH}_{3}\right), 25.9$ (tBu-Si), $20.5\left(\mathrm{CH}_{3}-\mathrm{Ph}\right), 18.3$ (tBu-Si), 18.1 (C-6), -3.8 and $-4.6\left(\mathrm{CH}_{3}-\mathrm{Si}\right)$.

HRMS. Calc. For $\mathrm{C}_{20} \mathrm{H}_{34} \mathrm{O}_{5} \mathrm{Si}-\mathrm{H}: 381.2097$. Found : 381.2099 . 


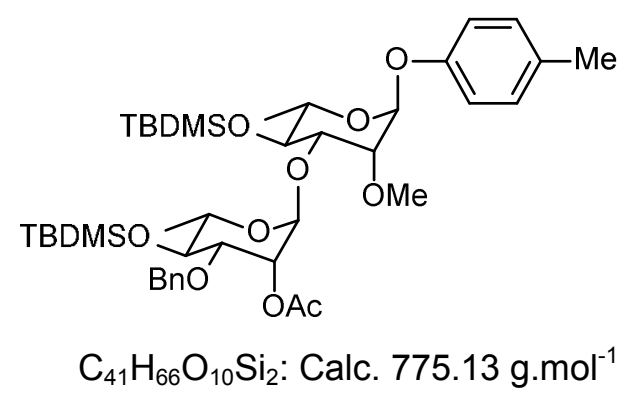

4-methylphenyl 3-O-(-2-O-acetyl-3-O-benzyl-4-O-tertbutyldimethylsilyl-6-deoxy- $\alpha-L-$ mannopyranosyl-)-4-O-tertbutyldimethylsilyl-6-deoxy-2-O-methyl-a-Lmannopyranoside (28)

$[\alpha]_{D}=-61.5^{\circ}(c 1.09$, chloroform $)$

${ }^{1} \mathrm{H} \mathrm{NMR}\left(400 \mathrm{MHz}, \mathrm{CDCl}_{3}\right): \delta=7.12$ and $7.00\left(2 \mathrm{~d},{ }^{3} \mathrm{~J}=8.5 \mathrm{~Hz}, 2 \times 2 \mathrm{H}\right.$, Phenol), 5.66 (dd, ${ }^{3} \mathrm{~J}=$ 3.0, $\left.1.5 \mathrm{~Hz} 1 \mathrm{H}, \mathrm{H}-2^{\prime}\right), 5.51\left(\mathrm{~d},{ }^{3} \mathrm{~J}=1.5 \mathrm{~Hz}, 1 \mathrm{H}, \mathrm{H}-1\right), 4.98\left(\mathrm{~d},{ }^{3} \mathrm{~J}=1.5 \mathrm{~Hz}, 1 \mathrm{H}, \mathrm{H}-1\right.$ '), 4.72 and $4.42\left(2 \mathrm{~d},{ }^{3} \mathrm{~J}=11.0 \mathrm{~Hz}, 2 \times 1 \mathrm{H}, \mathrm{CH}_{2}-\mathrm{Ph}\right), 4.02(\mathrm{~m}, 1 \mathrm{H}, \mathrm{H}-3), 3.95\left(\mathrm{~m},{ }^{3} \mathrm{~J}=9.0,6.5 \mathrm{~Hz}, 1 \mathrm{H}, \mathrm{H}-\right.$ 5), $3.83\left(\mathrm{dd},{ }^{3} \mathrm{~J}=2.5,1.5 \mathrm{~Hz}, 1 \mathrm{H}, \mathrm{H}-2\right), 3.78\left(\mathrm{dd},{ }^{3} \mathrm{~J}=9.0,3.0 \mathrm{~Hz}, 1 \mathrm{H}, \mathrm{H}-3^{\prime}\right), 3.73(\mathrm{~m}, 2 \mathrm{H}, \mathrm{H}-$ 4, $\mathrm{H}-5$ ), 3.63 (dd, ${ }^{3} \mathrm{~J}=9.0,9.0 \mathrm{~Hz}, 1 \mathrm{H}, \mathrm{H}-4$ ) $, 3.50\left(\mathrm{~s}, 3 \mathrm{H}, \mathrm{OCH}_{3}\right), 2.33$ (s, 3H, $\left.\mathrm{CH}_{3}-\mathrm{Ph}\right), 2.16$ (s, 3H, $\left.\mathrm{CH}_{3}-\mathrm{Ac}\right), 1.35$ (d, $\left.{ }^{3} \mathrm{~J}=6.0 \mathrm{~Hz}, 3 \mathrm{H}, \mathrm{H}-6^{\prime}\right), 1.25(\mathrm{~m}, 3 \mathrm{H}, \mathrm{H}-6), 0.90$ and $0.89(2 \mathrm{~s}, 2 \mathrm{x} 9 \mathrm{H}$, tBu-Si), 0.23, 0.13, 0.08 and $-0.01\left(4 \mathrm{~s}, 4 \times 3 \mathrm{H}, \mathrm{CH}_{3}-\mathrm{Si}\right)$.

${ }^{13} \mathrm{C}$ NMR $\left(100.6 \mathrm{MHz}, \mathrm{CDCl}_{3}\right): \delta=169.9(\mathrm{C}=\mathrm{O}), 154.5$ 138.0, 131.5, 129.9, 128.1, 127.9, 127.4, 116.2, 100.7 (C-1'), 94.7 (C-1), 80.6 (C-3), 80.2 (C-2), 77.8 (C-3'), 73.0 (C-4'), 72.2 (C-4), $71.1\left(\mathrm{CH}_{2}-\mathrm{Ph}\right), 70.2(\mathrm{C}-5), 69.6\left(\mathrm{C}-5^{\prime}\right), 68.3\left(\mathrm{C}-2^{\prime}\right), 58.0\left(\mathrm{OCH}_{3}\right), 25.9$ and 25.8 (tBu$\mathrm{Si}), 20.9\left(\mathrm{CH}_{3} \mathrm{Ac}\right), 20.5\left(\mathrm{CH}_{3}-\mathrm{Ph}\right), 18.6$ and 18.6 (C-6, C-6'), 18.2 and 17.9 (tBu-Si), -3.2, $3.8,-3.8$ and $-4.6\left(\mathrm{CH}_{3}-\mathrm{Si}\right)$.

HRMS. Calc. for $\mathrm{C}_{41} \mathrm{H}_{66} \mathrm{O}_{10} \mathrm{Si}{ }_{2} \mathrm{Na}: 797.4092$. Found : 797.4080 .

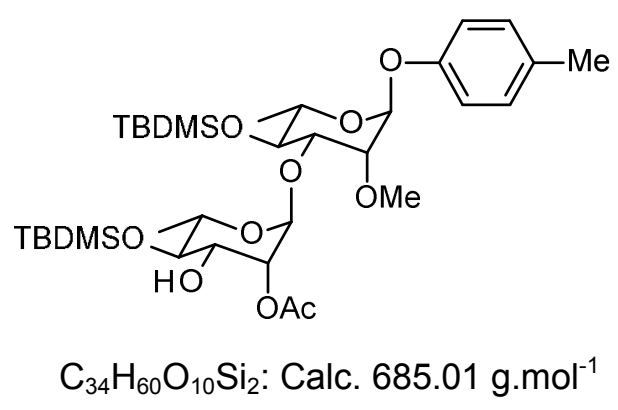

4-methylphenyl 3-O-(-2-O-acetyl-4-O-tertbutyldimethylsilyl-6-deoxy-a-Lmannopyranosyl-)-4-O-tertbutyldimethylsilyl-6-deoxy-2-O-methyl-a-Lmannopyranoside (29)

$[\alpha]_{D}=-81.7^{\circ}(c 1.28$, chloroform $)$ 
${ }^{1} \mathrm{H}$ NMR $\left(400 \mathrm{MHz}, \mathrm{CDCl}_{3}\right): \delta=7.11$ and $6.99\left(2 \mathrm{~d},{ }^{3} \mathrm{~J}=8.5 \mathrm{~Hz}, 2 \times 2 \mathrm{H}\right.$, Phenol), $5.49\left(\mathrm{~d},{ }^{3} \mathrm{~J}=\right.$ $1.5 \mathrm{~Hz}, 1 \mathrm{H}, \mathrm{H}-1$ ), 5.35 (dd, ${ }^{3} \mathrm{~J}=3.0,1.0 \mathrm{~Hz} 1 \mathrm{H}, \mathrm{H}-2$ '), 4.98 (d, $\left.{ }^{3} \mathrm{~J}=1.0 \mathrm{~Hz}, 1 \mathrm{H}, \mathrm{H}-1^{\prime}\right), 4.02$ (m, $1 \mathrm{H}, \mathrm{H}-3), 4.00\left(\mathrm{dd},{ }^{3} \mathrm{~J}=9.0,3.0 \mathrm{~Hz}, 1 \mathrm{H}, \mathrm{H}-3^{\prime}\right), 3.90\left(\mathrm{~m},{ }^{3} \mathrm{~J}=9.0,6.0 \mathrm{~Hz}, 1 \mathrm{H}, \mathrm{H}-5^{\prime}\right), 3.79$ (dd, ${ }^{3} J=2.5,1.5 \mathrm{~Hz}, 1 \mathrm{H}, \mathrm{H}-2$ ), $3.72(\mathrm{~m}, 2 \mathrm{H}, \mathrm{H}-4, \mathrm{H}-5), 3.52$ (dd, ${ }^{3} \mathrm{~J}=9.0,9.0 \mathrm{~Hz}, 1 \mathrm{H}, \mathrm{H}-4$ '), 3.51 (s, 3H, $\mathrm{OCH}_{3}$ ), 2.32 (s, 3H, $\mathrm{CH}_{3}-\mathrm{Ph}$ ), 2.17 (s, 3H, $\mathrm{CH}_{3}-\mathrm{Ac}$ ), 1.33 (d, ${ }^{3} \mathrm{~J}=6.0 \mathrm{~Hz}, 3 \mathrm{H}, \mathrm{H}-6$ '), $1.24(\mathrm{~m}, 3 \mathrm{H}, \mathrm{H}-6), 0.93$ and $0.90(2 \mathrm{~s}, 2 \times 9 \mathrm{H}, t \mathrm{Bu}-\mathrm{Si}), 0.19,0.17,0.15$ and $0.12(4 \mathrm{~s}, 4 \times 3 \mathrm{H}$, $\left.\mathrm{CH}_{3}-\mathrm{Si}\right)$.

${ }^{13} \mathrm{C}$ NMR (100.6 MHz, $\left.\mathrm{CDCl}_{3}\right): \delta=170.6(\mathrm{C}=0), 154.5$ 131.5, 129.9, 116.2, $100.0\left(\mathrm{C}-1^{\prime}\right), 94.8$ (C-1), 80.2 (C-3), 80.1 (C-2), 74.8 (C-4'), 72.6 (C-2'), 72.3 (C-4), 70.6 (C-3'), 70.2 (C-5), 69.1 (C-5'), $58.1\left(\mathrm{OCH}_{3}\right), 25.9$ and 25.8 (tBu-Si), $20.9\left(\mathrm{CH}_{3} \mathrm{Ac}\right), 20.5\left(\mathrm{CH}_{3}-\mathrm{Ph}\right), 18.6(\mathrm{C}-6), 18.3$ (C-6'), 18.2 and 17.9 (tBu-Si), -3.5, -3.8, -3.8 and $-4.5\left(\mathrm{CH}_{3}-\mathrm{Si}\right)$.

HRMS. Calc. for $\mathrm{C}_{34} \mathrm{H}_{60} \mathrm{O}_{10} \mathrm{Si}_{2} \mathrm{Na}:$ 707.3623. Found : 707.3641.

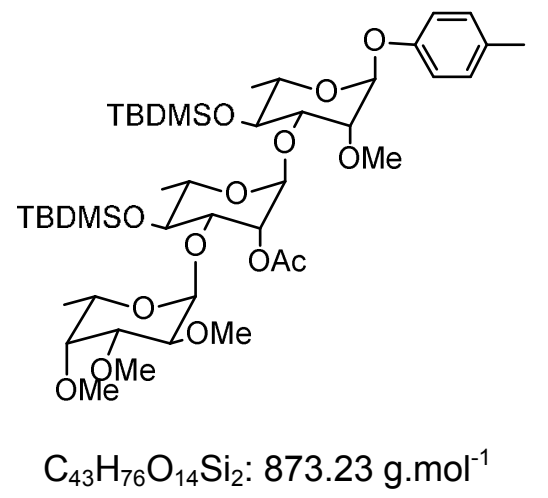

\section{4-methylphenyl 3-0-(-2-0-acetyl-4-O-tertbutyldimethylsilyl-6-deoxy-3-0-(-6-deoxy-

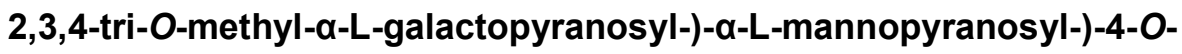 tertbutyldimethylsilyl-6-deoxy-2-O-methyl-a-L-mannopyranoside (30)}

$[\alpha]_{D}=-65.6^{\circ}(c 0.64$, chloroform $)$

${ }^{1} \mathrm{H}$ NMR $\left(400 \mathrm{MHz}, \mathrm{CDCl}_{3}\right): \delta=7.11$ and $6.99\left(2 \mathrm{~d},{ }^{3} \mathrm{~J}=8.5 \mathrm{~Hz}, 2 \times 2 \mathrm{H}\right.$, Phenol), $5.50\left(\mathrm{~d},{ }^{3} \mathrm{~J}=\right.$ $1.5 \mathrm{~Hz}, 1 \mathrm{H}, \mathrm{H}-1), 5.42\left(\mathrm{br}, 1 \mathrm{H}, \mathrm{H}-2^{\prime}\right), 5.11\left(\mathrm{~d},{ }^{3} \mathrm{~J}=3.5 \mathrm{~Hz}, 1 \mathrm{H}, \mathrm{H}-1\right.$ '), $5.05\left(\mathrm{~d},{ }^{3} \mathrm{~J}=1.5 \mathrm{~Hz}, 1 \mathrm{H}\right.$, $\left.\mathrm{H}-1^{\prime}\right), 4.01-3.92\left(\mathrm{~m}, 3 \mathrm{H}, \mathrm{H}-3, \mathrm{H}-3^{\prime}, \mathrm{H}-5\right.$ "), $3.91\left(\mathrm{~m},{ }^{3} \mathrm{~J}=9.0,6.0 \mathrm{~Hz}, 1 \mathrm{H}, \mathrm{H}-5\right.$ '), 3.81 (dd, ${ }^{3} \mathrm{~J}=$ 2.5, $1.5 \mathrm{~Hz}, 1 \mathrm{H}, \mathrm{H}-2), 3.72\left(\mathrm{dd}, 2 \mathrm{H},{ }^{3} \mathrm{~J}=9.0,9.0 \mathrm{~Hz}, 1 \mathrm{H}, \mathrm{H}-4\right.$ '), 3.70 (m, 2H, H-4, H-5), 3.67 (dd, ${ }^{3} \mathrm{~J}=10.0,2.5 \mathrm{~Hz}, 1 \mathrm{H}, \mathrm{H}-3$ "), 3.61 (dd, ${ }^{3} \mathrm{~J}=10.0,3.5 \mathrm{~Hz}, 1 \mathrm{H}, \mathrm{H}-2$ "), 3.60, 3.53, 3.49 and $3.4\left(4 \mathrm{~s}, 4 \times 3 \mathrm{H}, \mathrm{OCH}_{3}\right), 3.43\left(\mathrm{~m}, 1 \mathrm{H}, \mathrm{H}-4\right.$ "), 2.31 (s, 3H, $\left.\mathrm{CH}_{3}-\mathrm{Ph}\right), 2.15$ (s, 3H, $\left.\mathrm{CH}_{3}-\mathrm{Ac}\right), 1.31$ (d, ${ }^{3} \mathrm{~J}=6.0 \mathrm{~Hz}, 3 \mathrm{H}, \mathrm{H}-6$ '), $1.23(\mathrm{~m}, 3 \mathrm{H}, \mathrm{H}-6), 1.18$ (d, ${ }^{3} \mathrm{~J}=6.5 \mathrm{~Hz}, 3 \mathrm{H}, \mathrm{H}-6$ "), 0.94 and 0.91 (2s, $2 x 9 \mathrm{H}, t \mathrm{Bu}-\mathrm{Si}), 0.27,0.22,0.14$ and $0.11\left(4 \mathrm{~s}, 4 \times 3 \mathrm{H}, \mathrm{CH}_{3}-\mathrm{Si}\right)$.

${ }^{13} \mathrm{C}$ NMR (100.6 MHz, $\left.\mathrm{CDCl}_{3}\right): \delta=170.1(\mathrm{C}=0), 154.5$ 131.5, 129.9, 116.2, $99.5\left(\mathrm{C}-1^{\prime}\right), 98.8$ (C-1"), 94.5 (C-1), 81.0 (C-3), 80.2 (C-2), 79.8 (C-3"), 79.6 (C-4"), 78.9 (C-3'), 77.8 (C-2”), 73.0 (C-2'), 72.4 (C-4'), 72.0 (C-4), 70.2 (C-5), 69.5 (C-5'), 67.2 (C-5”), 61.9, 58.6, 58.2 and $57.8\left(\mathrm{OCH}_{3}\right), 26.0$ and $25.8(t \mathrm{Bu}-\mathrm{Si}), 21.2\left(\mathrm{CH}_{3} \mathrm{Ac}\right), 20.5\left(\mathrm{CH}_{3}-\mathrm{Ph}\right), 18.9\left(\mathrm{C}-6^{\prime}\right), 18.6(\mathrm{C}-6)$, 17.9 (tBu-Si), 16.2 (C-6"), -3.1, -3.2, -3.6 and $-4.0\left(\mathrm{CH}_{3}-\mathrm{Si}\right)$. 
HRMS. Calc. for $\mathrm{C}_{43} \mathrm{H}_{76} \mathrm{O}_{14} \mathrm{Si}_{2} \mathrm{Na}:$ 895.4671. Found : 895.4667.

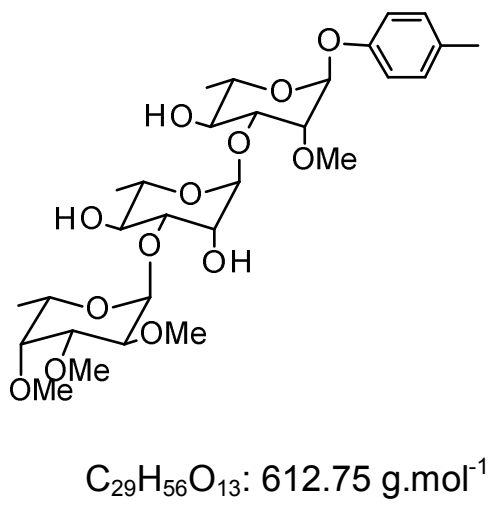

4-methylphenyl 3-O-(-6-deoxy-3-O-(-6-deoxy-2,3,4-tri-O-methyl-a-L-galactopyranosyl-)-

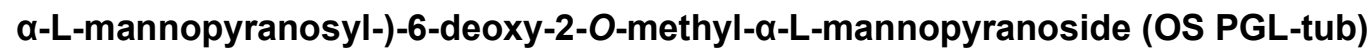

$[\alpha]_{D}=-155.8^{\circ}(c 0.55$, methanol)

${ }^{1} \mathrm{H}$ NMR (400MHz, $\left.\mathrm{CD}_{3} \mathrm{OD}\right): \delta=7.12$ and $6.98\left(2 \mathrm{~d},{ }^{3} \mathrm{~J}=8.5 \mathrm{~Hz}, 2 \times 2 \mathrm{H}\right.$, Phenol), $5.53\left(\mathrm{~d},{ }^{3} \mathrm{~J}=\right.$ $1.5 \mathrm{~Hz}, 1 \mathrm{H}, \mathrm{H}-1$ ), 5.28 (d, ${ }^{3} \mathrm{~J}=3.5 \mathrm{~Hz}, 1 \mathrm{H}, \mathrm{H}-1$ "), 5.07 (d, ${ }^{3} \mathrm{~J}=1.5 \mathrm{~Hz}, 1 \mathrm{H}, \mathrm{H}-1$ ') 4.16 (br q, ${ }^{3} \mathrm{~J}$ $=6.0 \mathrm{~Hz}, 1 \mathrm{H}, \mathrm{H}-5$ "), 4.09 (dd, ${ }^{3} \mathrm{~J}=3.0,1.5 \mathrm{~Hz}, 1 \mathrm{H}, \mathrm{H}-2$ '), 4.03 (dd, ${ }^{3} \mathrm{~J}=9.5,3.0 \mathrm{~Hz}, 1 \mathrm{H}, \mathrm{H}-3$ ), $3.85\left(\mathrm{dq},{ }^{3} \mathrm{~J}=9.5,6.0 \mathrm{~Hz}, 1 \mathrm{H}, \mathrm{H}-5\right.$ '), 3.81 (dd, $\left.{ }^{3} \mathrm{~J}=9.5,3.0 \mathrm{~Hz}, 1 \mathrm{H}, \mathrm{H}-3^{\prime}\right), 3.74$ (dd, ${ }^{3} \mathrm{~J}=3.0$, $1.5 \mathrm{~Hz}, 1 \mathrm{H}, \mathrm{H}-2), 3.72$ (dd, ${ }^{3} \mathrm{~J}=9.5,3.0 \mathrm{~Hz}, 1 \mathrm{H}, \mathrm{H}-3$ ) $), 3.68$ (dq, $\left.{ }^{3} \mathrm{~J}=9.5,6.0 \mathrm{~Hz}, 1 \mathrm{H}, \mathrm{H}-5\right)$, 3.63 (dd, ${ }^{3} \mathrm{~J}=9.5,9.5 \mathrm{~Hz}, 1 \mathrm{H}, \mathrm{H}-4$ '), 3.60 (dd, ${ }^{3} \mathrm{~J}=3.0,1.0 \mathrm{~Hz}, 1 \mathrm{H}, \mathrm{H}-4$ "), 3.57 (m, $1 \mathrm{H}, \mathrm{H}-2$ "), $3.54\left(\mathrm{dd},{ }^{3} \mathrm{~J}=9.5,9.5 \mathrm{~Hz}, 1 \mathrm{H}, \mathrm{H}-4\right), 3.58,3.55,3.54$ and $3.53\left(4 \mathrm{~s}, 4 \times 3 \mathrm{H}, \mathrm{OCH}_{3}\right), 2.30(\mathrm{~s}, 3 \mathrm{H}$, $\mathrm{CH}_{3}-\mathrm{Ph}$ ), 1.34 (d, ${ }^{3} \mathrm{~J}=6.0 \mathrm{~Hz}, 3 \mathrm{H}, \mathrm{H}-6$ ), 1.24 (d, ${ }^{3} \mathrm{~J}=6.0 \mathrm{~Hz}, 3 \mathrm{H}, \mathrm{H}-6$ "), 1.22 (d, ${ }^{3} \mathrm{~J}=6.5 \mathrm{~Hz}$, $3 \mathrm{H}, \mathrm{H}-6)$.

${ }^{13} \mathrm{C}$ NMR (100.6 MHz, CD $\left.\mathrm{CD}_{3} \mathrm{OD}\right): \delta=154.2,131.4,129.5,116.2,102.6$ (C-1'), 98.8 (C-1"), 95.4 (C-1), 80.2 (C-2), 79.9 (C-3"), 79.2 (C-3'), 79.1 (C-4"), 78.2 (C-2"), 77.9 (C-3), 72.0 (C4), 71.7 (C-4'), 70.7 (C-2'), 69.5 (C-5), 69.1 (C-5'), 66.6 (C-5”), 60.6, 58.0, 57.5 and 56.8 $\left(\mathrm{OCH}_{3}\right), 19.2\left(\mathrm{CH}_{3}-\mathrm{Ph}\right), 16.7$ (C-6'), $16.6(\mathrm{C}-6), 15.3$ (C-6").

HRMS. Calc for $\mathrm{C}_{29} \mathrm{H}_{46} \mathrm{O}_{13} \mathrm{Na}: 626.2836$. Found : 625.2840 .

References: (4-6) 
III. Copies of ${ }^{1} \mathrm{H}$ and ${ }^{13} \mathrm{C}$ NMR Spectra for all new compounds

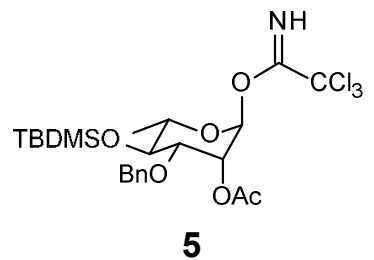

${ }^{1} \mathrm{H}$ NMR

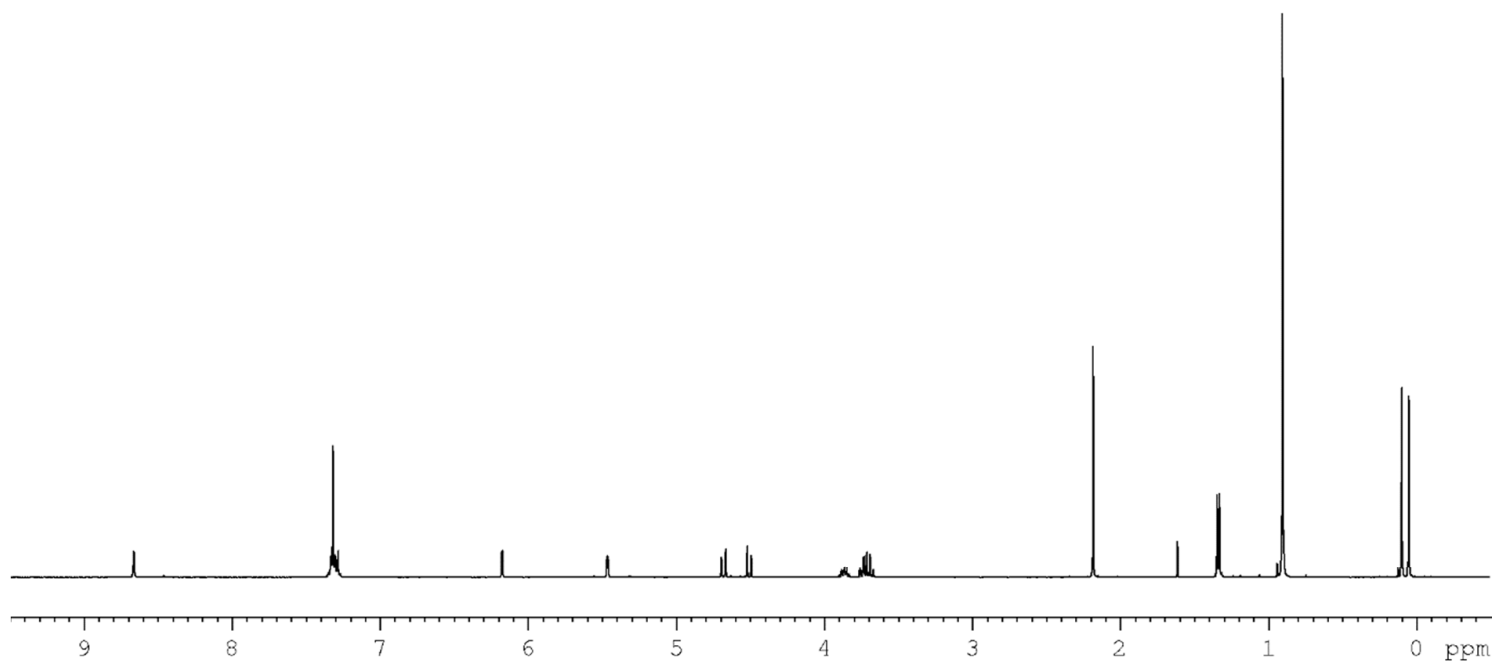

${ }^{13} \mathrm{C}$ NMR

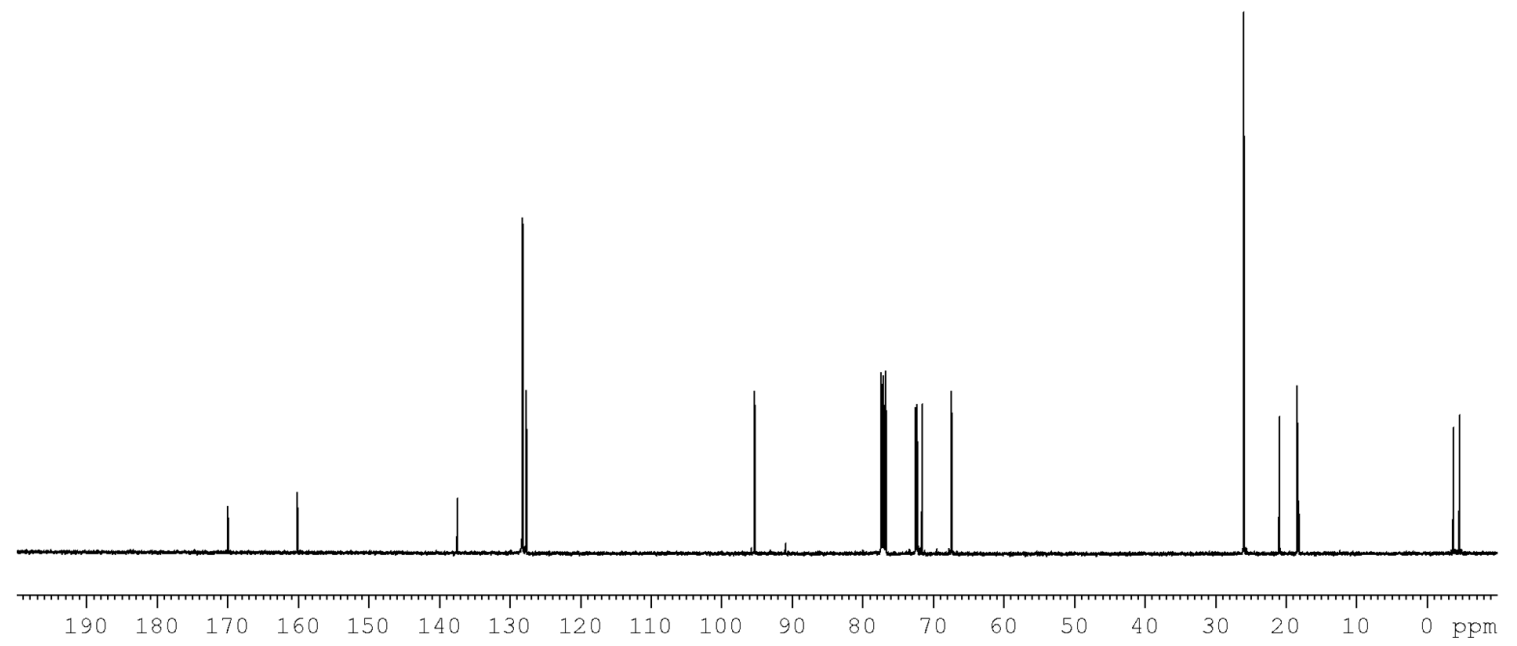




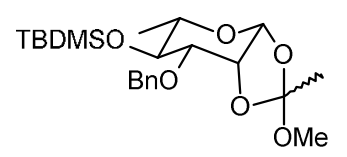

12

${ }^{1} \mathrm{H}$ NMR

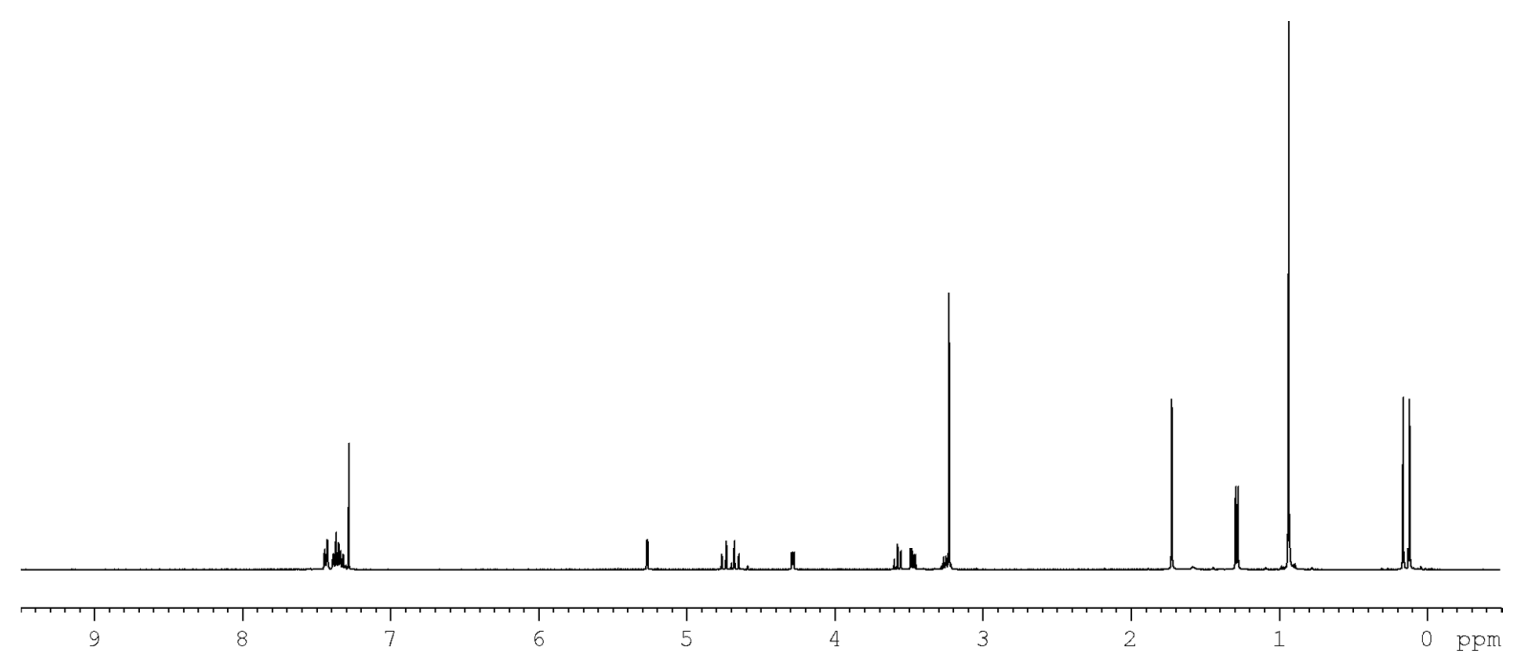

${ }^{13} \mathrm{C}$ NMR

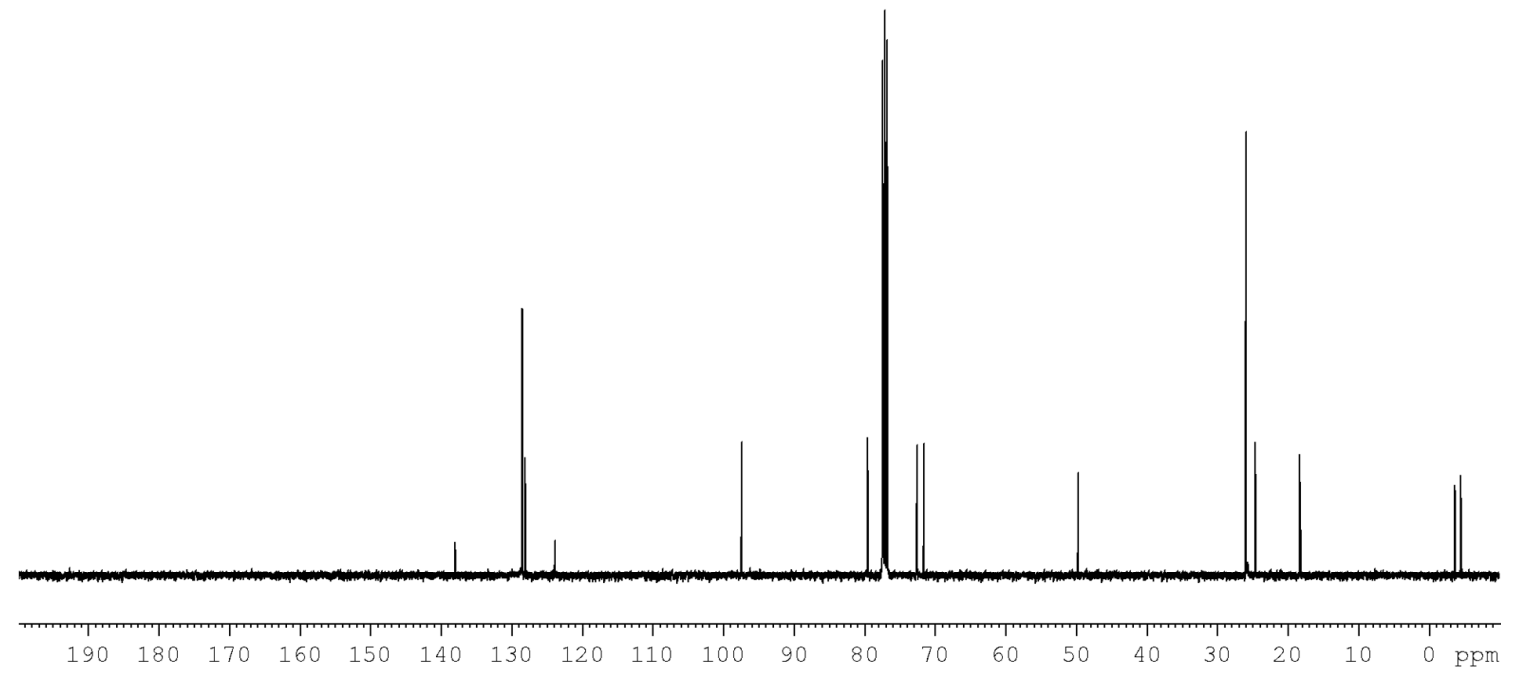




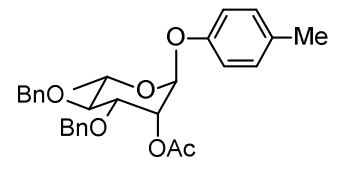

14

${ }^{1} \mathrm{H}$ NMR

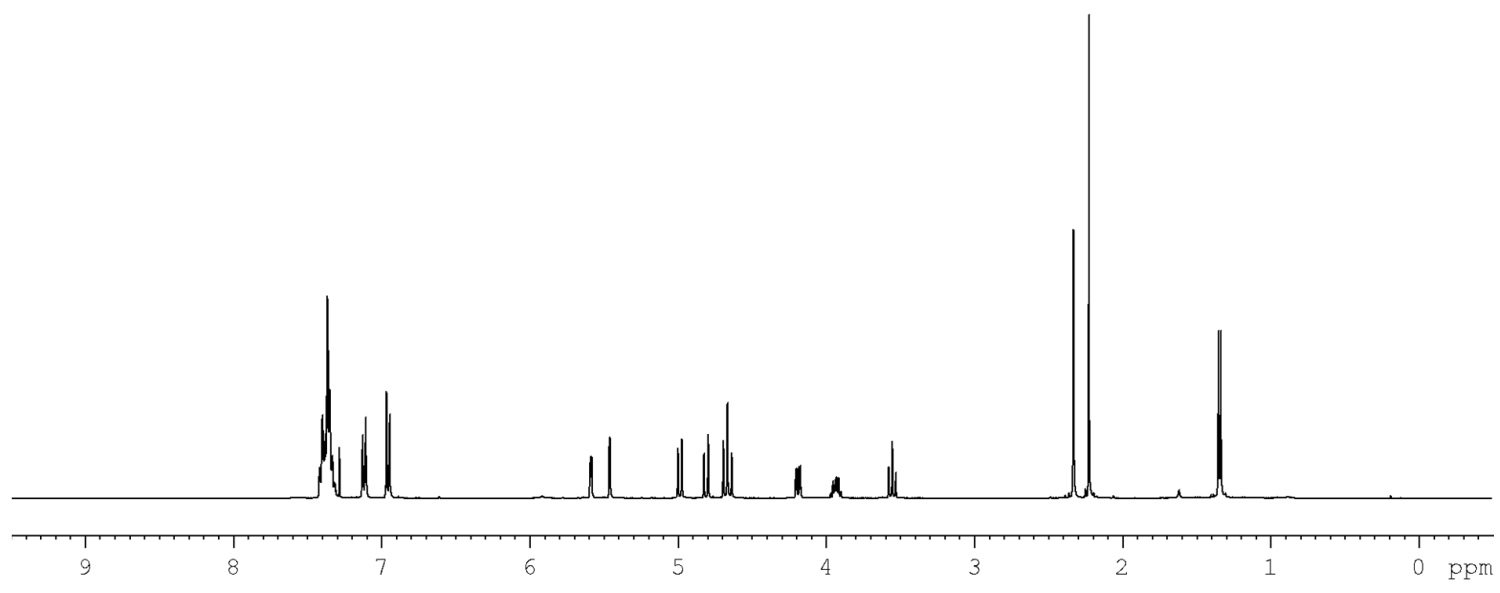

${ }^{13} \mathrm{C}$ NMR

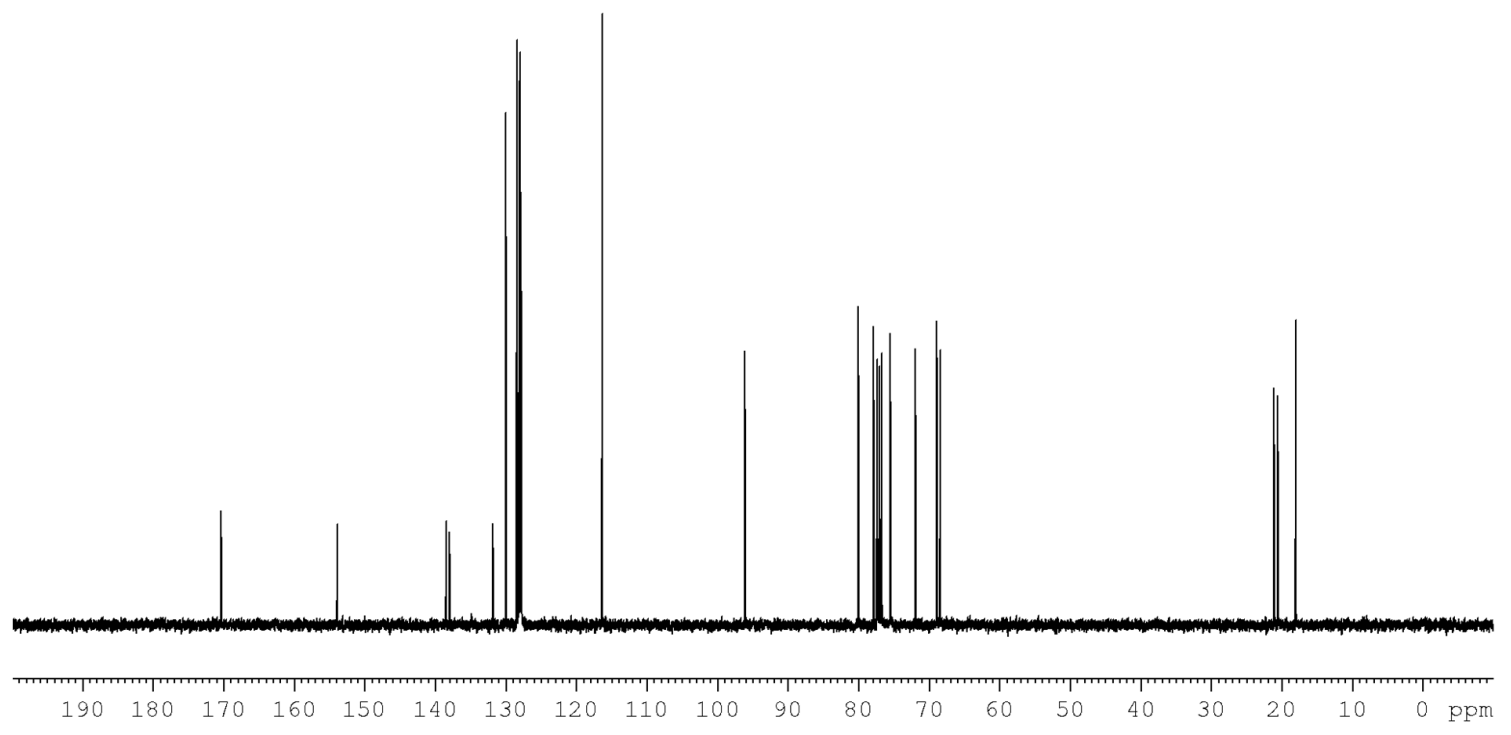

20 


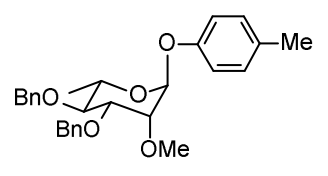

16

${ }^{1} \mathrm{H}$ NMR

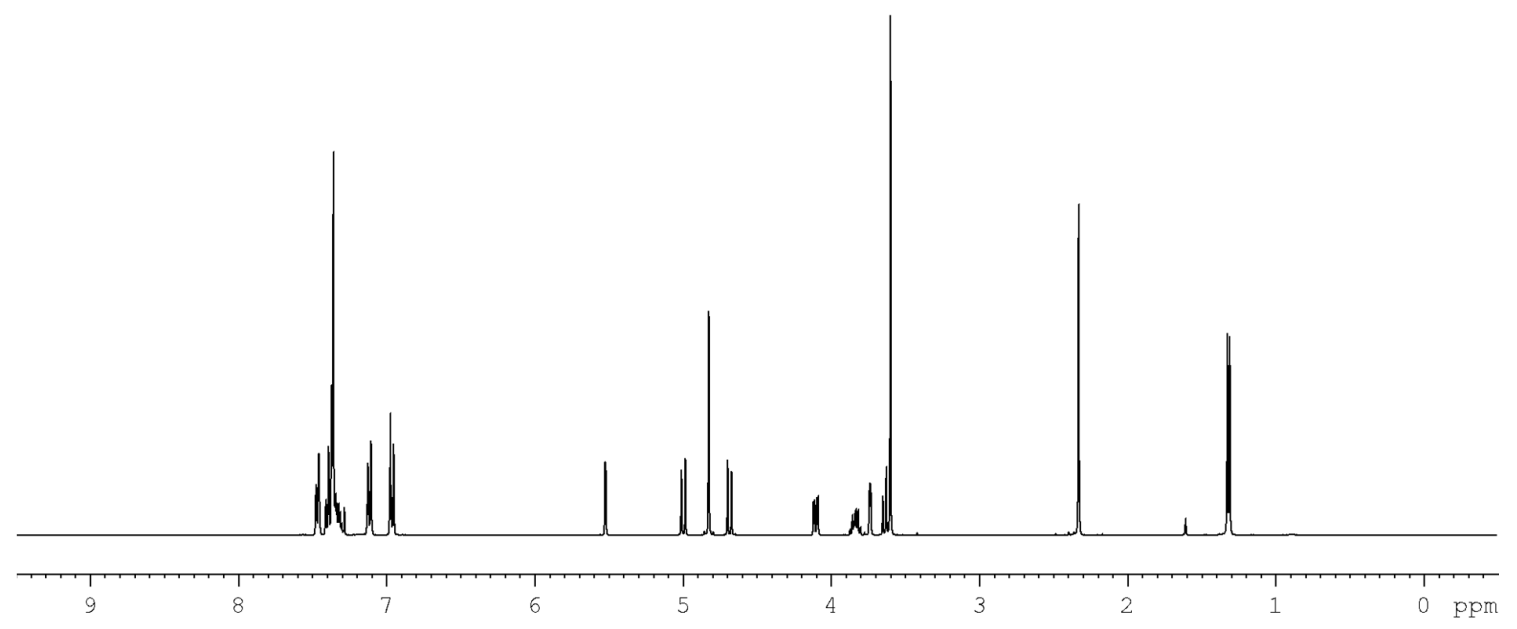

${ }^{13} \mathrm{C}$ NMR

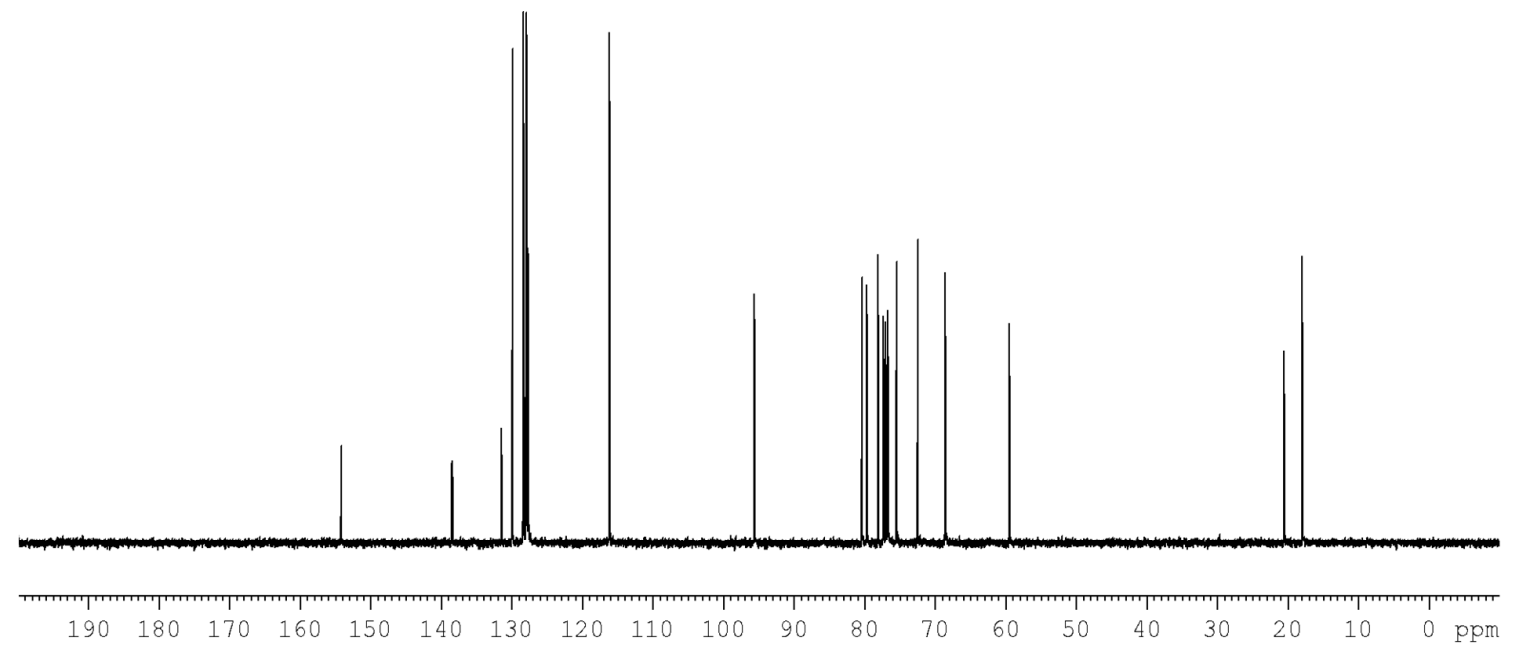




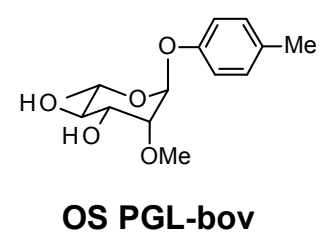

${ }^{1}$ H NMR

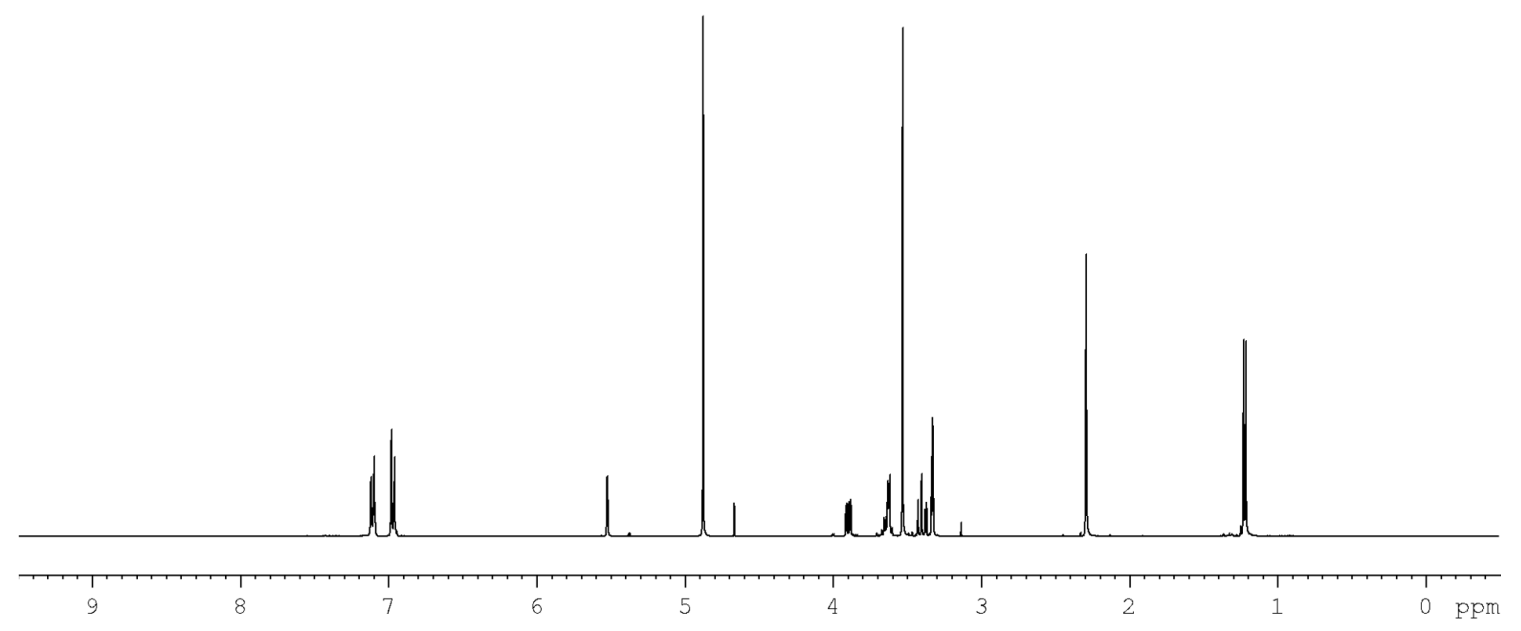

${ }^{13} \mathrm{C}$ NMR

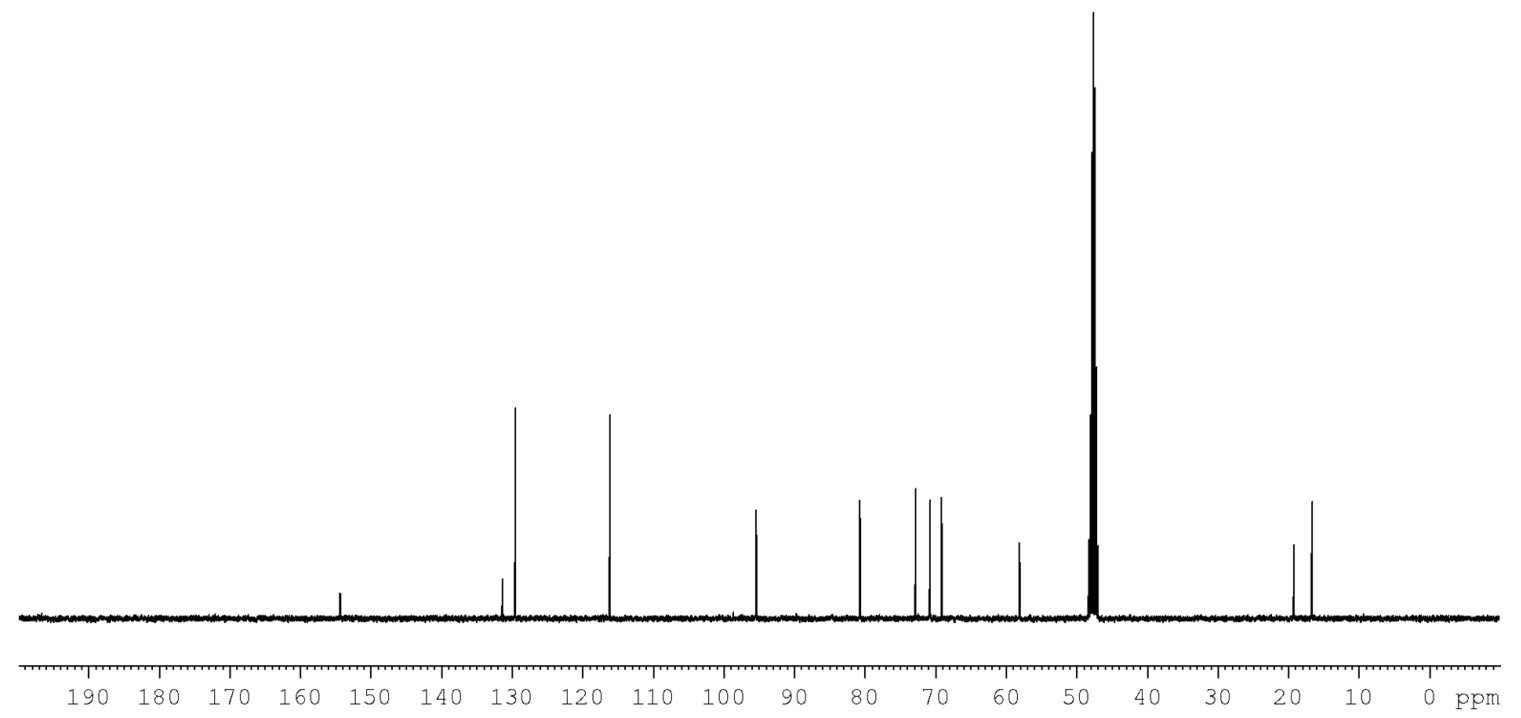




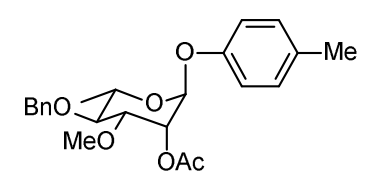

17

${ }^{1}$ H NMR

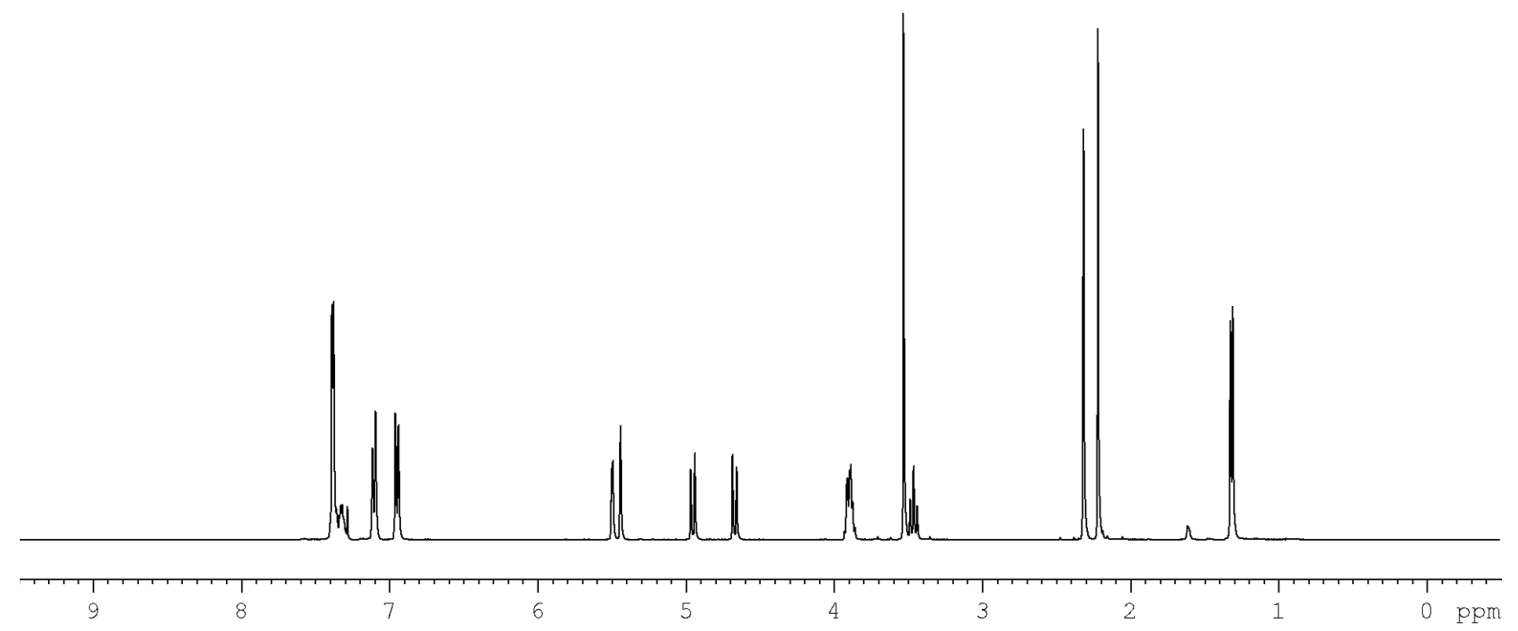

${ }^{13} \mathrm{C}$ NMR

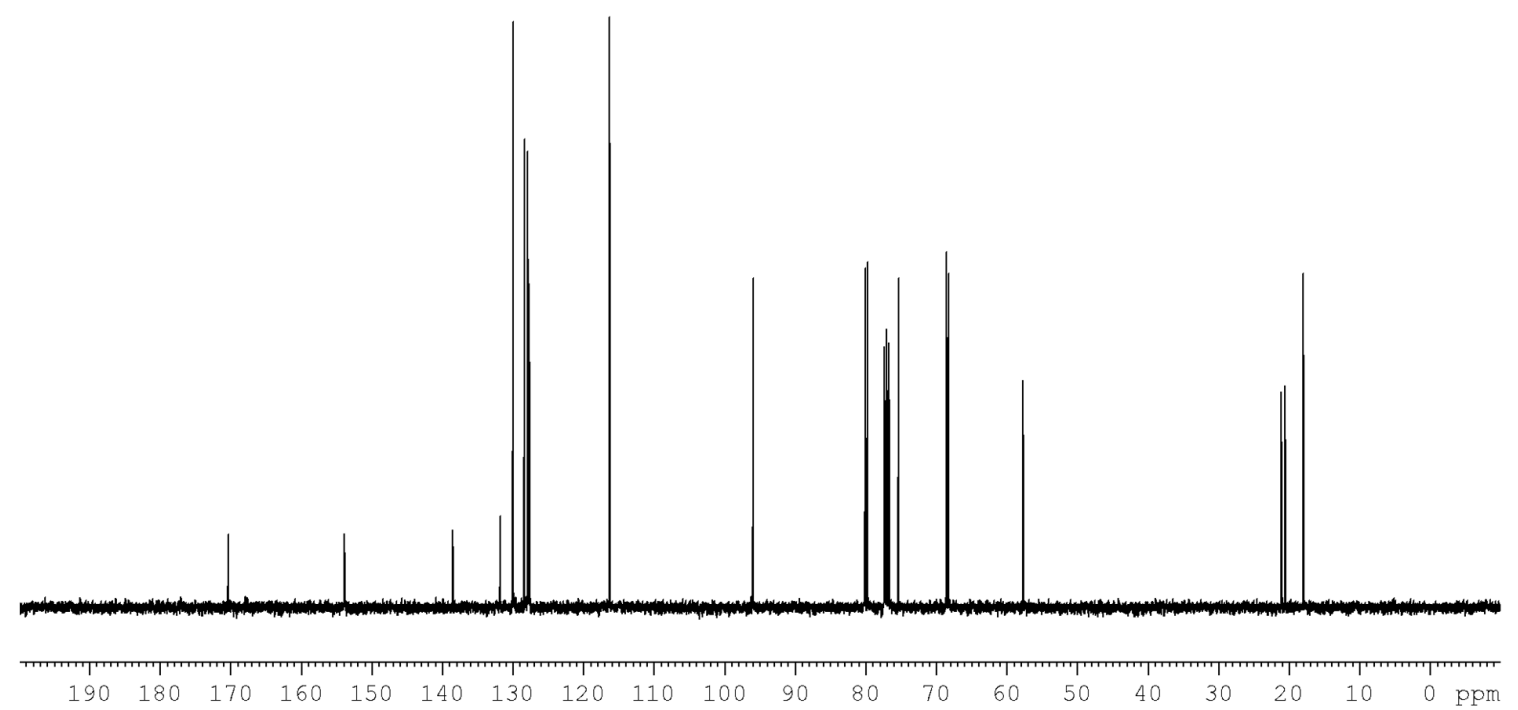




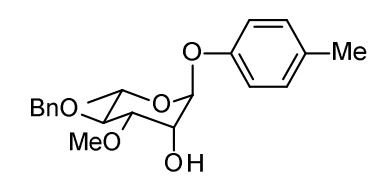

${ }^{1}$ H NMR

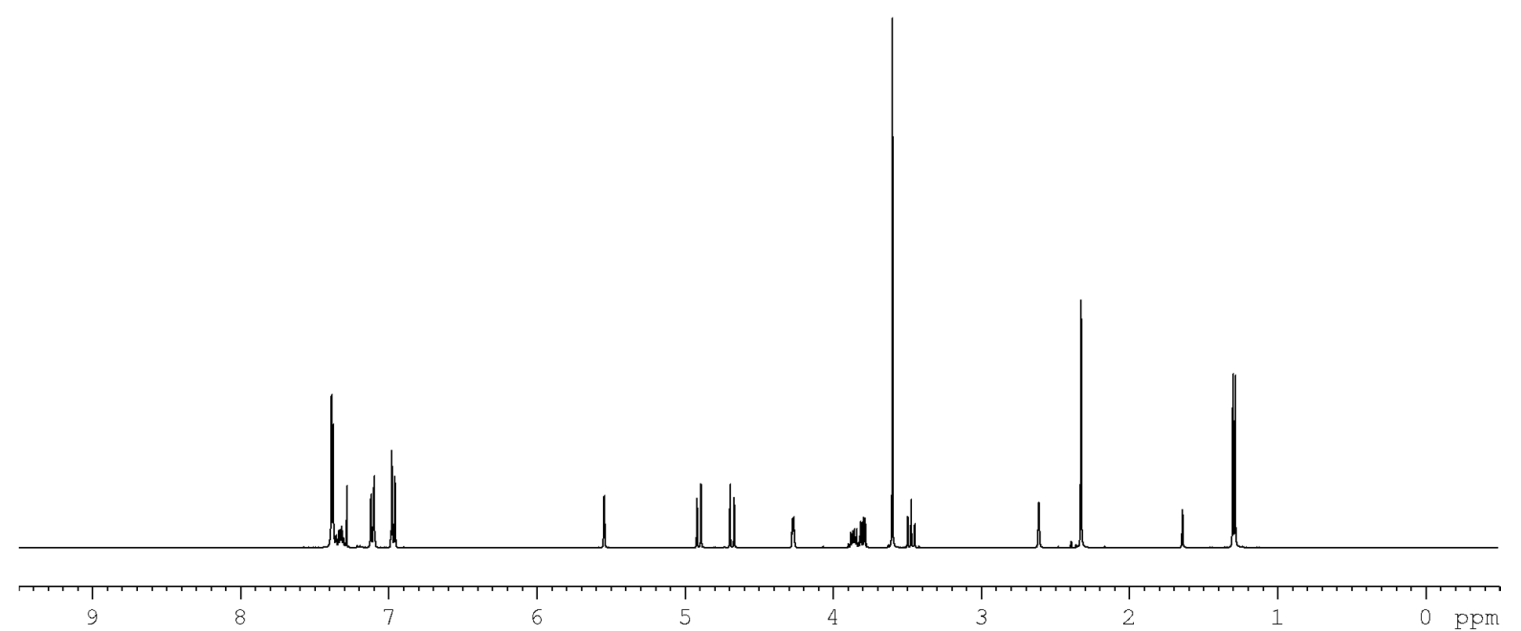

${ }^{13}$ C NMR

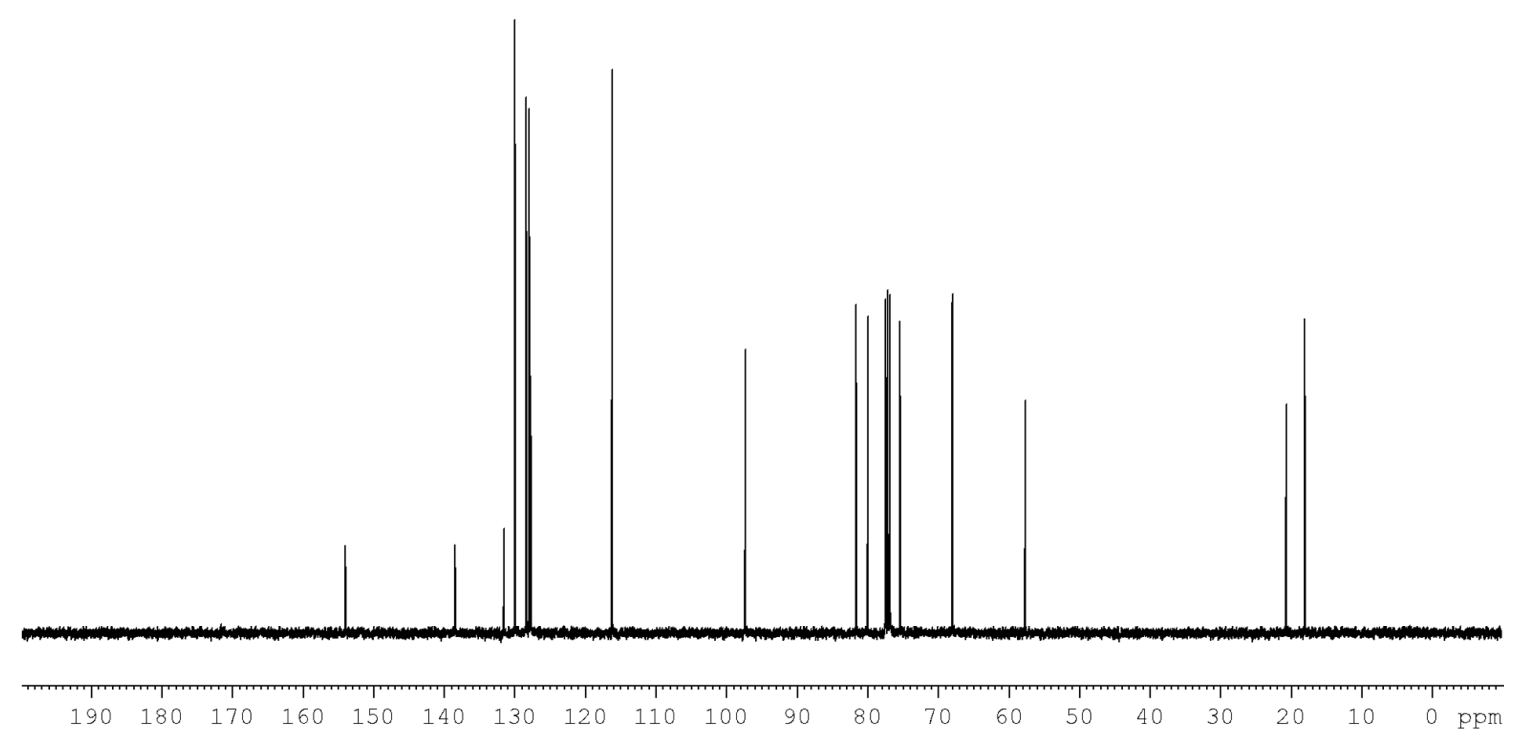




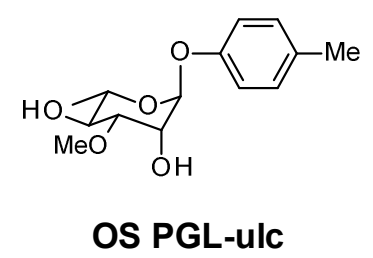

${ }^{1}$ H NMR

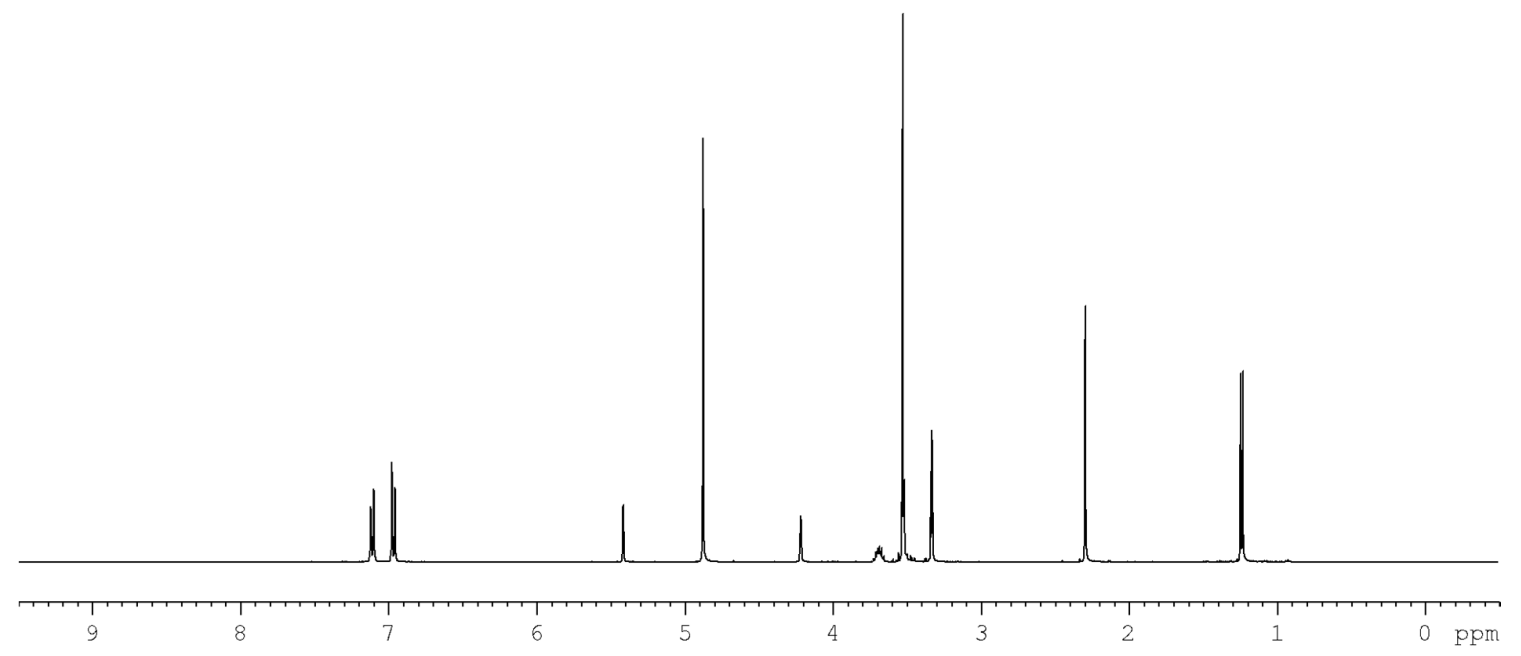

${ }^{13} \mathrm{C}$ NMR

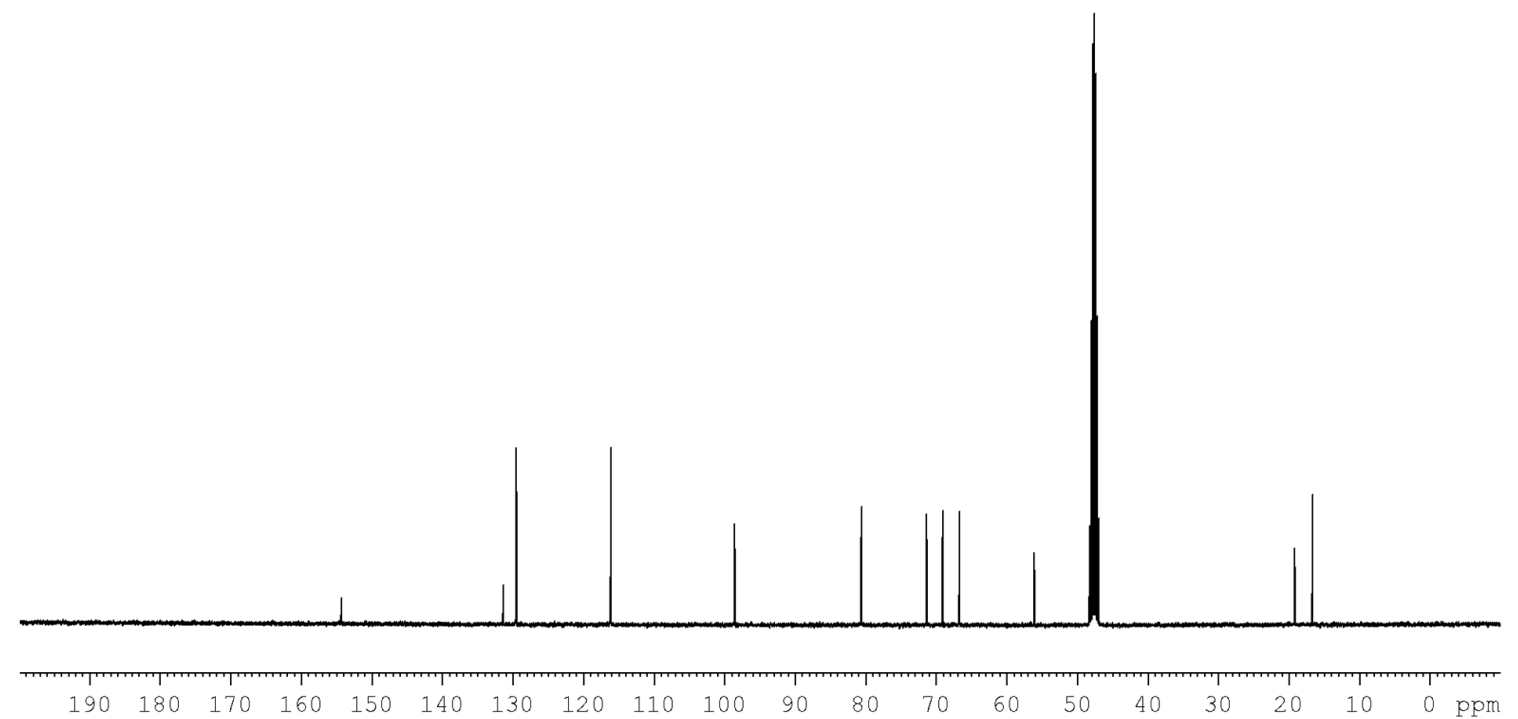




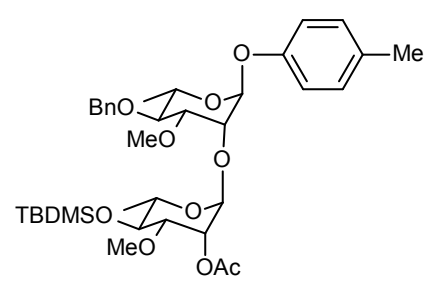

19

${ }^{1}$ H NMR

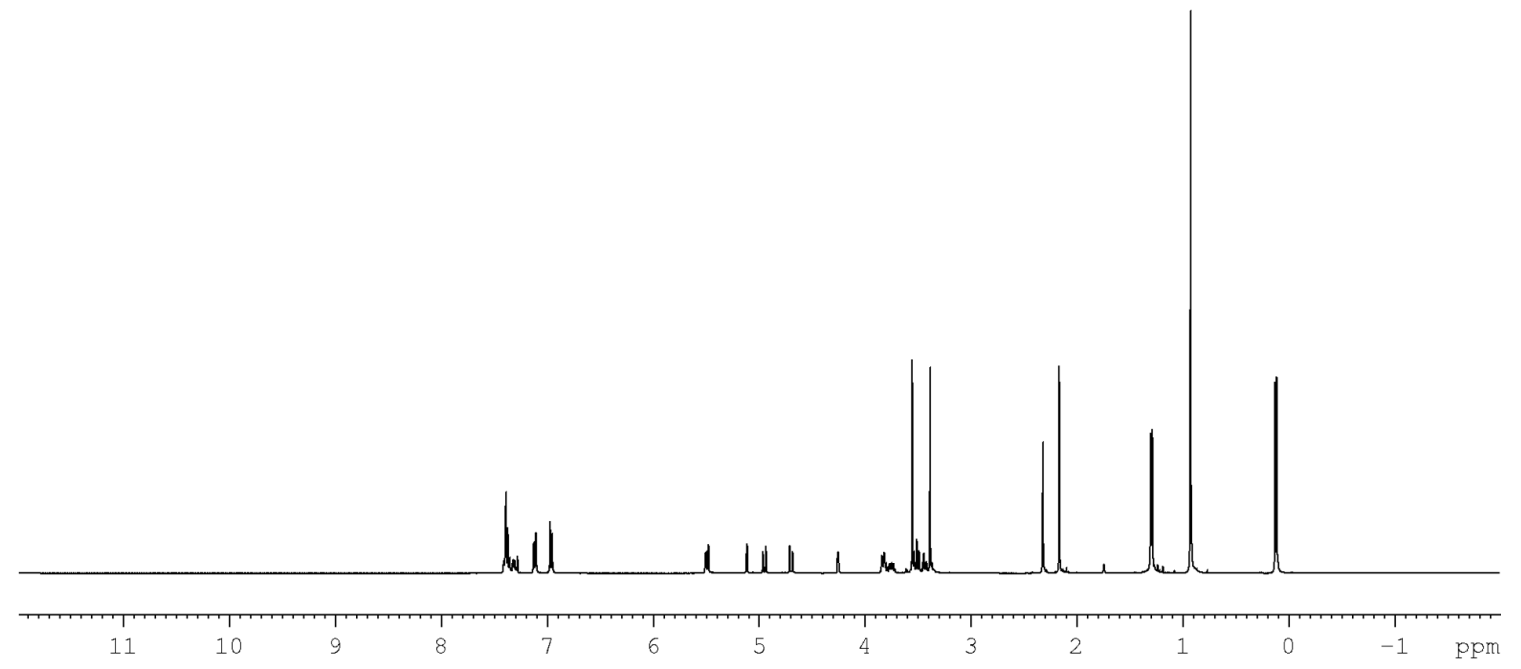

${ }^{13} \mathrm{C}$ NMR

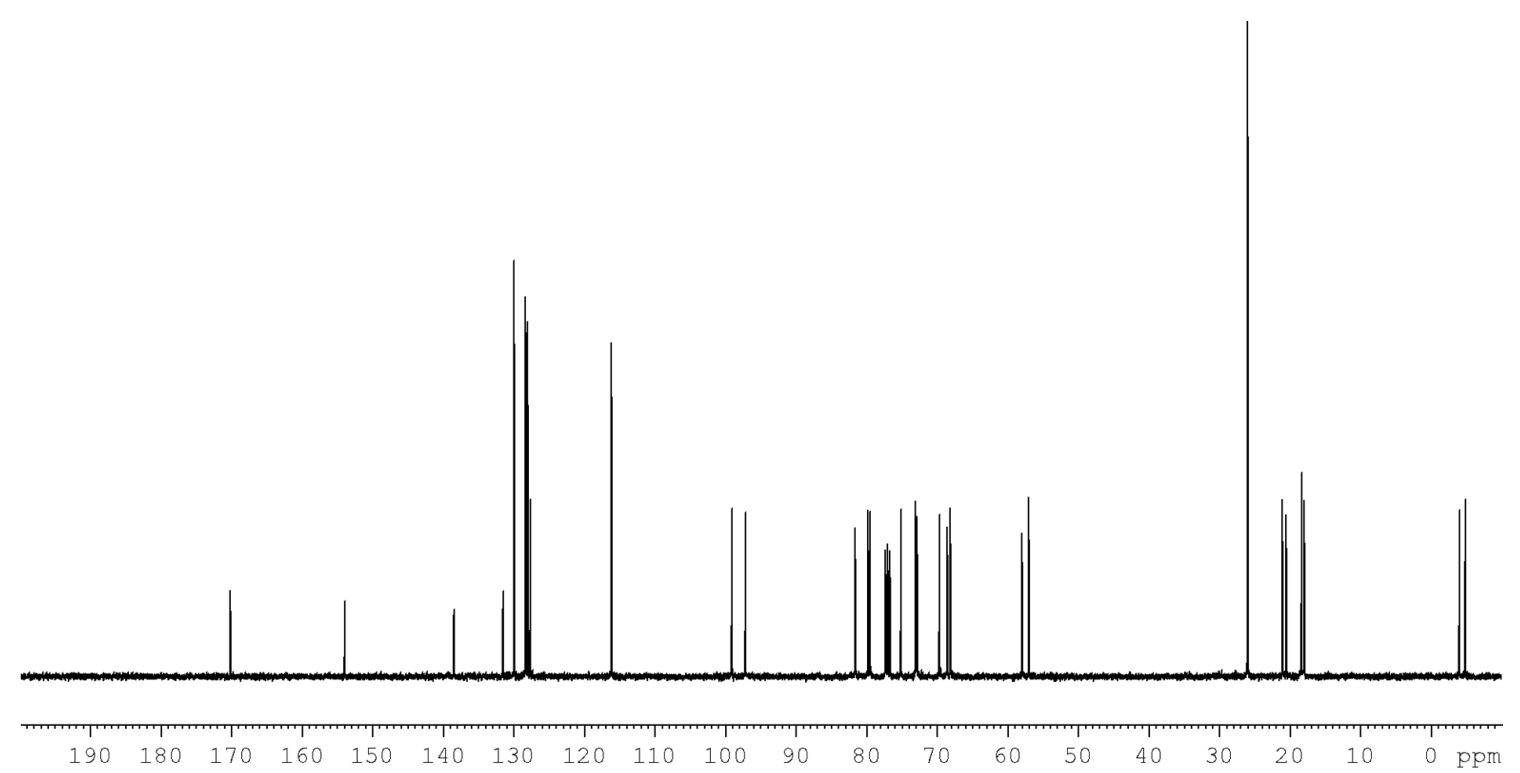




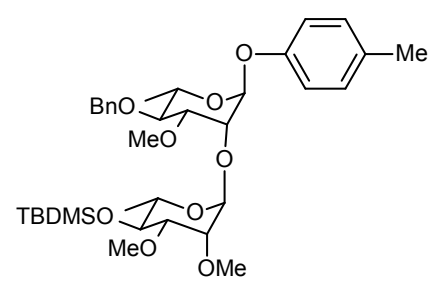

21

${ }^{1}$ H NMR

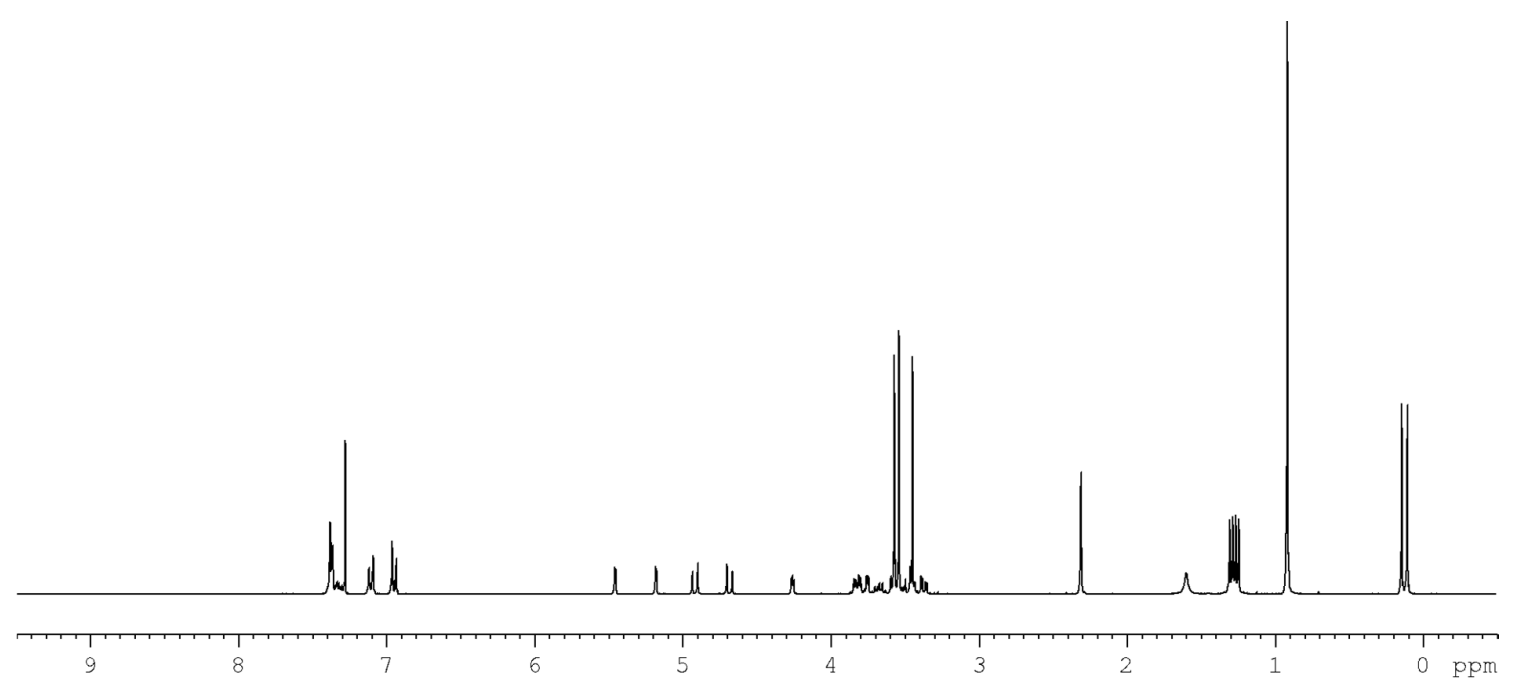

${ }^{13} \mathrm{C}$ NMR

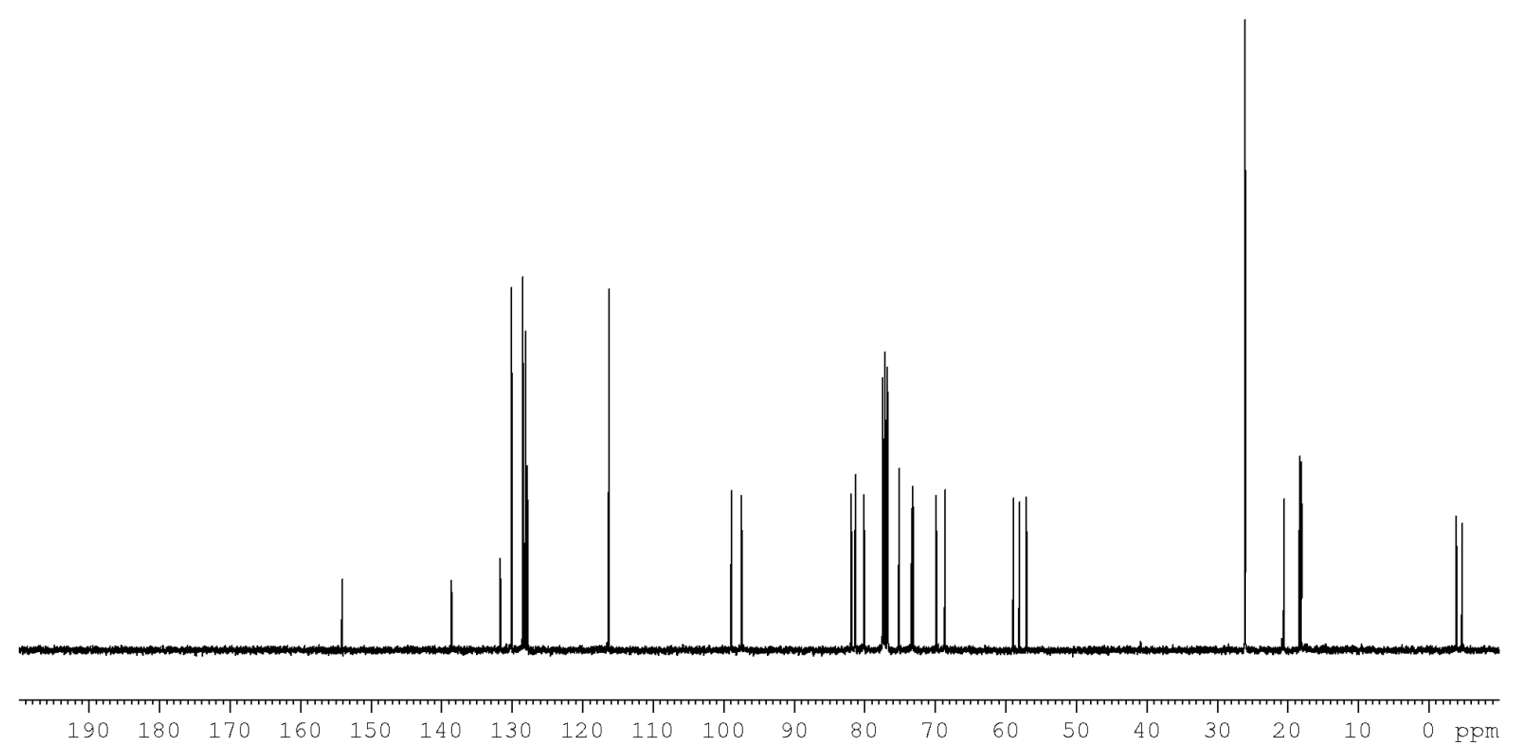




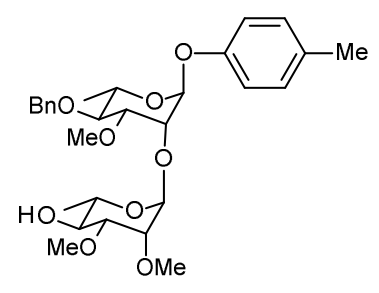

22

${ }^{1}$ H NMR

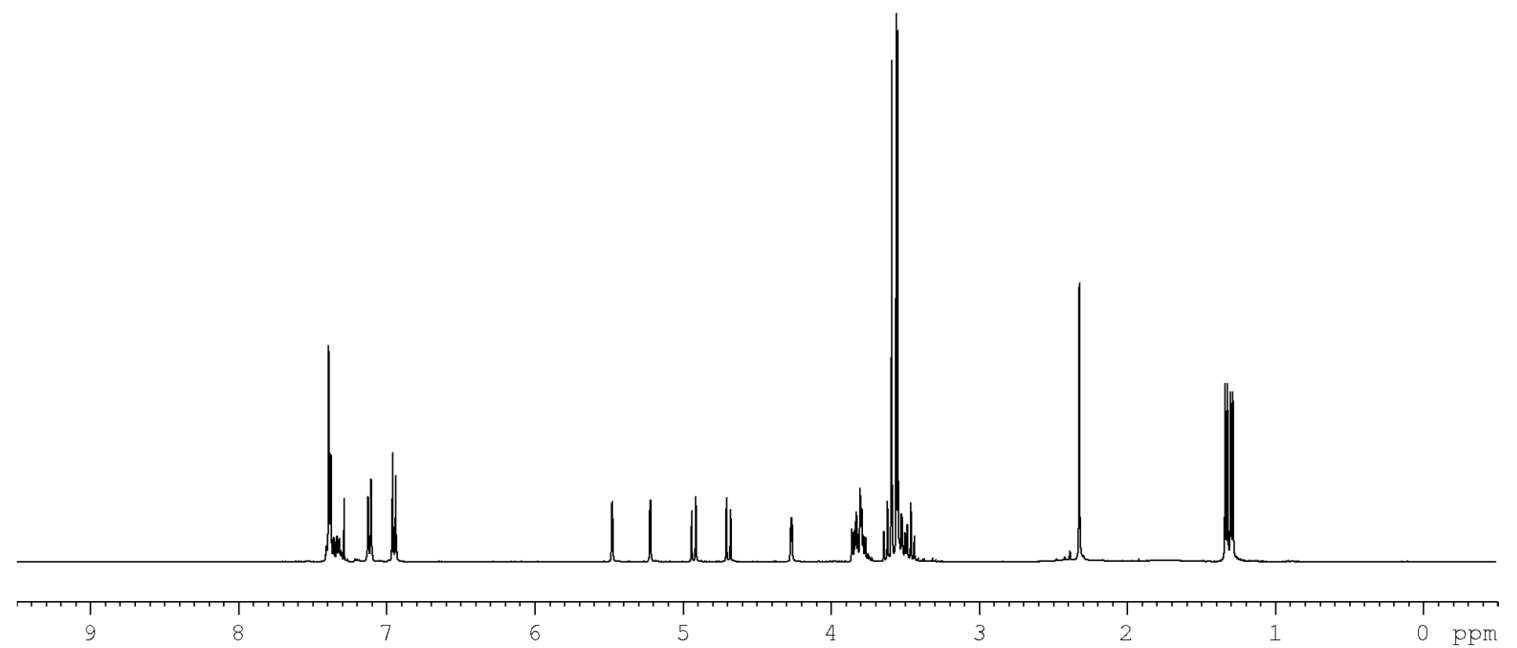

${ }^{13} \mathrm{C}$ NMR

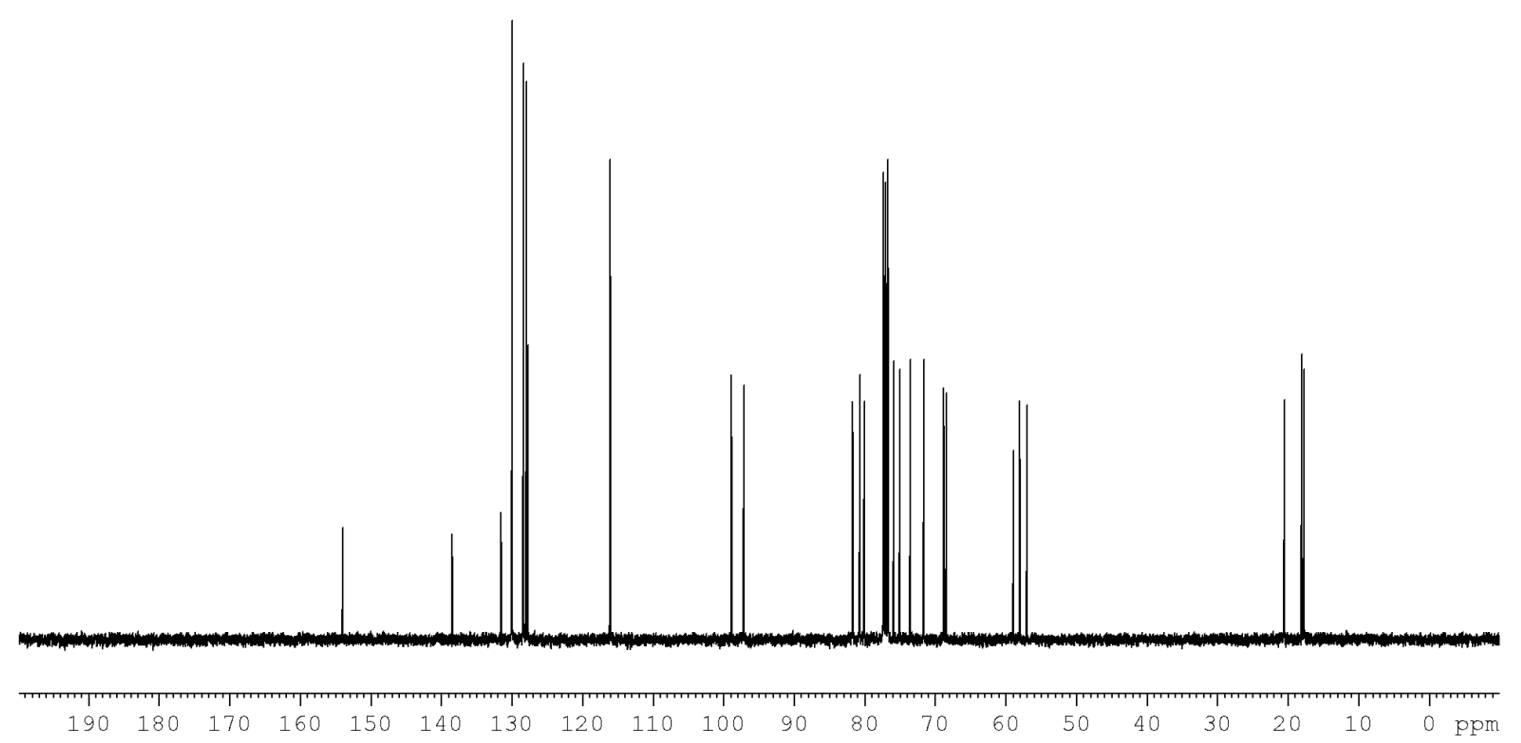




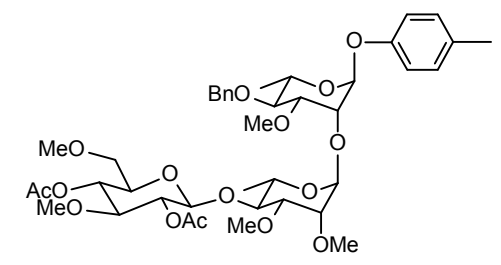

23

${ }^{1} \mathrm{H}$ NMR

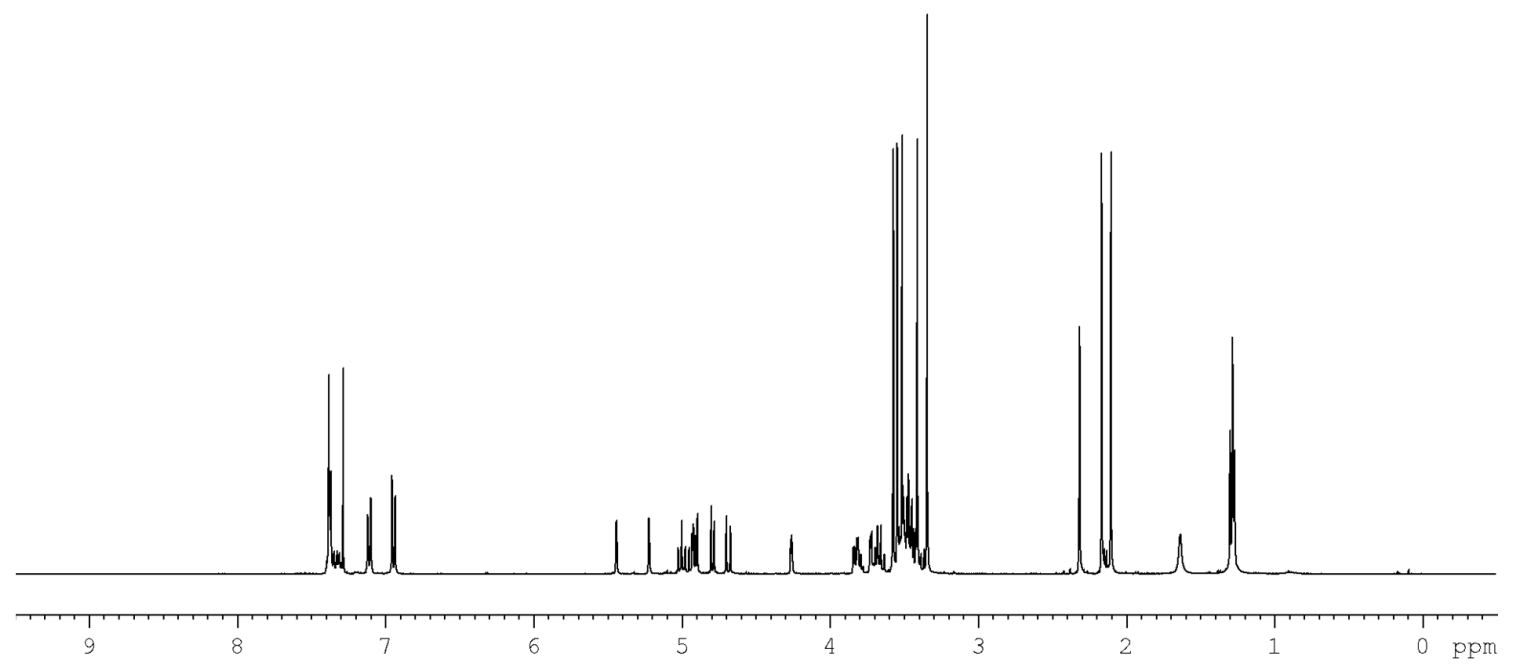

${ }^{13} \mathrm{C}$ NMR
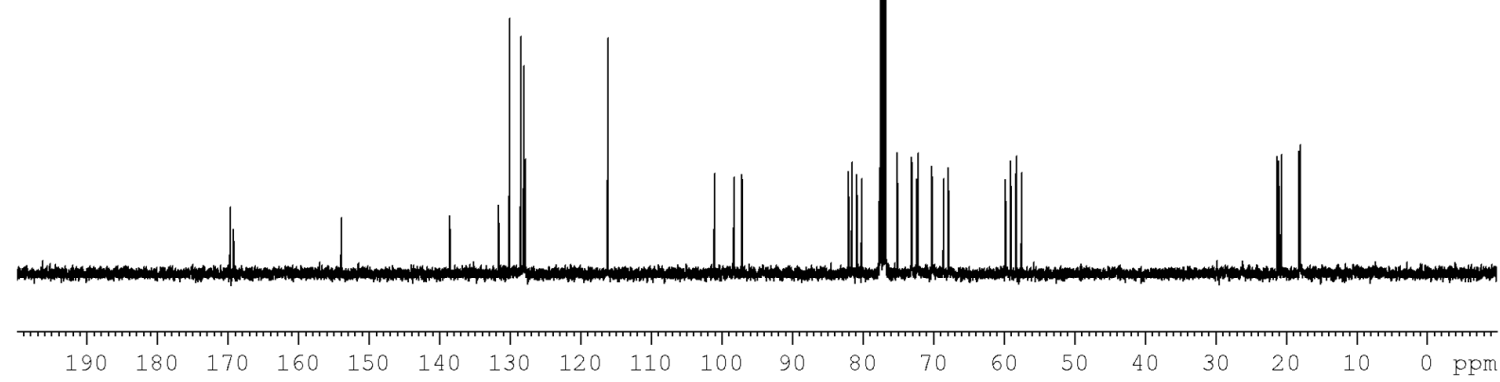


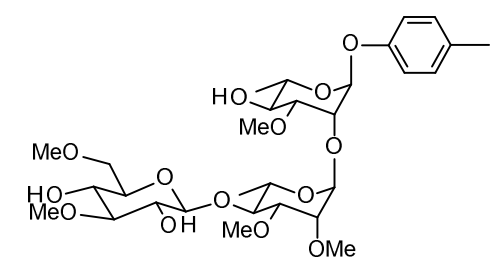

OS PGL-1

${ }^{1}$ H NMR

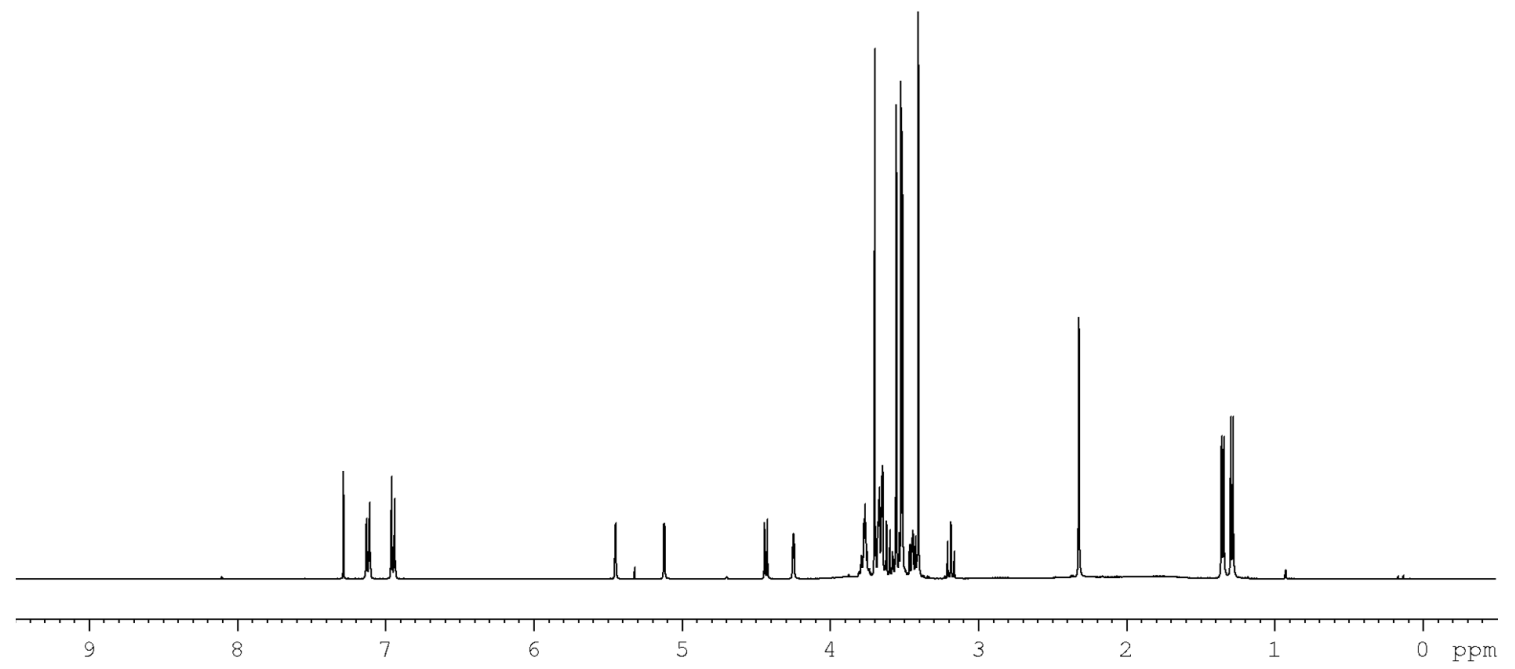

${ }^{13} \mathrm{C}$ NMR

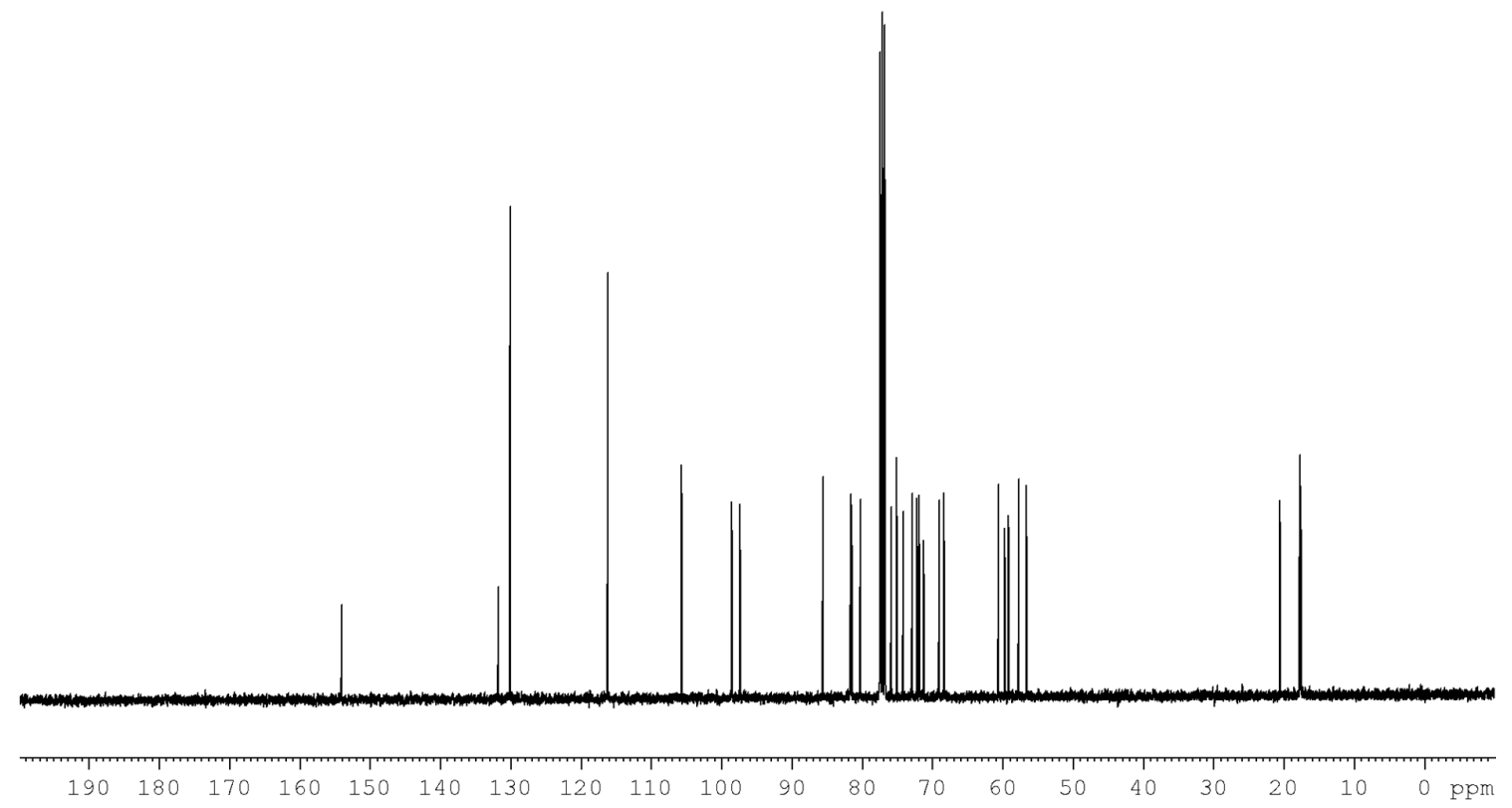




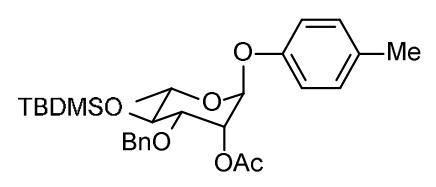

24

${ }^{1}$ H NMR

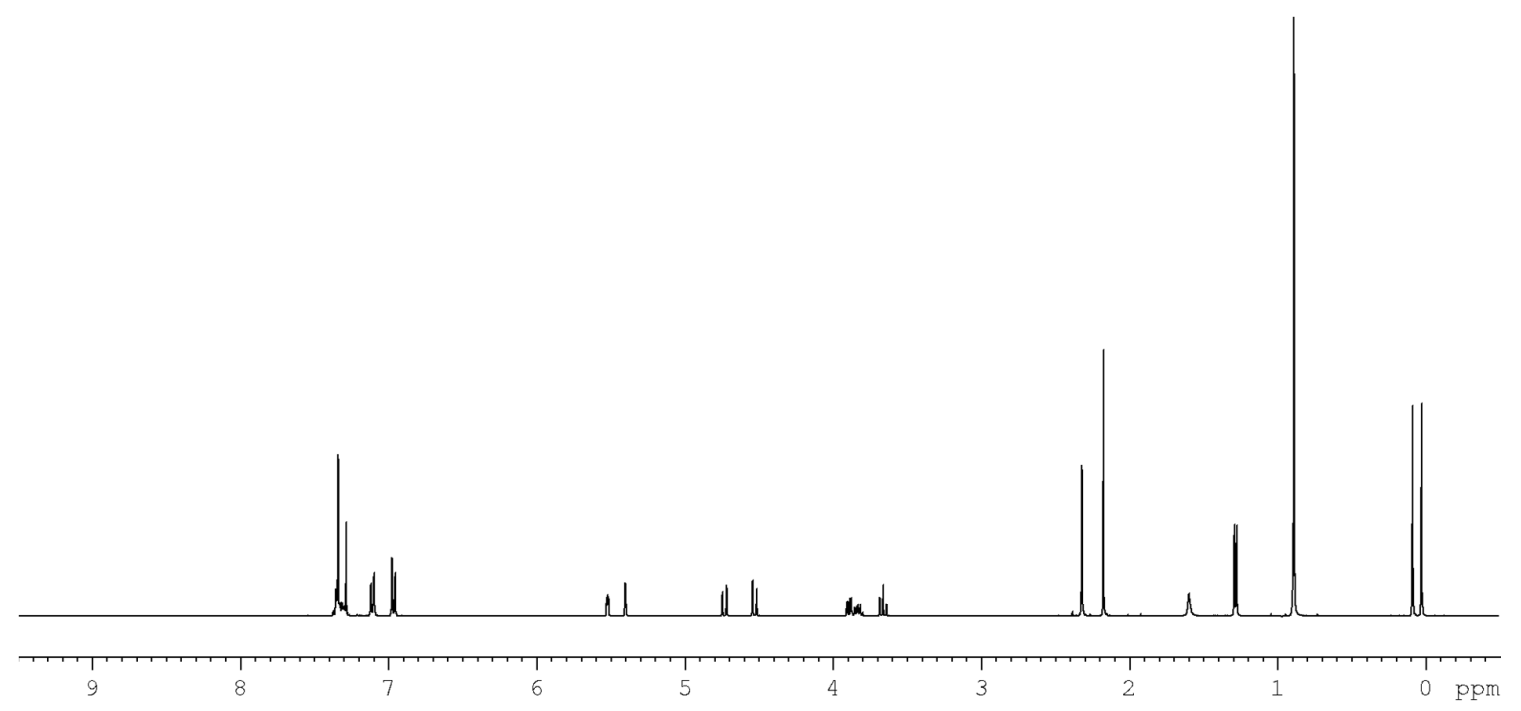

${ }^{13} \mathrm{C}$ NMR

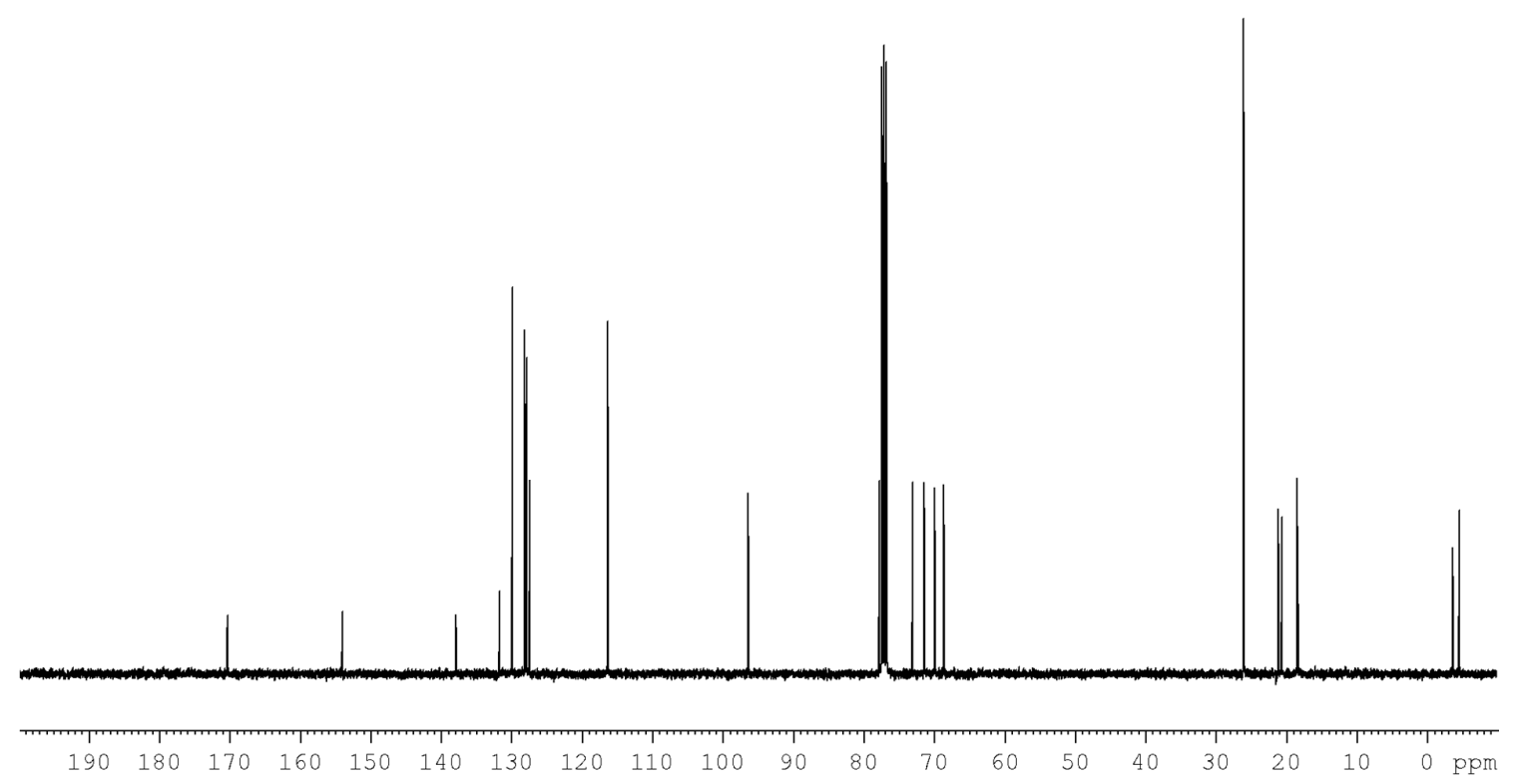




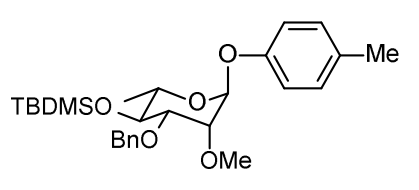

26

${ }^{1} \mathrm{H}$ NMR

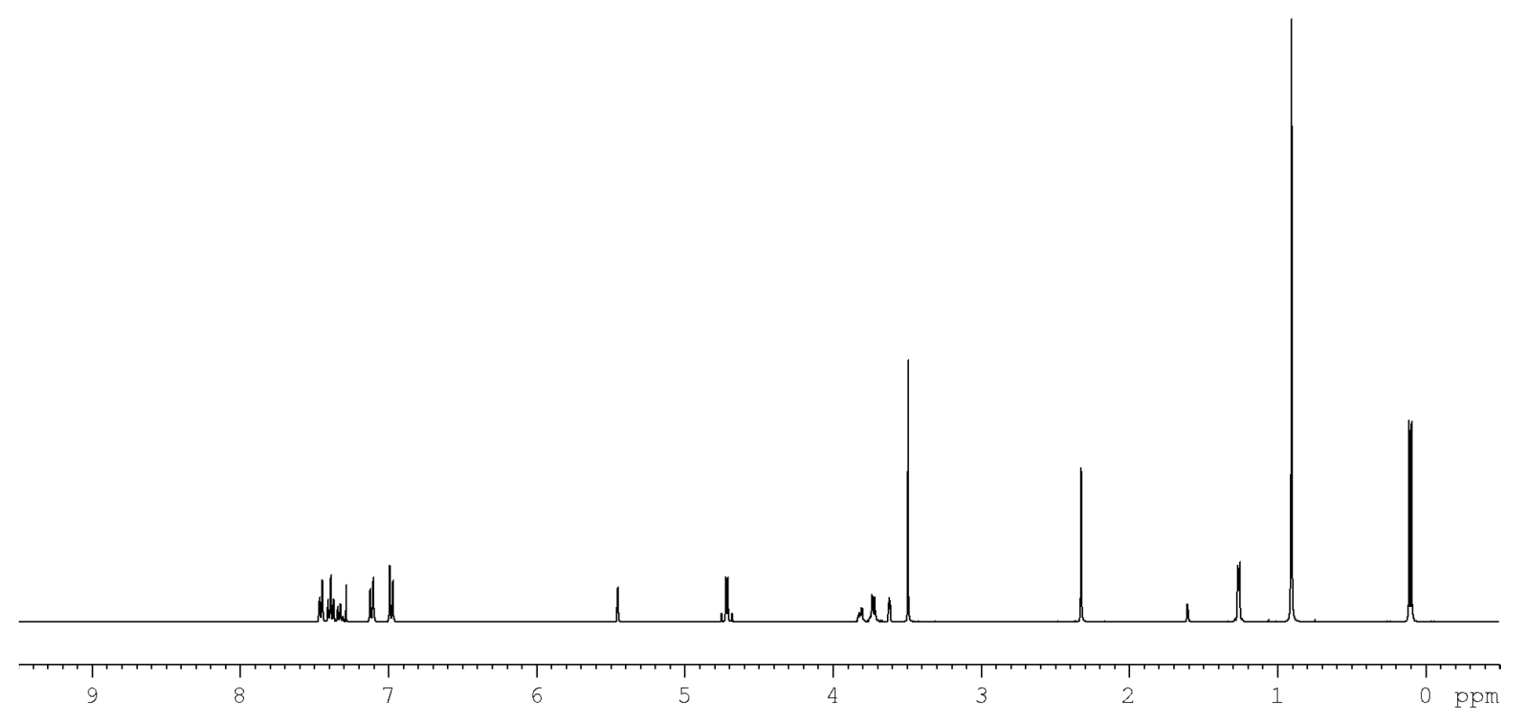

${ }^{13}$ C NMR
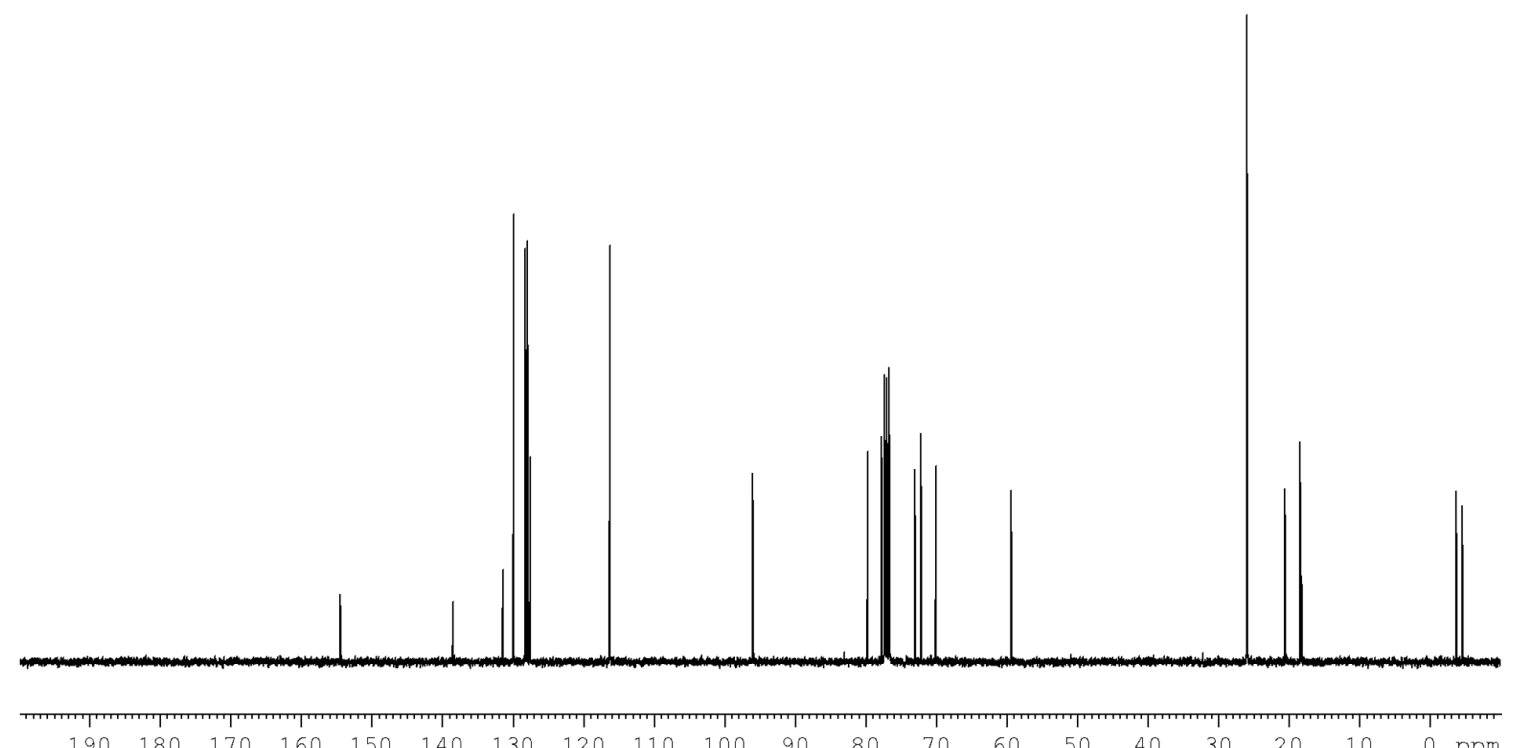


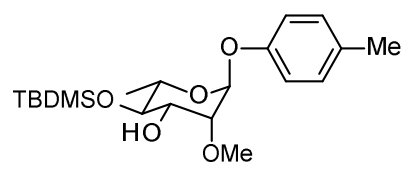

27

${ }^{1}$ H NMR

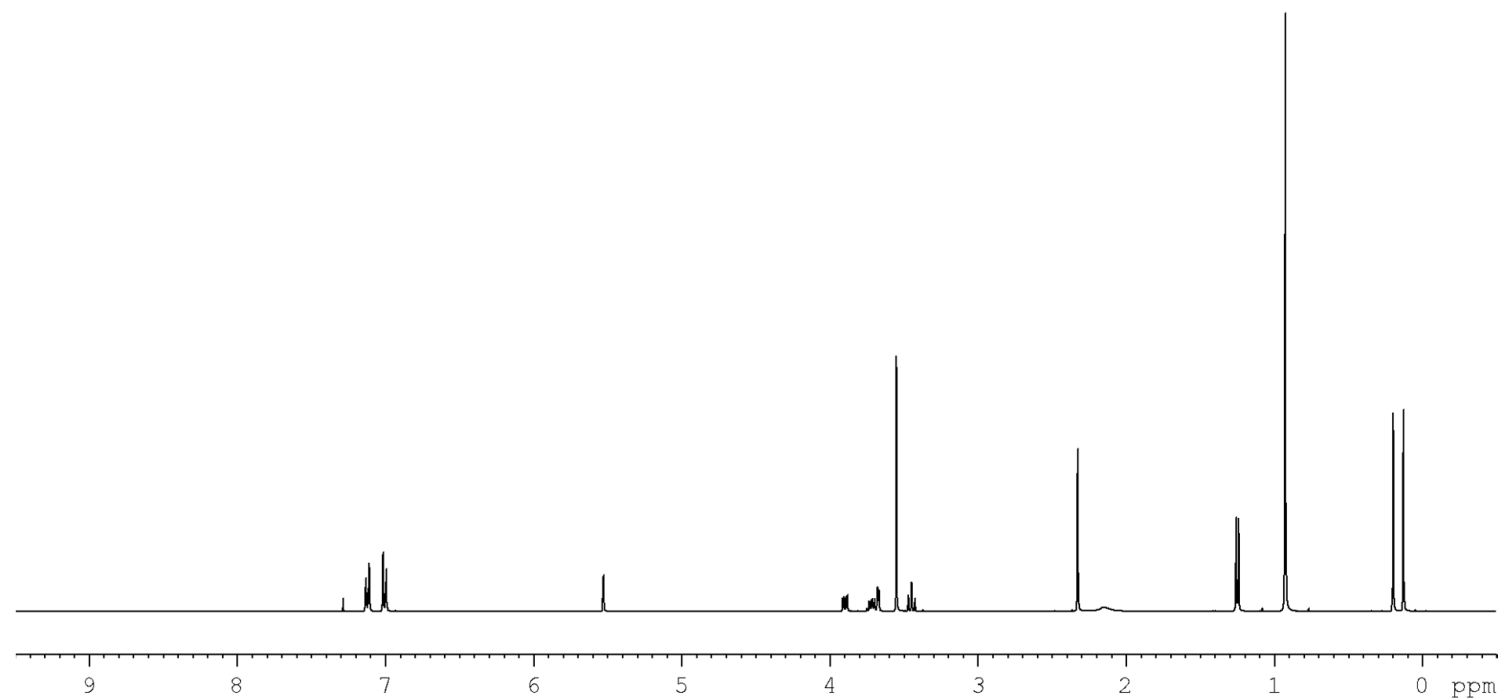

${ }^{13}$ C NMR

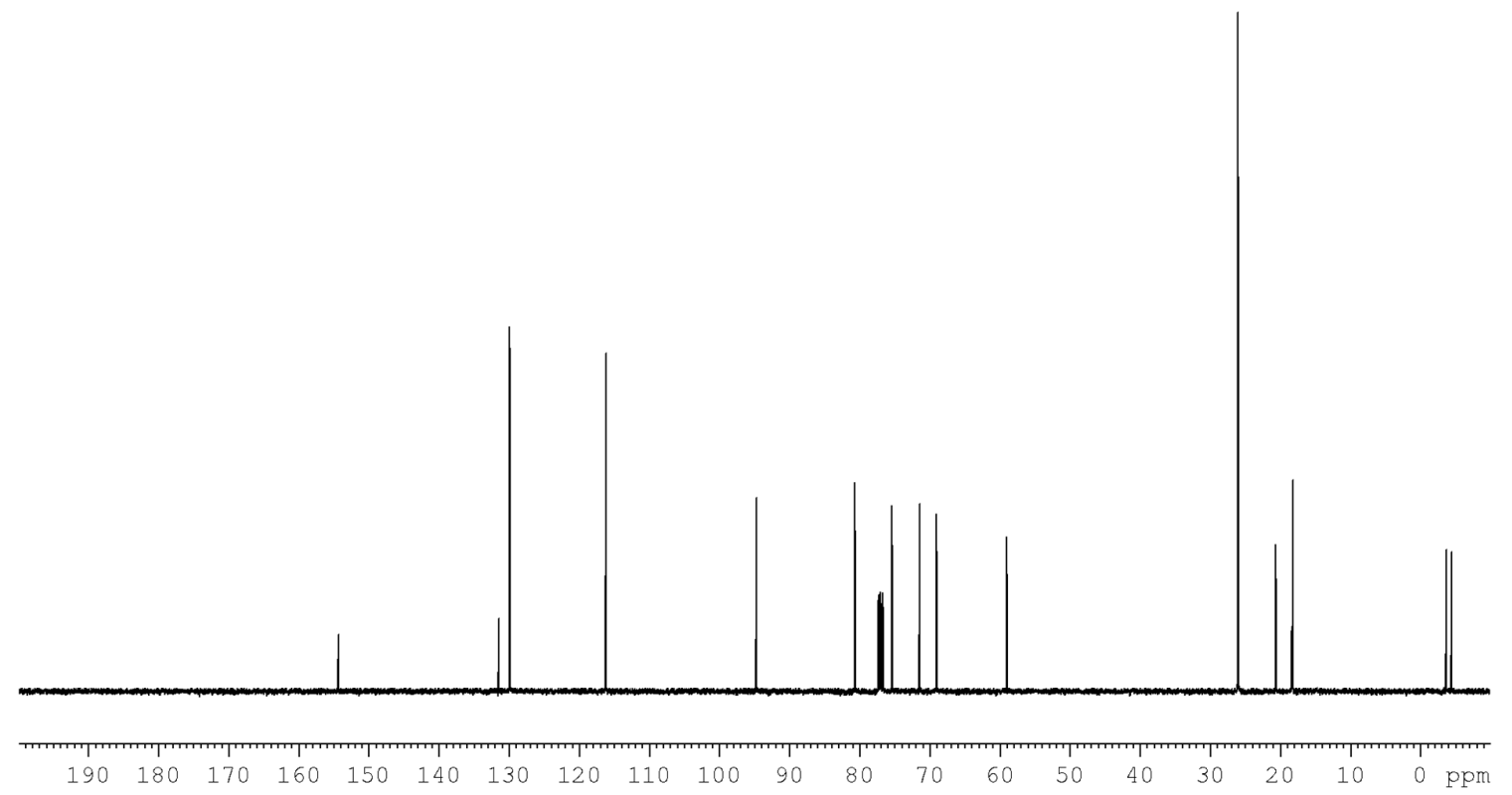




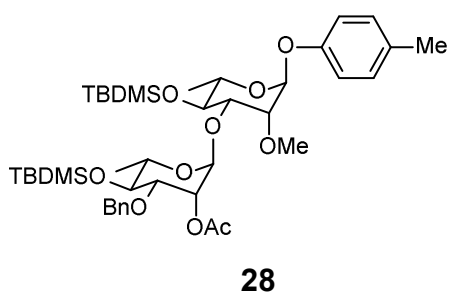

${ }^{1}$ H NMR

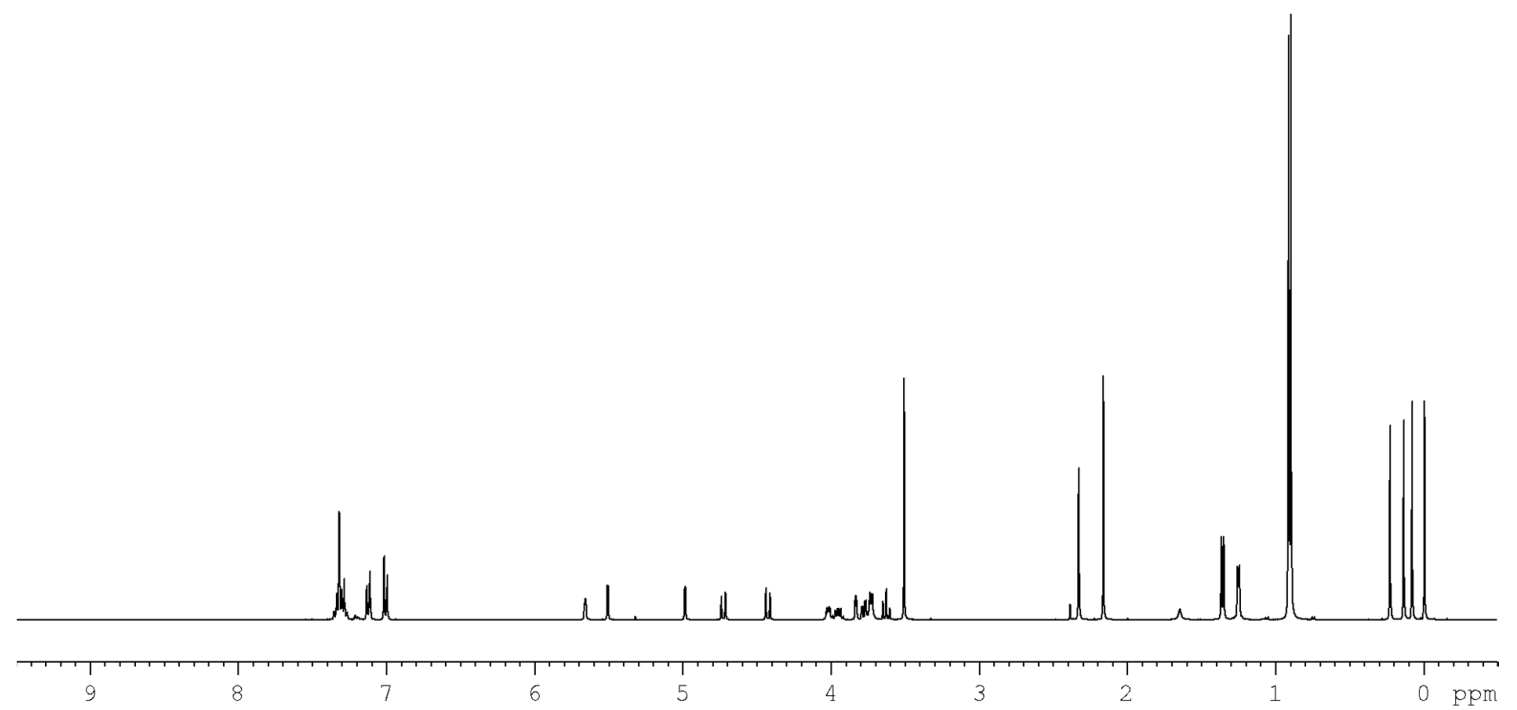

${ }^{13}$ C NMR

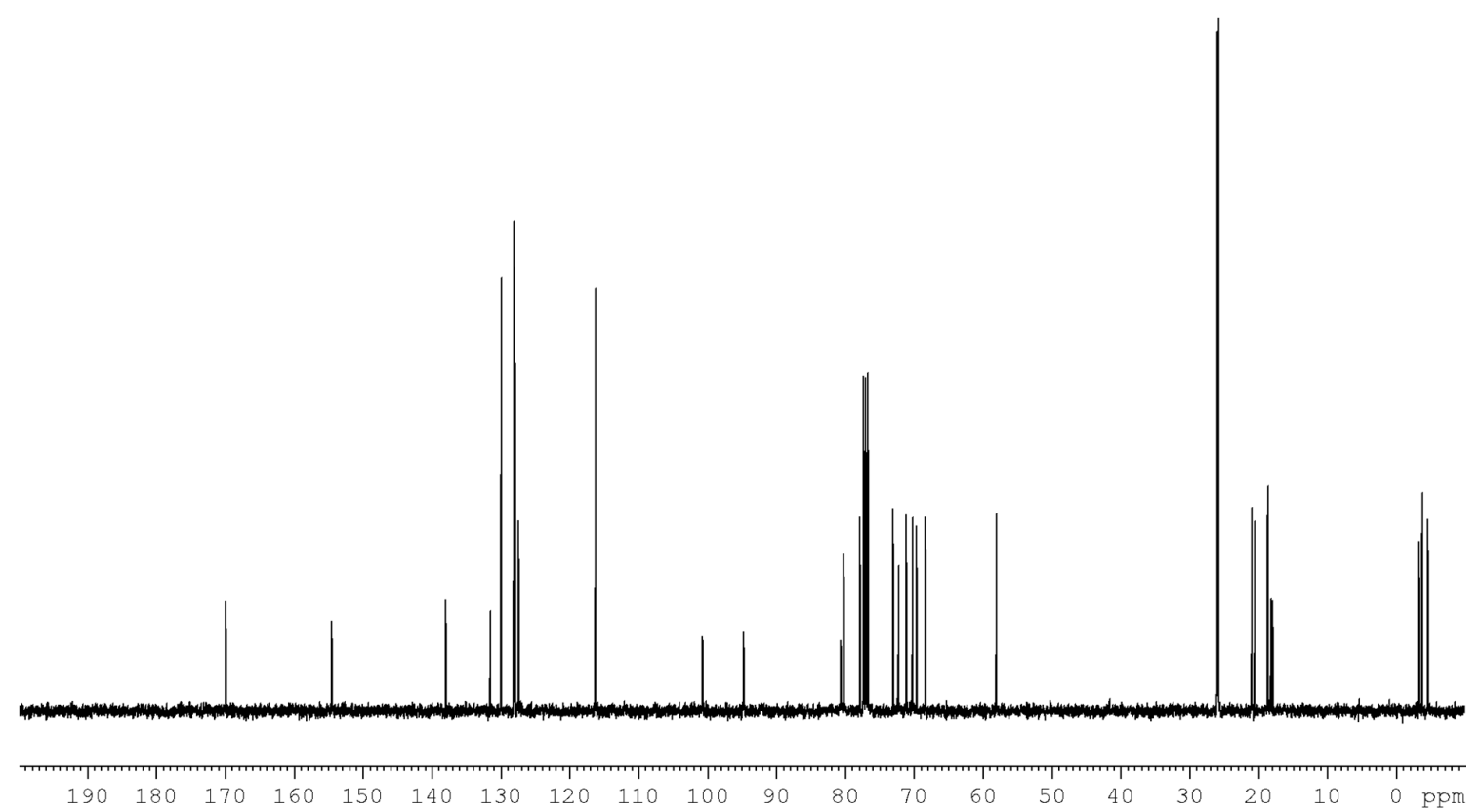




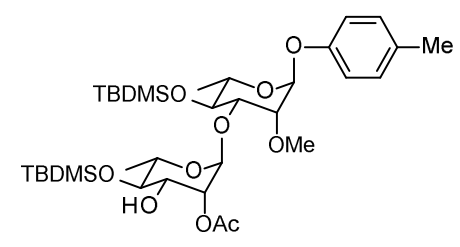

29

${ }^{1} \mathrm{H}$ NMR

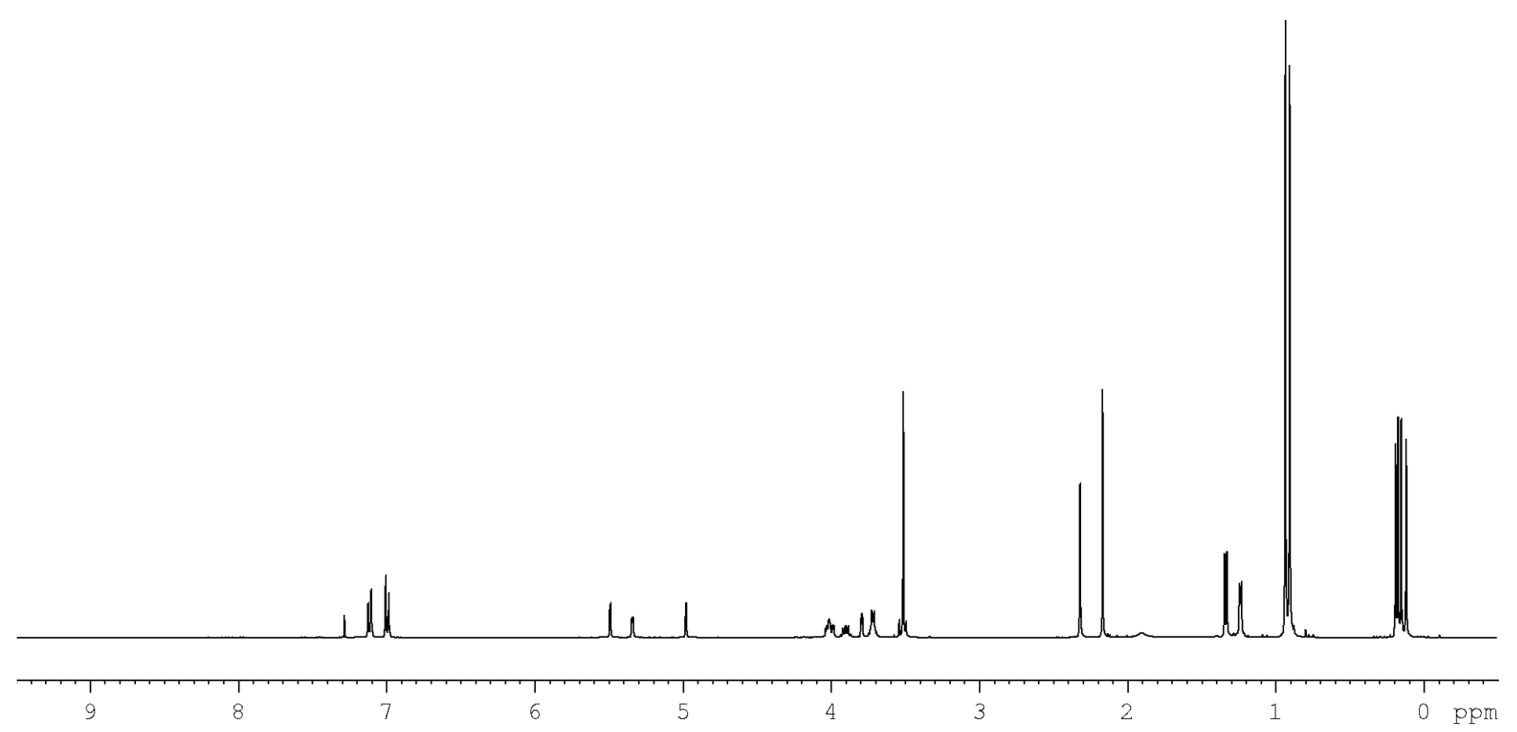

${ }^{13}$ C NMR

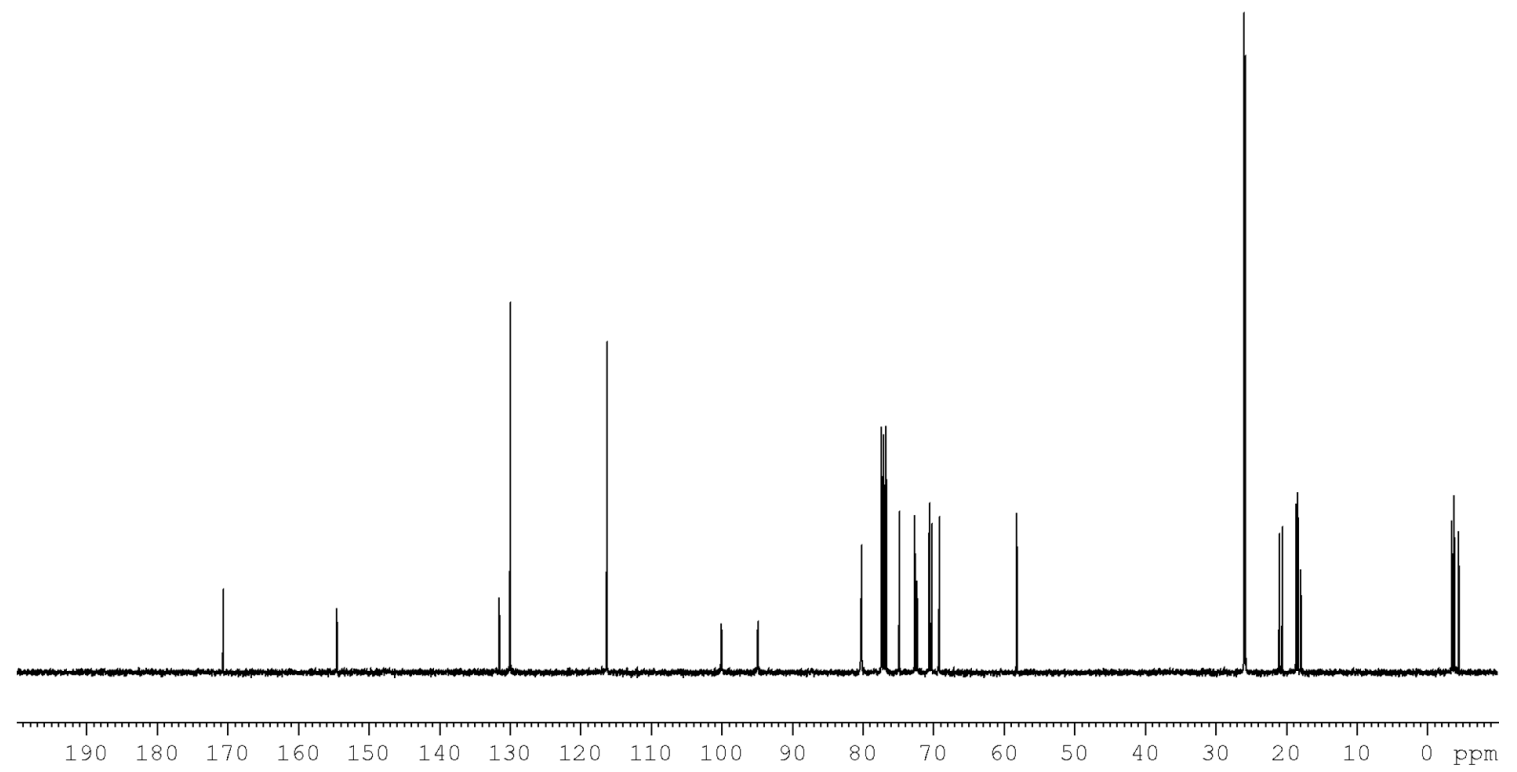




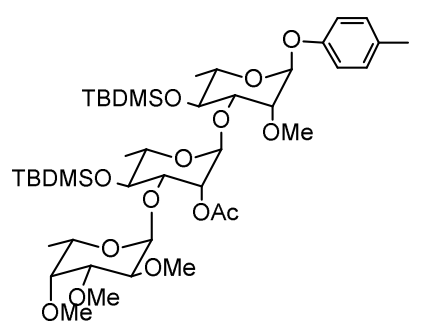

30

${ }^{1}$ H NMR

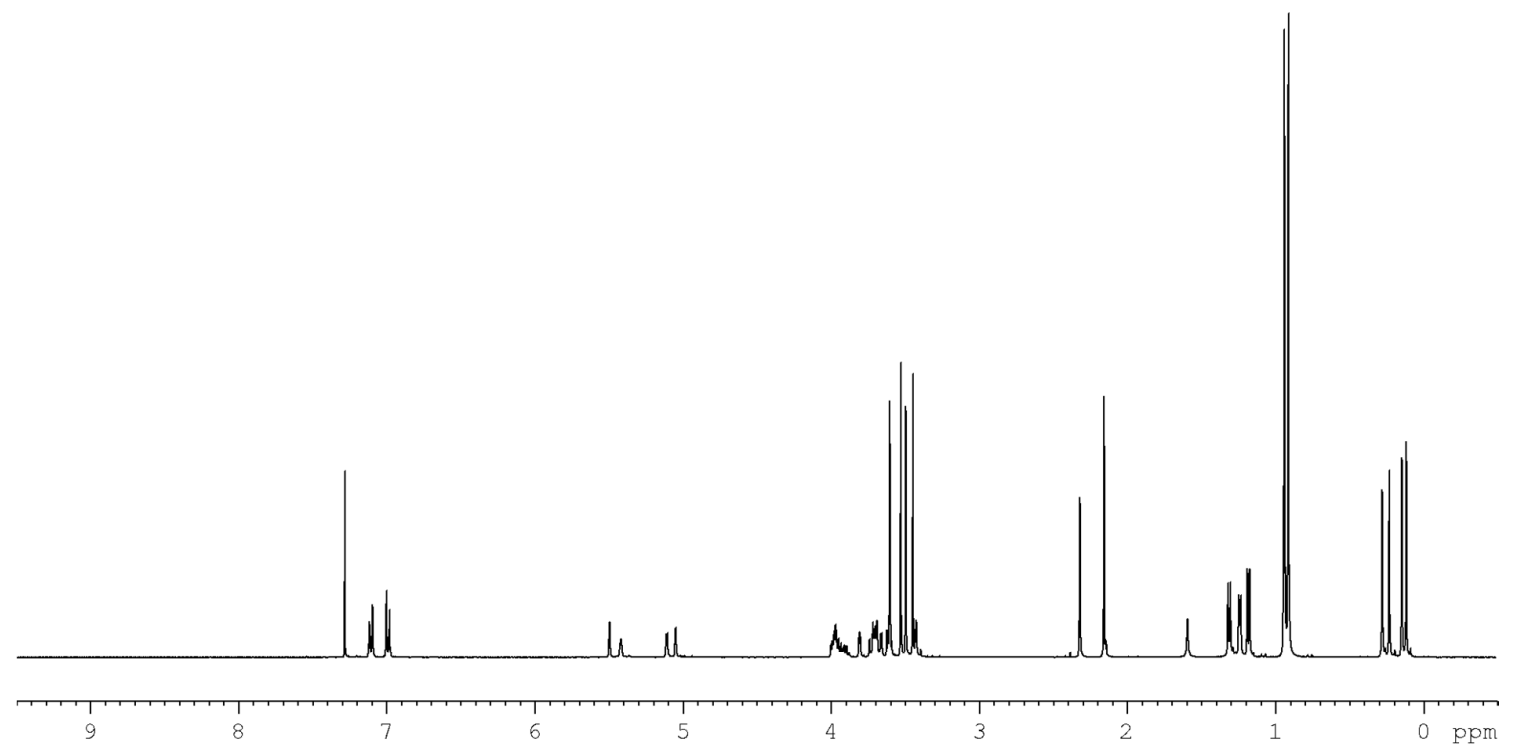

${ }^{13} \mathrm{C}$ NMR

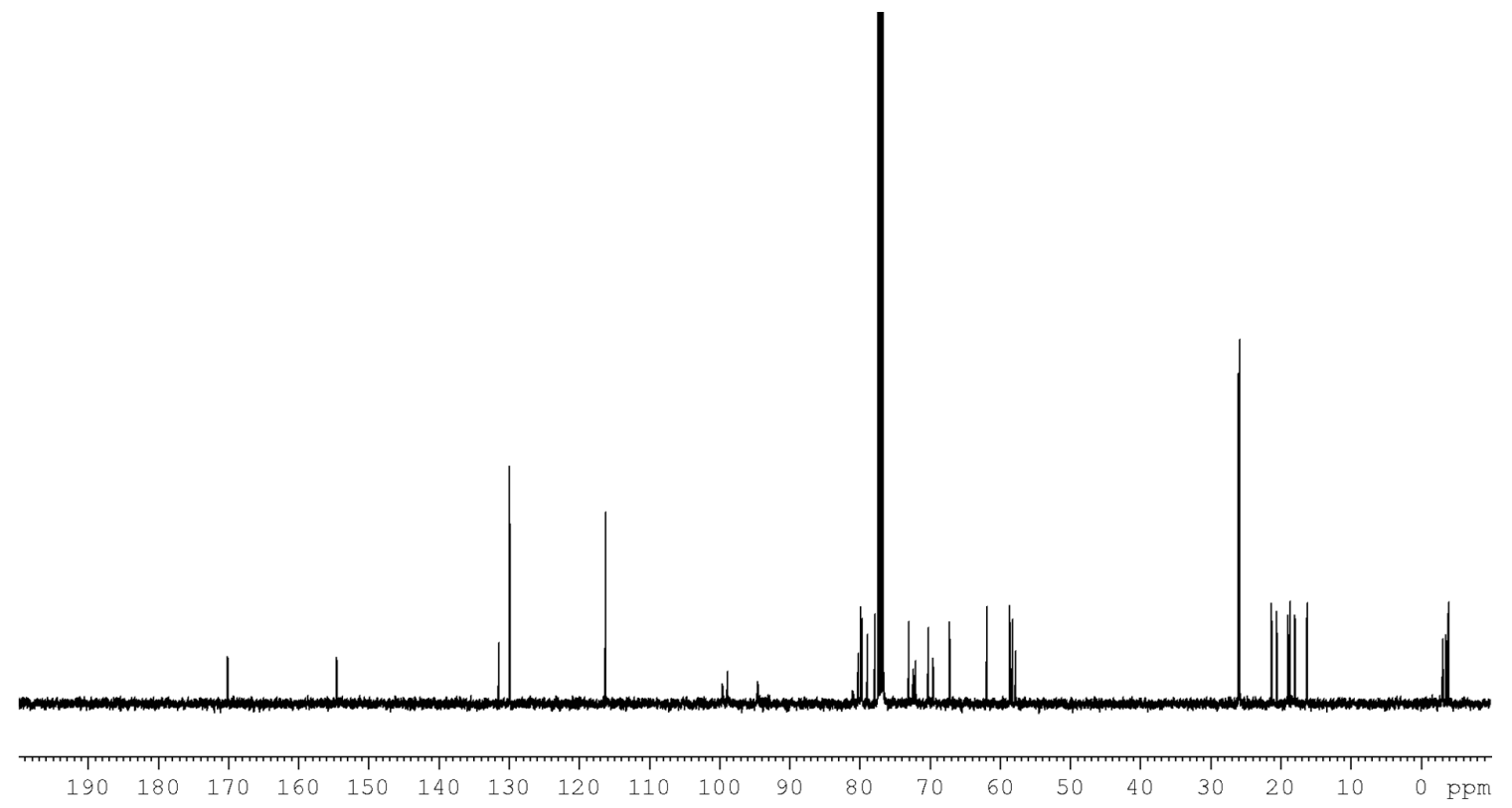



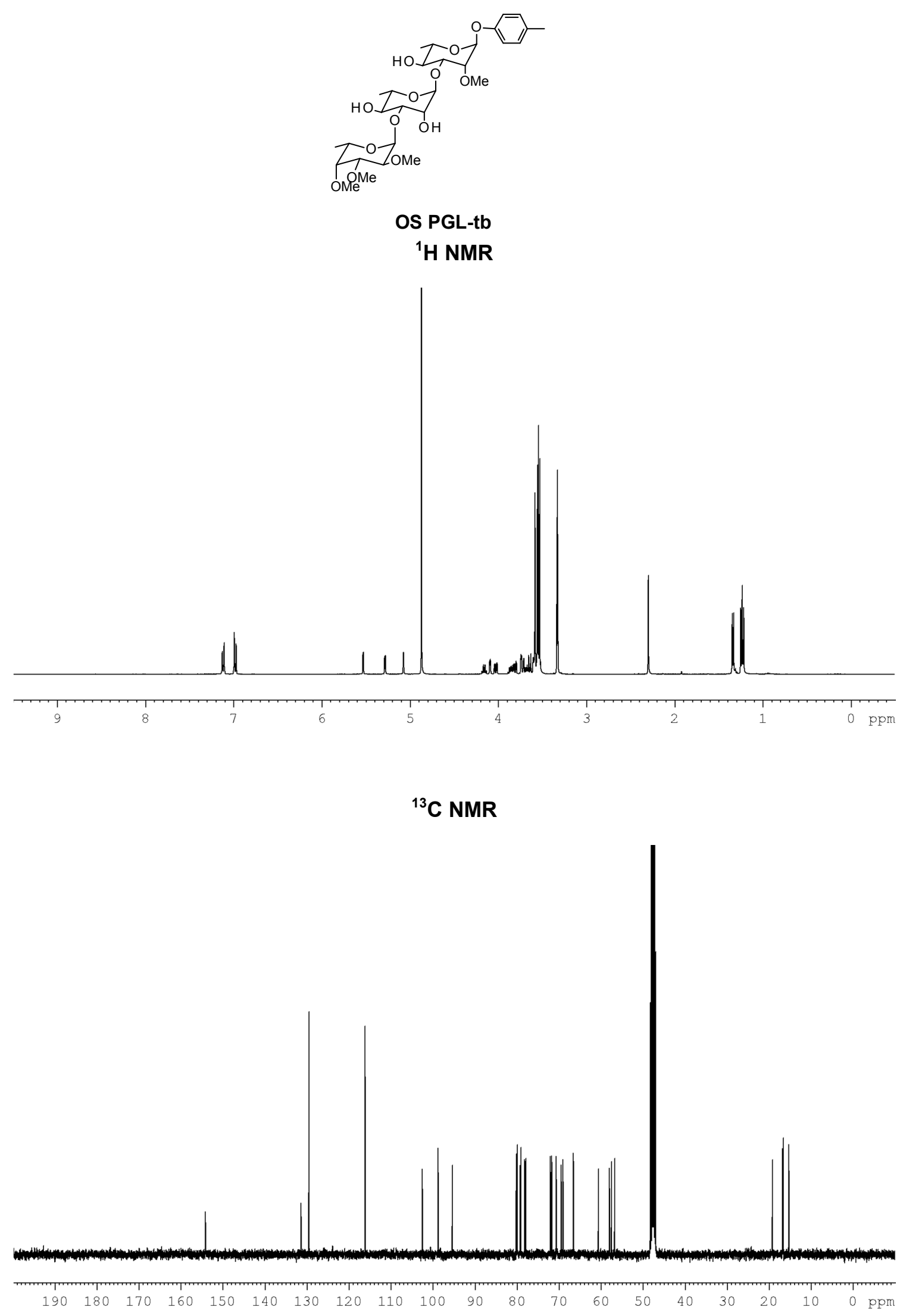


\section{NMR analysis of PGL purified from rBCG $\triangle R v 2959::$ ML0126}

All the proton resonances typifying a phenolphthiocerol structure linked to a monosaccharide were observed in the $1 \mathrm{D}{ }^{1} \mathrm{H}$-NMR spectrum of the native compound: $p$-substituted phenolic group ( $\mathrm{g}, \mathrm{h}$ at 6.97 and $7.10 \mathrm{ppm}$ ), methine protons of the esterified $\beta$-glycol (a, $4.84 \mathrm{ppm}$ ), multimethyl-branched fatty acids (e, 0.8-1 ppm; f, $1.14 \mathrm{ppm}, \mathrm{d}, 2.52 \mathrm{ppm}$ ), methoxyl group on the phthiocerol (b, $3.33 \mathrm{ppm}$ and $\mathrm{c}, 2.85 \mathrm{ppm}$ ). The presence of a single deshielded anomeric proton confirmed the occurrence of a monosaccharide in the putative PGL-ulc (i, $5.53 \mathrm{ppm})$. In addition, only one signal attributable to proton resonance of methoxyl group linked to the sugar part (j, $3.55 \mathrm{ppm}$ ) was observed in the spectrum of native glycolipid. This was supported by the occurrence, upon per-O-acetylation, of two distinct methyl groups of acetyl substituents $\left({ }^{*}, 2.10\right.$ and $2.17 \mathrm{ppm}$ ) indicating the presence of two non-substituted hydroxyl groups in the native compound. Moreover, the per-O-acetylation resulted in a shift of the resonance of protons linked to the carbons bearing the acetoxy group downfield by about 1-1.4 ppm; it was thus possible to distinguish free from substituted hydroxyl groups. Assignments of resonances are summarized in the table on the basis of chemical shift correlations deduced from the 2D-COSY spectra of native and per-O-acetylated PGL. The resonances of the protons 2 and 4 of the rhamnosyl residue were shifted after per-Oacetylation indicating that the hydroxyl groups in position 2 and 4 were free in the glycolipid.

${ }^{1} \mathrm{H}$ NMR spectrum of PGL purified from rBCG $\Delta R v 2959::$ ML0126

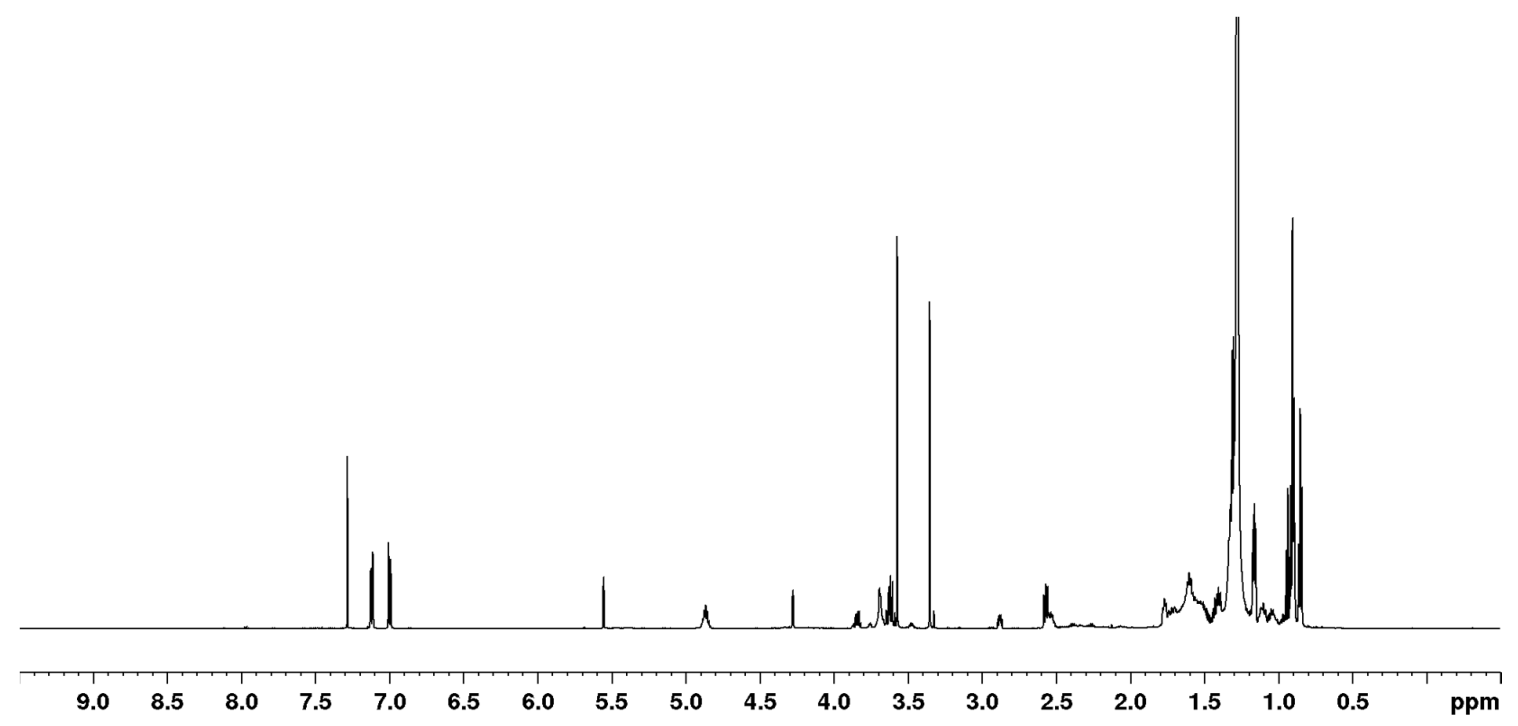


${ }^{1} \mathrm{H}$ NMR spectrum of DIM

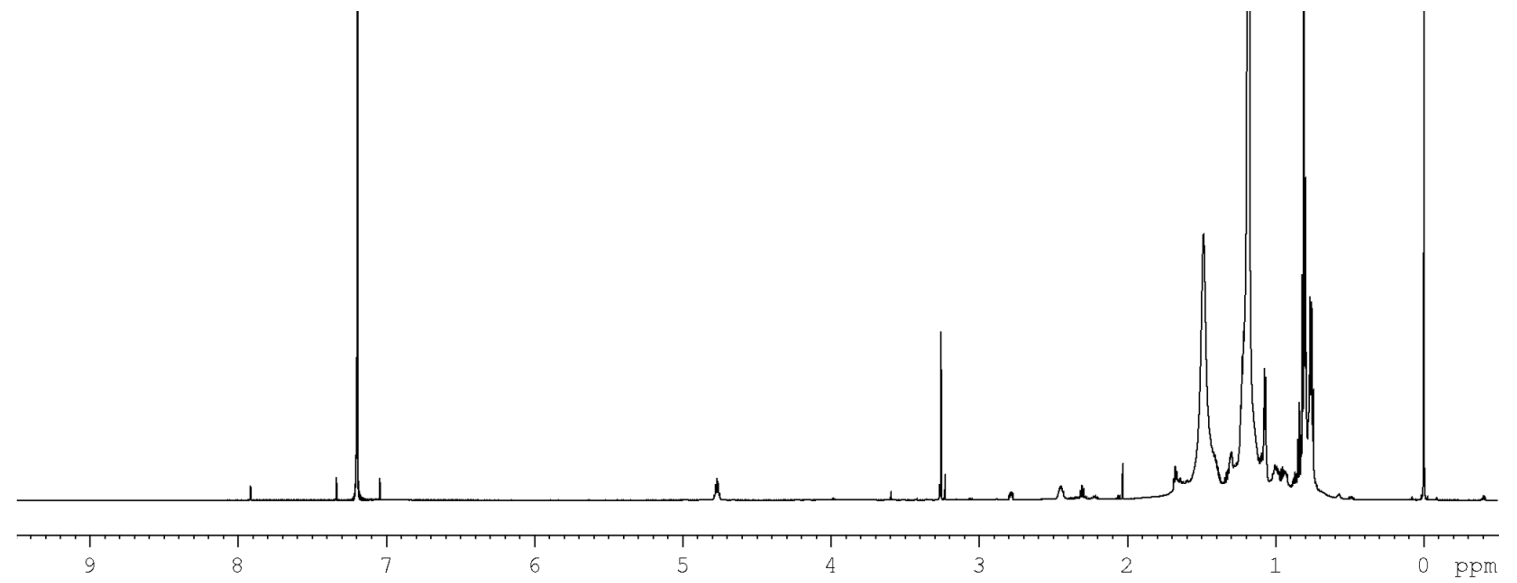




\section{Methods}

Antibodies and reagents. Mouse monoclonal antibodies (Ab) against CD11b (2LPM19c and VIM12), normal mouse IgG1 and rabbit polyclonal $\mathrm{Ab}$ against Lyn and Syk were purchased from Santa Cruz Biotechnology. Specific anti-PGL-1 Ab was provided by the BEI Resources, NIAID, NIH. Various secondary Ab, Horseradish peroxidase (HRP)-coupled goat anti-mouse (BioRad), HPR-coupled goat anti-rabbit (Sigma-Aldrich) and Rhodamine Redconjugated goat anti-rabbit (Invitrogen), were used.

Recombinant human CR3 and TLR2 were purchased from R\&D Systems, and purified, native $M$. leprae PGL-1 was obtained through BEI Resources, NIAID, NIH. Control scrambled and pre-designed ON-TARGETplus SMARTpool siRNAs targeting human Lyn and Syk were purchased from GE Dharmacon. The rest of reagents were purchased from Sigma-Aldrich, except specifically mentioned.

Synthesis of PGL epitopes. All reactions were run in anhydrous glassware under an argon atmosphere. Reagents were used as received. Anhydrous dichloromethane, methanol and toluene were obtained from a Pure Solv MD5 apparatus (Innovative Tehnology Inc.). Dry THF was distilled from benzophenone-sodium just before use. Chromatographic separations were run on a PuriFlash 430 automatic chromatographer (Interchim) using prepacked cartridges of $30 \mu \mathrm{m}$ spherical silica. NMR spectra were recorded at the Laboratoire de Chimie de Coordination (Toulouse, France) on Bruker AV 300, AV 400 and Av III 400 spectrometers, working respectively at $300 \mathrm{MHz}$ and $400 \mathrm{MHz}$ for ${ }^{1} \mathrm{H}, 75 \mathrm{MHz}$ and $100 \mathrm{MHz}$ for ${ }^{13} \mathrm{C}$. Chemical shifts are expressed in part per million $(\mathrm{ppm})$ from tetramethylsilane $(\mathrm{s}$ : singlet; d: doublet, t: triplet, q: quadruplet, m: multiplet; br: broad). Optical rotations were measured at $25^{\circ} \mathrm{C}$ on a Perkin-Elmer 41 polarimeter. High resolution mass data were obtained from the Service Commun de Spectrométrie de Masse of the University Paul Sabatier (Toulouse, France) using electrospray or chemical ionization $\left(\mathrm{CH}_{4}\right)$ techniques.

Construction of plasmids and recombinant $M$. bovis BCG strains. Construction of $M$. bovis BCG $\triangle R$ R2959c (PMM130) and plasmid pWM122, was previously described (7). Briefly, plasmid pWM122 was constructed by insertion of two PCR fragments, containing genes ML0126-ML0128 and ML2346-ML2348, between the Ndel and Spel sites of plasmid pMV361g, a derivative of pMV361 containing the mycobacterial promoter $p B l a F^{*}(7)$.

Plasmid pWM123 was constructed by insertion of two PCR fragments in Spel site of plasmid pMV361g.The first PCR fragment, containing genes Rv1511 (gmdA) and Rv1512 (epiB), was obtained using primers gmdA (5'- TTATACATATGAAGCGAGCGCTCATCAC-3') and epiB (5'-AATATACTAGTCATTGCCGAACCGTTCCC-3'), and the second fragment, containing 
gene Rv2958c, was amplified using primers Rv2958C (5'-CGCAACTAGTGGTCGGTGTGA3') and Rv2958D (5'-ATAACTAGTTAGCAGACGAGCCGCAGC-3').

A PCR fragment, containing genes ML0126, ML0127 and ML0128, was obtained with primers ML0126 (5'-ATACATATGAGAGCAGCCGAAGCTTC-3') and ML0128 (5'ATAACTAGTGACACTCAATCCGGTCACC-3'), using plasmid pBNF03 as template DNA, and cloned in pGEM52 to generate plasmid pWM111. Subsequently, a Ndel-EcoRI (previously blunt-ended), containing gene ML0126, was released and between the Ndel-Spel (previously blunt-ended) sites of vector pMV361g to obtain plasmid pWM247.

The plasmids described above were transferred in M. bovis BCG (pWM123) or PMM130 (pWM122 and pWM247) by electrotransformation and transformants were selected on $7 \mathrm{H} 11$ agar plates (Difco) supplemented with $10 \%(\mathrm{v} / \mathrm{v})$ OADC $(0.005 \%(\mathrm{v} / \mathrm{v})$ oleic acid, $0.5 \%(\mathrm{w} / \mathrm{v})$ bovine serum albumin fraction $\mathrm{V}(\mathrm{BSA}), 0.2 \%(\mathrm{w} / \mathrm{v})$ dextrose, $0.0003 \%(\mathrm{w} / \mathrm{v})$ beef catalase) (Difco) and $40 \mu \mathrm{g} \mathrm{ml}^{-1}$ kanamycin.

The various $M$. bovis BCG strains were rendered fluorescent by the transfer of plasmid pWM124, a derivative of the mycobacterial plasmid pMIP12H allowing expression of gfp gene from pblaF* promoter (7).

Biochemical analysis of $M$. bovis BCG recombinant strains. PGL produced by the newly constructed rBCG-PGL-ulc were extracted and purified from $100 \mathrm{ml}$ culture as described previously $(8,9)$. NMR spectroscopy experiments were carried out at $298^{\circ} \mathrm{K}$ on a Bruker AVANCE spectrometer operating at $600.13 \mathrm{MHz}$ with a $5-\mathrm{mm}$ triple resonance $\mathrm{TCl}^{1} \mathrm{H}^{13} \mathrm{C}{ }^{15} \mathrm{~N}$ pulsed field z-gradient cryoprobe. Samples were dissolved in $99.9 \% \mathrm{CDCl}_{3} .{ }^{1} \mathrm{H} \mathrm{NMR}$ studies on the native and the per-O-acetylated glycolipid were performed using one-dimensional and two-dimensional chemical shift correlation spectroscopy (COSY). Chemical shifts are expressed in ppm using chloroform signal as an internal reference (7.26 ppm).

Purification of DIM and PGLs. M. canetti was used as source for DIM isolation and speciesspecific PGLs were obtained from WT BCG and the various PGL-expressing rBCGs. Total mycobacterial lipids were extracted from $100 \mathrm{ml}$ stationary cultures as previously described (8). Briefly, bacteria were left in $\mathrm{CH}_{3} \mathrm{OH} / \mathrm{CHCl}_{3} 2: 1(\mathrm{v} / \mathrm{v})$ for $48 \mathrm{~h}$ and, then, in $\mathrm{CH}_{3} \mathrm{OH} / \mathrm{CHCl}_{3}$ $1: 1(\mathrm{v} / \mathrm{v})$ for $24 \mathrm{~h}$. The organic phases were recovered and pooled, washed with water and dried. Subsequently, total lipids were recovered in $\mathrm{CHCl}_{3}$ and chromatographic separations of PGLs and DIM were run on a PuriFlash 430 automatic chromatographer (Interchim) using prepacked cartridges of $30 \mu \mathrm{m}$ spherical silica and an elution gradient of increasing chloroform/methanol 9/1 (0-50\% (v/v)) in chloroform, or manually using Sep-Pak Silica Classic Cartridges (55-105 $\mu \mathrm{m}$ particle size; Waters) an elution gradient of increasing diethylether $(0-10 \%(v / v))$ in petroleum ether, respectively. Fractions containing the isolated 
compounds were pooled and dried. Before use, solutions of the lipids at the desired concentrations were prepared: PGLs were diluted in ethanol; DIM were first recovered in a small volume of chloroform, before being added to the aqueous solution and, then, sonicated until complete suspension.

Mycobacterial strains and growth conditions. $M$. bovis BCG and its recombinant derivative strains expressing the various species-specific PGLs, and carrying a mycobacterial replicative plasmid coding for GFP, were used in this study. Mycobacteria were grown at $37^{\circ} \mathrm{C}$ in Middlebrook $7 \mathrm{H} 9$ broth (Difco) supplemented with $10 \%(\mathrm{v} / \mathrm{v})$ ADC $(0.5 \%(\mathrm{w} / \mathrm{v})$ BSA, $0.2 \%(\mathrm{w} / \mathrm{v})$ dextrose, $0.0003 \%(\mathrm{w} / \mathrm{v})$ beef catalase) (Difco) and $0.05 \%(\mathrm{v} / \mathrm{v})$ Tween-80. When required, kanamycin and hygromycin were added to the medium to a final concentration of $40 \mu \mathrm{g} \mathrm{ml}^{-1}$ and $50 \mu \mathrm{g} \mathrm{ml}^{-1}$ respectively.

hMDM culture and infection. Human blood, from fully-anonymous non-tuberculous donors, was purchased from the Etablissement Français du Sang of Toulouse. Peripheral blood mononuclear cells (PBMC) and hMDM were prepared as previously described (7). Briefly, monocytes were isolated from PBMCs by adhesion and allowed to differentiate for 7 days in RPMI 1640 (Gibco) supplemented with $2 \mathrm{mM}$ glutamine (Gibco) and 7\% (v/v) heatinactivated human $\mathrm{AB}$ serum at $37^{\circ} \mathrm{C}$ in $5 \% \mathrm{CO}_{2}$. hMDM were washed twice with serum-free RPMI medium before use.

Mycobacterial infection was performed as previously described (7). Shortly, Exponentiallygrowing, GFP-expressing mycobacteria were pelleted by centrifugation and subsequently dispersed in serum-free RPMI 1640 medium using glass beads. The number of bacteria per $\mathrm{ml}$ in the suspension was then estimated by measurement of the optical density at $600 \mathrm{~nm}$. hMDM were then infected for $2 \mathrm{~h}$ at the indicated $\mathrm{MOI}$ in serum-free RPMI at $37^{\circ} \mathrm{C}$ in $5 \%$ CO2. Extracellular bacteria were then removed by three successive washes with fresh medium.

Phagocytosis experiments. Phagocytosis was assessed as previously described (7). Briefly, hMDM cultured on sterile glass coverslips in 24 -well culture plates $\left(5 \times 10^{5}\right.$ cells per well) were infected at a $\mathrm{MOI}$ of 10 . When indicated, hMDM were incubated before infection for $30 \mathrm{~min}$ with anti-CD11b Ab at $10 \mu \mathrm{g} \mathrm{ml}^{-1}$ or an irrelevant isotype-matched antibody, used as control. After infection, hMDM were fixed with $4 \%$ (w/v) PFA and extracellular mycobacteria were labelled with rabbit anti-mycobacteria $A b$, which was detected by $a$ Rhodamine Red-conjugated goat anti-rabbit secondary Ab. The percentage of cells having ingested at least one bacterium was determined by fluorescence microscopy using a Leica 
DM-RB epifluorescence microscope. For each set of conditions, duplicate experiments were performed, and at least 200 cells were counted per slide.

hMDM siRNA transfection. hMDM were transfected with $100 \mathrm{nM}$ scrambled siRNA control or siRNAs targeting Lyn or Syk using HiPerFect transfection reagent (Qiagen), as described previously (10). Briefly, siRNAs were mixed with HiPerFect transfection reagent and serumfree RPMI medium and incubated at room temperature for $10 \mathrm{~min}$. The lipid-siRNA complexes $(125 \mu \mathrm{l})$ were added drop-wise onto the medium $(250 \mu \mathrm{l})$ of day $5 \mathrm{hMDM}$ and incubated for $6 \mathrm{~h}$ at $37^{\circ} \mathrm{C}$ and $5 \% \mathrm{CO}_{2}$. After transfection, $500 \mu \mathrm{l}$ of RPMI containing $7 \%(\mathrm{w} / \mathrm{v})$ autologous serum was added and cells were incubated at $37^{\circ} \mathrm{C}$ and $5 \% \mathrm{CO} 2$ for additional $72 \mathrm{~h}$ before infection. Efficiency of gene knockdown was assessed by western blot analysis using specific $\mathrm{Ab}$.

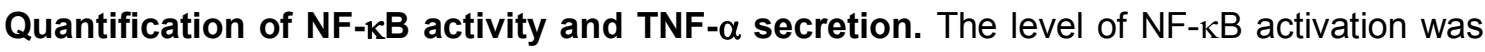
studied using THP-1 Dual ${ }^{\mathrm{TM}}$ and HEK-Blue ${ }^{\mathrm{TM}}$ hTLR2 reporter cell lines (InvivoGen). These cell lines are stably transfected with a reporter plasmid expressing a secreted embryonic alkaline phosphatase (SEAP) gene under the control of a NF-кB-dependent promoter. In all cases, cells were used in 96-well plates according to manufacturer instructions. THP-1 cells were first differentiated into macrophages through treatment with $5 \mathrm{ng} \mathrm{ml}^{-1}$ PMA (Phorbol 12myristate 13-acetate) for $24 \mathrm{~h}$, then washed and rested for two days to ensure that they came back to a resting phenotype. Cells were treated with $10 \mathrm{ng} \mathrm{ml}^{-1}$ Pam3CSK4 (InvivoGen) and, simultaneously, with the purified and synthetic compounds to test at the specified concentrations. Unstimulated cells together with the solvent use to dissolve the compounds to test were used as negative controls, whereas Pam3CSk4-stimulated cells without the compounds were used as positive controls. After a $16 \mathrm{~h}$ incubation, QUANTIBlue $^{\mathrm{TM}}$ detection medium (InvivoGen) was used following manufacturer specifications and

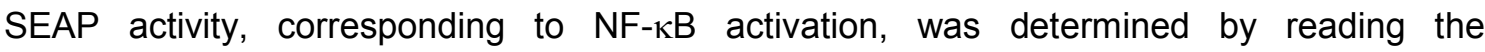
absorbance at $630 \mathrm{~nm}$. For infection experiments, THP-1 dual cells were infected at MOI 1 for $16 \mathrm{~h}$ and NF-kB activity was subsequently detected as described.

To assess TNF- $\alpha$ secretion levels, hMDM were infected as described above and, after $2 \mathrm{~h}$ of contact, supernatants were harvested and filtered. TNF- $\alpha$ secretion was quantified in supernatants using BD OptEIA ${ }^{\mathrm{TM}}$ human TNF ELISA Set (BD), according to the recommendations of the manufacturer.

\section{PGL-1 binding assays}


PGL-1 binding to immobilized receptors. Human receptors (CR3 and TLR2) in coating buffer (25 mM Tris- $\mathrm{HCl} \mathrm{pH} 8.0,150 \mathrm{mM} \mathrm{NaCl}, 2 \mathrm{mM} \mathrm{MgCl}$ ) were coated on 96-well MaxiSorp ELISA plates (Nunc) overnight at $4^{\circ} \mathrm{C}$. After washing and blocking $(3 \%(\mathrm{w} / \mathrm{v}) \mathrm{BSA}$ in coating buffer), specified concentrations of PGL-1 diluted in binding buffer ( $25 \mathrm{mM}$ Tris$\mathrm{HCl} \mathrm{pH} \mathrm{7.4,} 150 \mathrm{mM} \mathrm{NaCl}, 1 \mathrm{mM} \mathrm{MgCl} 2,1 \mathrm{mM} \mathrm{CaCl}, 1 \%$ (w/v) BSA) were added and incubated at $37^{\circ} \mathrm{C}$ for $1 \mathrm{~h}$. Bound PGL-1 was detected by an indirect method using an antiPGL-1 Ab, followed by addition of a secondary HRP-coupled anti-mouse Ab and 1-Step ${ }^{T M}$ Ultra TMB-ELISA substrate (Thermo Scientific), according to manufacturer instructions. HRP activity, corresponding to bound PGL-1, was determined by reading the absorbance at 450 $\mathrm{nm}$.

Competition experiments. Purified, native PGL-1 diluted in ethanol absolute (VWR) was added into 96-well PolySorp ${ }^{\mathrm{TM}}$ ELISA plates (Nunc) and ethanol was let to evaporate. After washing and blocking (25 mM Tris- $\mathrm{HCl} \mathrm{pH} 7.4,150 \mathrm{mM} \mathrm{NaCl}, 1 \mathrm{mM} \mathrm{MgCl}, 1 \mathrm{mM} \mathrm{CaCl}, 3 \%$ $(w / v)$ BSA), CR3 diluted in binding buffer was pre-incubated with the synthetic oligosaccharide domains of the different PGLs (OS PGLs), diluted at $50 \mu \mathrm{M}$ in binding buffer, for $1 \mathrm{~h}$ at $37^{\circ} \mathrm{C}$. Bound $\mathrm{CR} 3$ was subsequently detected by an indirect method using an antiCD11b Ab (2LPM19c), followed by addition of a HRP-coupled secondary Ab and 1-Step ${ }^{T M}$ Ultra TMB-ELISA substrate. HRP activity, corresponding to bound CR3, was determined by reading the absorbance at $450 \mathrm{~nm}$.

\section{Statistics}

Results are expressed as means \pm standard error of the mean (SEM) of the indicated number of experiments $(n)$ performed at least in duplicate. Data were analysed by two-tailed Student's $t$-tests using the GraphPad PRISM (GraphPad Software, GPW5-078069-NBH$9780)$ and $P<0.05$ was used as the limit of statistical significance.

\section{References}

1. Fujiwara, T., and Izumi, S. (1987) Synthesis of the neoglycoconjugates of the phenolic glycolipid-related trisaccharides for the serodiagnosis of leprosy, Agric Biol Chem 51, 2539-2547.

2. Chatterjee, D., Cho, S. N., Stewart, C., Douglas, J. T., Fujiwara, T., and Brennan, P. J. (1988) Synthesis and immunoreactivity of neoglycoproteins containing the trisaccharide unit of phenolic glycolipid I of Mycobacterium leprae, Carbohydr Res 183, 241-260.

3. Elsaidi, H. R., and Lowary, T. L. (2014) Inhibition of cytokine release by mycobacterium tuberculosis phenolic glycolipid analogues, Chembiochem : a European journal of chemical biology 15, 1176-1182. 
4. Fujiwara, T. (1991) Synthesis of the trisaccharide-protein conjugate of the phenolic glycolipid of Mycobacterium tuberculosis for the serodiagnosis of tuberculosis, Agric Biol Chem 55, 2123-2128.

5. Barroso, S., Castelli, R., Baggelaar, M. P., Geerdink, D., ter Horst, B., Casas-Arce, E., Overkleeft, H. S., van der Marel, G. A., Codee, J. D., and Minnaard, A. J. (2012) Total synthesis of the triglycosyl phenolic glycolipid PGL-tb1 from Mycobacterium tuberculosis, Angew Chem Int Ed 51, 11774-11777.

6. Bourke, J., Brereton, C. F., Gordon, S. V., Lavelle, E. C., and Scanlan, E. M. (2014) The synthesis and biological evaluation of mycobacterial p-hydroxybenzoic acid derivatives (p-HBADs), Org Biomol Chem 12, 1114-1123.

7. Tabouret, G., Astarie-Dequeker, C., Demangel, C., Malaga, W., Constant, P., Ray, A., Honore, N., Bello, N. F., Perez, E., Daffe, M., and Guilhot, C. (2010) Mycobacterium leprae phenolglycolipid-1 expressed by engineered M. bovis BCG modulates early interaction with human phagocytes, PLoS pathogens 6, e1001159.

8. Constant, P., Perez, E., Malaga, W., Laneelle, M. A., Saurel, O., Daffe, M., and Guilhot, C. (2002) Role of the pks15/1 gene in the biosynthesis of phenolglycolipids in the Mycobacterium tuberculosis complex. Evidence that all strains synthesize glycosylated p-hydroxybenzoic methyl esters and that strains devoid of phenolglycolipids harbor a frameshift mutation in the pks15/1 gene, The Journal of biological chemistry 277, 38148-38158.

9. Daffe, M., and Servin, P. (1989) Scalar, dipolar-correlated and J-resolved 2D-NMR spectroscopy of the specific phenolic mycoside of Mycobacterium tuberculosis, Eur $\mathrm{J}$ Biochem 185, 157-162.

10. Troegeler, A., Lastrucci, C., Duval, C., Tanne, A., Cougoule, C., Maridonneau-Parini, I., Neyrolles, O., and Lugo-Villarino, G. (2014) An efficient siRNA-mediated gene silencing in primary human monocytes, dendritic cells and macrophages, Immunology and cell biology 92, 699-708. 


\section{Supplementary Figures}

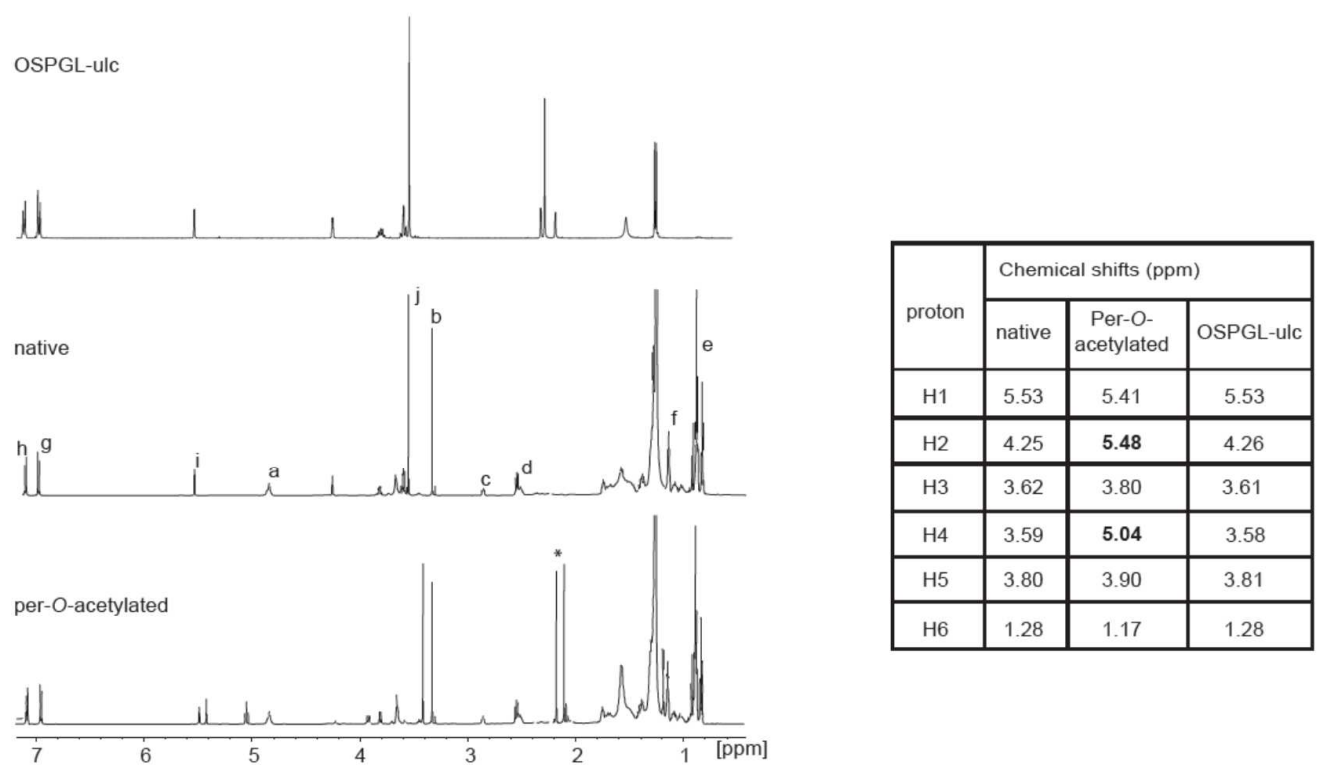

Figure S1. NMR analysis of PGL purified from rBCG $\triangle R v 2959::$ ML0126 and OS PGLulc. 1D ${ }^{1} \mathrm{H}-\mathrm{NMR}$ spectra (0.76-7.2 ppm) of native (middle), per-O-acetylated (bottom) glycolipids $\left(600 \mathrm{MHz}\right.$, in $\mathrm{CDCl}_{3}$ ) and synthetic OS PGL-ulc (upper, $400 \mathrm{MHz}$ in $\mathrm{CDCl}_{3}$ ). The table summarized the assignments of resonances on the basis of chemical shift correlations deduced from the 2D-COSY spectra of native, per-O-acetylated PGL and synthetic OS PGLulc. Proton resonances shifted by acetylation are written in bold. 